\title{
Jenni Salminen
}

\section{The Teacher as a Source of Educational Support}

Exploring Teacher-Child Interactions and Teachers' Pedagogical Practices in Finnish Preschool Classrooms

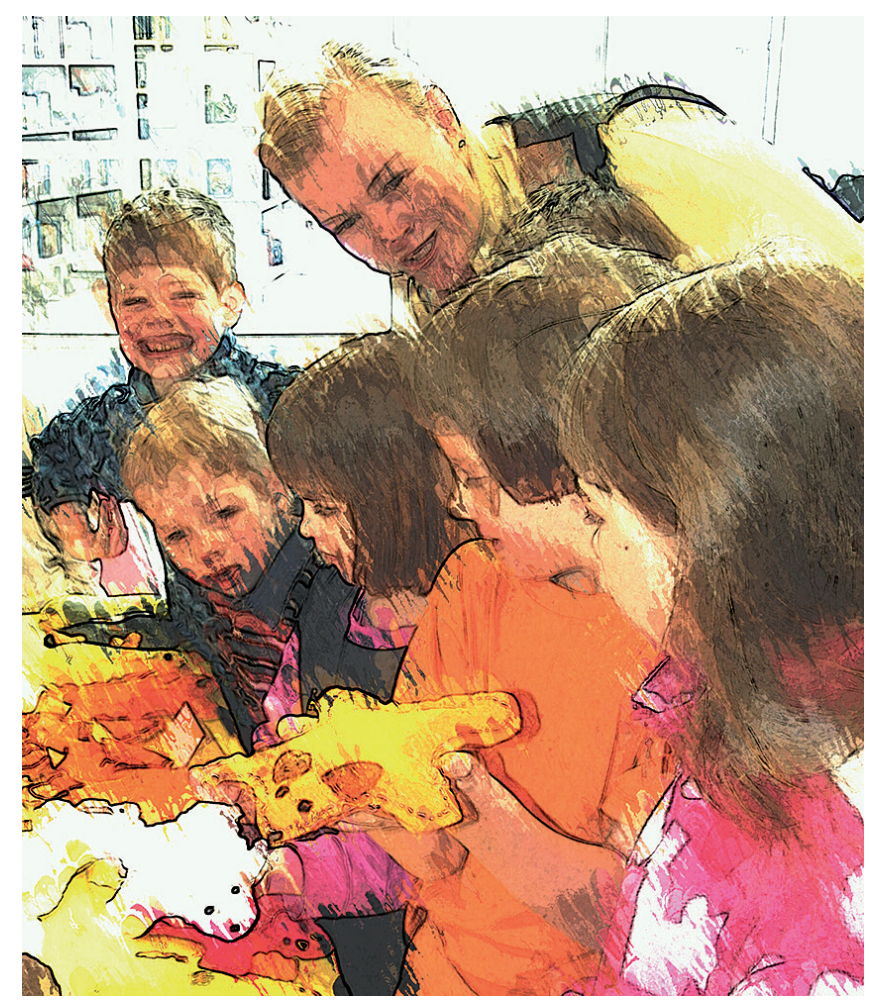




\section{Jenni Salminen}

\section{The Teacher as a Source of Educational Support}

\section{Exploring Teacher-Child Interactions and Teachers' Pedagogical Practices in Finnish Preschool Classrooms}

Esitetään Jyväskylän yliopiston kasvatustieteiden tiedekunnan suostumuksella julkisesti tarkastettavaksi yliopiston vanhassa juhlasalissa S212 joulukuun 13. päivänä 2014 kello 12.

Academic dissertation to be publicly discussed, by permission of the Faculty of Education of the University of Jyväskylä,

in building Seminarium, auditorium S212, on December 13, 2014 at 12 o'clock noon.

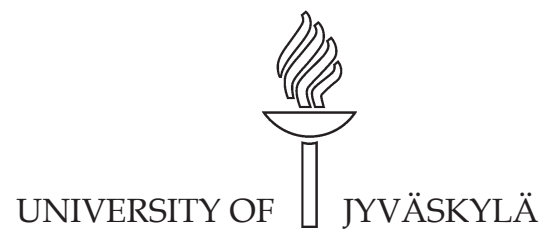

JYVÄSKYLÄ 2014 


\section{The Teacher as a Source of Educational Support}

Exploring Teacher-Child Interactions and Teachers' Pedagogical Practices in Finnish Preschool Classrooms 


\title{
Jenni Salminen
}

\section{The Teacher as a Source of Educational Support}

\author{
Exploring Teacher-Child Interactions \\ and Teachers' Pedagogical Practices \\ in Finnish Preschool Classrooms
}

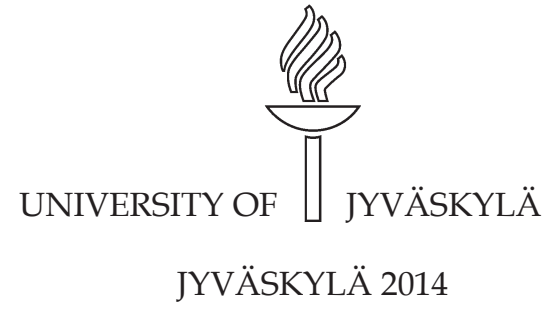


Editors

Markku Leskinen

Department of Education, University of Jyväskylä

Pekka Olsbo, Ville Korkiakangas

Publishing Unit, University Library of Jyväskylä

Cover photo by Tarja Vänskä-Kauhanen.

URN:ISBN:978-951-39-5982-1

ISBN 978-951-39-5982-1 (PDF)

ISBN 978-951-39-5981-4 (nid.)

ISSN 0075-4625

Copyright (C) 2014, by University of Jyväskylä

Jyväskylä University Printing House, Jyväskylä 2014 


\author{
ABSTRACT \\ Salminen, Jenni \\ The Teacher as a Source of Educational Support: Exploring Teacher-Child Interactions \\ and Teachers' Pedagogical Practices in Finnish Preschool Classrooms \\ University of Jyväskylä, 2014, 101 p. \\ (Jyväskylä Studies in Education, Psychology and Social Research \\ ISSN 0075-4625; 512) \\ ISBN 978-951-39-5981-4 (nid.) \\ ISBN 978-951-39-5982-1 (PDF) \\ Diss. \\ Finnish summary
}

This study was set to create a more profound knowledge and understanding of the role that teachers play in children's learning and development in Finnish preschool classrooms, and thus to contribute to the discussions on the complexity of classroom interaction and classroom quality. The first aim (1) was to examine what types of interaction and teachers' pedagogical practices contribute to the classroom quality in preschool classrooms, and the second aim (2) was to construct a timely description of teacherchild interactions and teachers' practices in preschool classrooms, the time when the transition to formal schooling is fast approaching. These aims were pursued in the three empirical studies that comprise this doctoral study. The data for all sub-studies were gathered as part of the longitudinal First Steps study, and pertained to its sample of 49 Finnish preschool teachers in spring 2007. Data were gathered through structured classroom observations, utilising the Classroom Assessment Scoring System (CLASS: Pianta, La Paro, \& Hamre, 2004, 2008), and Early Childhood Classroom Observation Measure (ECCOM: Stipek \& Byler, 2004) and by audio and video recording teacherchild interactions in the classrooms. The data thus included a variation of both quantitative (sub-study I) and qualitative (sub-studies II and III) information. The data were analysed and reported along the principles of sequential mixed methods research design, thus keeping the sub-studies separate until making the combining inferences as part of the summary report. The results of this study have indicated, firstly, that the majority of the classrooms in this sample represented generally high levels of observed quality with respect to teacher-child interactions. Secondly, teachers' emotionally sensitive and responsive practices (i.e., Emotional Support) combined with constructive classroom management (i.e., Classroom Organisation) created advantageous opportunities for instructionally supportive practices to take place, resulting in a higher classroom quality: When teachers had created a safe atmosphere and established clear goals and expectations for both social and pre-academic learning, the children in their classroom were observed to willingly participate in purposeful learning activities. Thirdly, the results reflect the teachers' pedagogical sensitivity in their interactions with the children. Pedagogical sensitivity was observed in teachers' noticing and timely reacting to children's individual social and pre-academic needs and was concretised in a variety of teachers' thoughtful practices, which, in many ways, prepared the children for their transition to primary school.

Keywords: teacher-child interaction; teachers' pedagogical practices; preschool education; classroom quality; the CLASS 
Jenni Salminen

Department of Education

Early Childhood Education

P.O. Box 35

FI-40014 University of Jyväskylä, Finland

jenni.e.salminen@jyu.fi

Supervisors

Professor Maritta Hännikäinen

Department of Education

Early Childhood Education

University of Jyväskylä, Finland

Professor Helena Rasku-Puttonen

Department of Teacher Education

University of Jyväskylä, Finland

University Researcher Pirjo-Liisa Poikonen

Department of Education

Early Childhood Education

University of Jyväskylä, Finland

Reviewers

Professor Kristiina Kumpulainen

Department of Teacher Education

University of Helsinki, Finland

Research Assistant Professor Jennifer LoCasale-Crouch Center for Advanced Study of Teaching and Learning University of Virginia, United States of America

Opponent

Professor Kristiina Kumpulainen

Department of Teacher Education

University of Helsinki, Finland 


\section{ACKNOWLEDGEMENTS}

Writing this doctoral dissertation has in many ways been like a long hike through an ever changing terrain. Some parts of my hike have required solitude but the people with whom I have shared the journey have made it an extraordinary experience. These words are dedicated to all of you who have helped me in the ups and downs on my researcher's path.

My deepest and most profound gratitude for finalising this doctoral study belongs to my three supervisors-Professor Maritta Hännikäinen, Professor Helena Rasku-Puttonen, and Doctor Pirjo-Liisa Poikonen-whose doors and hearts have always been open for me and my questions. Maritta - I thank you for your amazing attention for details in commenting my work and your deep wisdom in the field of early childhood education that you have shared with me throughout these years. Helena - I thank you for those many educational dialogues I have been privileged to share with you over the years: they have opened countless new avenues for my work. Pipsa - I thank you for your professional comments and the profound trust that you have shown toward me and my work. To all three of you, I extend my warmest gratitude for your guidance, encouragement and patience: I feel that you have not only been showing me the right path and leading the way, but also letting me walk side by side with you.

I will always be grateful for the constructive comments of the reviewers of this work. Professor Kristiina Kumpulainen and Research Assistant Professor Jennifer LoCasale-Crouch: Your thorough inspection of my work and your precise feedback helped me to construct a stronger study and made me re-examine and clarify my points of view. Further, thank you Professor Kumpulainen for being the opponent of my dissertation, your contribution means a lot to me.

I want to express my heartfelt thanks to Professor Marja-Kristiina Lerkkanen and Professor Anna-Maija Poikkeus for their warm and constructive support during the writing this dissertation. Without you, and without the access to the brilliant First Steps study and its data, I probably would have never considered becoming a doctoral student in the first place. I feel indebtedness for all the amazing opportunities that you have whole-heartedly provided me with throughout the process of preparing my dissertation and beyond. Relatedly, I want to thank Professor Jari-Erik Nurmi for the professional opportunity to work as a research coordinator for the First Steps study, as well as doctor Martti Siekkinen for collaboration and guidance while working on the First Steps study and writing articles. Thank you Eija, for your endless encouragement and spending (too) many hours helping me to understand and report mixture modelling. Beyond that, I also want to thank you for sharing joys and sorrows of human life in your whole-hearted manner. Discussions with you have made many problems smaller and many conference trips memorable. Thank you Jen$\mathrm{ni}$, for sharing the Alpo coordinatorship and other academic interests as well as for listening and sharing with a kind heart many other issues. 
I have been privileged to receive funding for my doctoral studies from several sources over the last five years. I want to thank the Faculty of Education, the rector of the University of Jyväskylä and the Finnish Cultural Foundation for funding my doctoral studies. I also want to thank the Finnish Concordia Fund and the Finnish Union of University Researchers and Teachers- member association of Jyväskylä (Jytte ry) for awarding me with funding for international conferences. Further, I would like to thank the Department of Education, and especially the current head of the department, Matti Kuorelahti, and the previous head, Anja-Riitta Lehtinen, for encouragement and having given me the opportunity to work at the premises of the department also at times when I was working on other grants. Karl-Heinz "Kalle" Rademacker, many thanks for the long-lasting cooperation on proofreading the English language of my dissertation and its three sub-studies. I also want to thank Markku Leskinen for his contribution to the scientific editing of my dissertation, as well as my colleague Marleena Mustola for proofreading the Finnish summary.

My amazing colleagues of the discipline of early childhood education: I thank each and every one of you for providing me with different sources of support and positive encouragement throughout the years. I could not have hoped for a better work community. I also wish to jointly thank all of the past and current members of the (1) official seminar group for doctoral students (facilitated by Professors Maritta Hännikäinen and Helena Rasku-Puttonen), (2) the Varjo group, and (3) 'the perky terriers' of the Taisto group. Thank you all for reading my research articles and commenting on my presentations and summary report, and, above all, for the great discussions and open-minded sharing of ideas within our many meetings.

Lopuksi tahdon kiittää suomeksi läheisimpiäni, jotka muistuttavat joka päivä läsnäolollaan siitä, että elämässä on paljon muutakin kuin työ. Kiitän lämpimästi lähintä ystäväpiiriäni, jonka seurassa saan nauraa, itkeä ja iloita: teidän seuranne kiinnittää minut elämään. Appivanhempiani Heliä ja Ollia kiitän lämpimästi vuosien varrella saamastani kannustuksesta ja korvaamattomasta lapsenhoitoavusta. Äiti ja isä, kukaan ei ole koskaan luottanut minuun ja tekemisiini yhtä lujasti ja vilpittömästi kuin te. Kiitos rakkaat, Jylppy teki sen! Rakas sisareni Nelli, kiitos että jaksoit koko projektin ajan kannustaa minua, vaikka toisinaan tuntui että olisit tarvinnut sitä itse enemmän. Aviomieheni Henri, sanat eivät riitä kertomaan kuinka paljon rakkautesi, kannustuksesi ja omintakeinen huumorintajusi ovat vuosien varrella merkinneet minulle ja tämän työn valmistumiselle. Kiitos kaikesta! Tyttäreni Tessa, äidin rakas arjen ilostuttaja ja pieni viisas papupata. Tämä kirja on omistettu sinulle.

Jyväskylä, November 2014, watching the fall turning into winter Jenni Salminen 


\section{ORIGINAL PAPERS}

This study is based on the following publications, which are referred to as substudies and by the Roman numerals I-III in this doctoral study:

Article I Salminen, J., Lerkkanen, M.-K., Poikkeus, A.-M., Pakarinen, E., Siekkinen, M., Hännikäinen, M., Poikonen, P.-L., \& Rasku-Puttonen, H. (2012). Observed Classroom Quality Profiles of Kindergarten Classrooms in Finland. Early Education and Development, 23, 654-677.

Article II Salminen, J., Hännikäinen, M., Poikonen, P.-L., \& Rasku-Puttonen, H. (2013). A Descriptive Case Analysis of Instructional Teaching Practices in Finnish Preschool Classrooms. Journal of Research in Childhood Education, 27, 127-152.

Article III Salminen, J., Hännikäinen, M., Poikonen, P.-L., \& Rasku-Puttonen, H. (2014). Teachers' Contribution to the Social life in Finnish Preschool Classrooms During Structured Learning Sessions. Early Child Development and Care, 184, 416-433.

The articles (sub-studies) are reprinted with the kind permission of the publishers. Copies of the articles are appended to this report.

The role of the first author has been as active one, conducting all of the three sub-studies. In the first sub-study, the statistical analysis was carried out by one of the co-writers; nevertheless, the first author had central responsibility for reporting the findings independently, with the co-writers providing assistance. The second and the third sub-studies were analysed and reported independently by the first author, with the co-writers having an advisory role. 


\section{FIGURES}

FIGURE 1 The subordinate nature of the data in the three sub-studies......... 43

FIGURE 2 Mixed methodological structure of this study (Adapted from

Teddlie \& Tashakkori, 2009)................................................................. 44

\section{TABLES}

TABLE 1 The connections between the purpose, aims and research

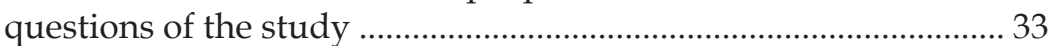

TABLE 2 Correlations between CLASS and ECCOM …................................... 38

TABLE 3 Overview of the sub-studies............................................................. 51 


\title{
CONTENTS
}

\author{
ABSTRACT \\ ACKNOWLEDGEMENTS \\ LIST OF THE ORIGINAL PAPERS \\ LIST OF FIGURES AND TABLES \\ CONTENTS
}

1 INTRODUCTION

2 TEACHER-CHILD INTERACTION AND TEACHERS' PRACTICES...... 15

2.1 Relational approach to learning and development ............................ 16

2.2 Interaction and relationships between teachers and children ........... 20

2.3 Teachers' pedagogical practices ............................................................ 22

3 TEACHERS' CONTRIBUTION TO CLASSROOM PROCESS

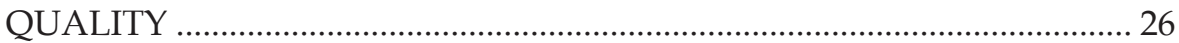

3.1 Teacher-child interactions in the Teaching Through

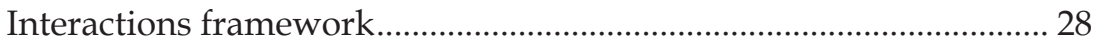

3.2 Teachers' practices in the ECCOM framework ...................................... 29

$4 \quad$ AIM AND RESEARCH QUESTIONS ……………………….................... 31

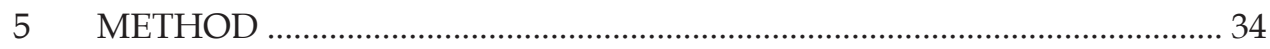

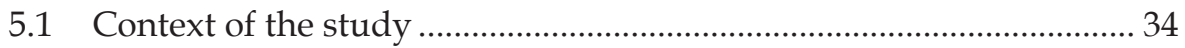

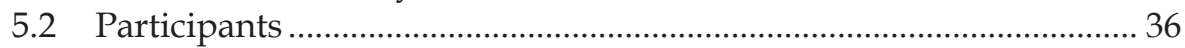

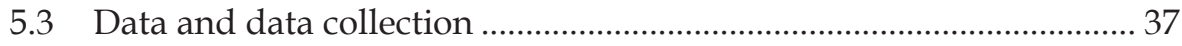

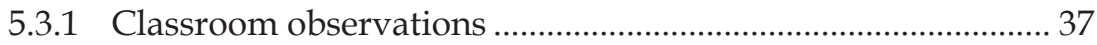

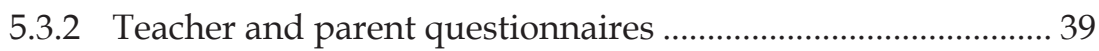

5.4 Ontological and epistemological assumptions....................................... 39

5.5 Mixing methods: Combining approaches to create a more

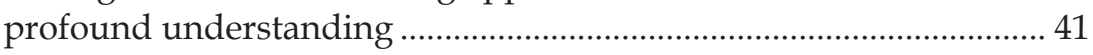

5.6 Sampling and analytical strategies......................................................... 45

5.6.1 Sub-study I: Mixture modelling procedure—latent profile

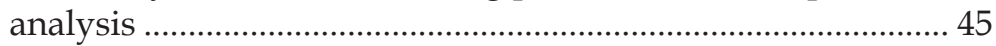

5.6.2 Sub-study II: Qualitative content analysis.................................. 47

5.6.3 Sub-study III: Thematic analysis..................................................... 48

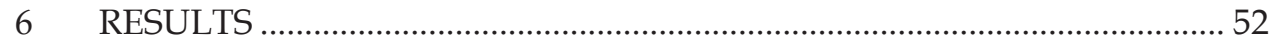

6.1 Profiles of teachers' practices and teacher-child interactions............. 52

6.2 Teachers' support for children's pre-academic skills and social

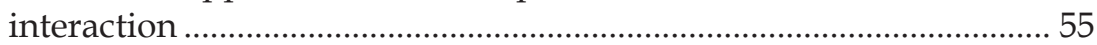

6.2.1 Teachers' support for pre-academic skills ................................. 56

6.2.2 Teachers' support for social interaction...................................... 58 
6.3 Teacher and classroom characteristics and teachers' observed

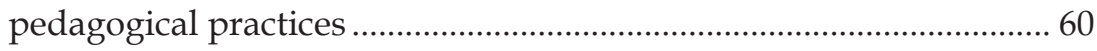

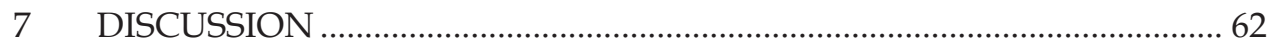

7.1 Classroom quality as a process: Teachers' contribution .......................62 62

7.2 Teacher-child interaction and teachers' practices: Subtle

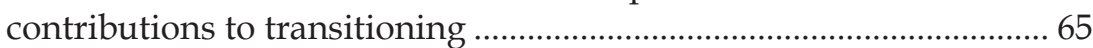

7.3 Methodological and theoretical implications ......................................... 68

7.4 Practical and pedagogical implications ................................................. 70

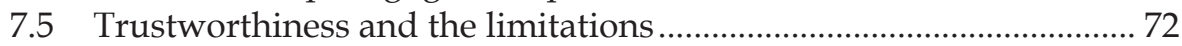

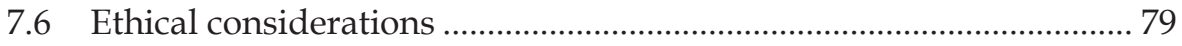

7.7 Concluding remarks and future directions........................................... 80

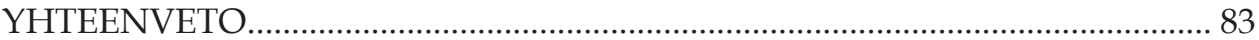

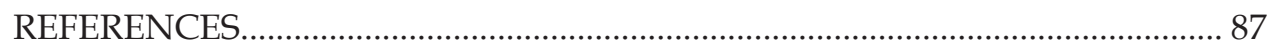




\title{
1 INTRODUCTION
}

\begin{abstract}
"An understanding heart is everything in teacher, and cannot be esteemed highly enough. One looks back with appreciation to the brilliant teachers, but with gratitude to those who touched our human feelings. The curriculum is essential raw material, but warmth is the vital element for the growing plant and for the soul of the child." (C. G. Jung)
\end{abstract}

The Majority of Finnish children spend a considerable amount of time in institutional educational contexts before they enter primary school at the age of seven. In these contexts-such as preschool classrooms ${ }^{1}$ - children cooperate with both peers and teachers and are engaged in different educational activities. In recent decades, much research has been devoted to identifying the keyfeatures that enhance children's development and learning in such contexts, both in early childhood (e.g., Buysse, Goldman, \& Skinner, 2003; Howes et al., 2008; Pianta et al., 2005) as well as during their primary school years (e.g., Bohn, Roehrig, \& Pressley, 2004; Curby, Rimm-Kaufman, \& Abry, 2013). This body of research often involves the concept of classroom quality. What is known is that structural features of classroom quality, such as class size and teachers' level of education or their work experience, are of importance to children's learning and development to a certain extent (Burchinal, Cryer, Clifford, \& Howes, 2002; Early et al., 2006). According to more recent understanding, however, such distal features are seen to exert their influence on children's outcomes via instructional and social processes such as teacher-child interactions (Pianta, Belsky, Vandergrift, Houts, \& Morrison, 2008). Teachers are considered as significant others with whom children create influential and proximal relationships (e.g., Birch \& Ladd, 1998; Bronfenbrenner \& Morris, 2006; Pianta, 1999; Pianta et al., 2005; Vygotsky, 1978) in their daily interaction. Children, thus, experience varying levels of teachers' support in different groups and classrooms over time (Curby et al., 2013). Studies have shown that such support

1 The term 'preschool' is used in this summary report to describe the education provided to Finnish 6-year-old children during the year before entering primary school. In sub-study I, the term 'kindergarten' is used instead of 'preschool' due to the established use of the term 'kindergarten' in the American educational system and publishing the paper in an American journal. 
in the form of interactional relationships between teacher and child are important contributors to classroom process quality (Pianta, La Paro, \& Hamre, 2008; Hamre, Pianta, Mashburn, \& Downer, 2007). Consequently, the doctoral study summarised in this report aimed to enable a deeper understanding of the complex nature of teacher-child interaction in Finnish preschool classrooms and to create a more profound pedagogical understanding of the role that teachers play in children's learning and development and how these aspects contribute to the classroom process quality.

On the basis of broad theoretical and empirical work on classroom process quality, teachers' support can be divided into three domains-Emotional, Organisational, and Instructional supports - which are the basis of the Teaching Through Interactions framework (Hamre et al., 2013) and the CLASS measure (Classroom Assessment Scoring System: Hamre \& Pianta, 2007; Hamre et al., 2007), used to objectively measure classroom quality. Studies using this kind of variable-centred conceptualisation of quality, that anchors classroom effects in verifiably observable indicators, are common in the United States (Hamre et al., 2007; Curby et al., 2013). The results have shown that classroom quality varies significantly between states as well as between classrooms, suggesting that the distribution of high quality teaching is not evenly distributed (LoCasale-Crouch et al., 2007; NICHD ECCRN, 2002). Furthermore, the Teaching Through Interactions framework and CLASS measure have been used in profiling studies to reveal in what types of combinations teachers' emotional, organisational, and instructional support exists in classrooms and how these combinations are connected to children's outcomes (LoCasale-Crouch et al., 2007; Curby et al., 2009). In the Finnish context, the provision of preschool education is somewhat more homogenous than in the United States, due to the high-quality unified university teacher training as well as the existence of mandatory national guidelines (National Core Curriculum for Pre-primary ${ }^{2}$ Education, 2010) for all preschool classrooms. Recent Finnish studies have suggested that the CLASS measure can also be used as a valid tool in an educational contexts differing from that of the United States (Pakarinen et al., 2010), and that it is possible to identify relationships between classroom quality and child outcomes (by using the CLASS) (Pakarinen et al., 2011; Siekkinen et al., 2013). However, it has not yet been established whether or not profiling studies can also be conducted in other contexts. Thus, one of the rationales for the current study was to examine what types of teacher-child interactions contribute to classroom quality in preschool classrooms in Finland and what types of classroom quality profiles can be identified utilising the observational CLASS measure. Relatedly, observational studies on classroom quality in the Finnish context are scarce, but the existing ones also emphasise the importance of the process features of classroom quality, namely the interaction between the child and teacher as well as between children (Hujala,

2 In the Core Curriculum for Preschool Education (2000), the wording 'preschool 'has been used to refer to the education provided to Finnish 6-year-old children, during the year before entering primary school. Please note that the title of the revised Core Curriculum for Preschool Education (2010) appears translated as National Core Curriculum for Pre-primary Education (2010). 
Fonsén, \& Elo, 2012). Therefore, the study needed to deliver relevant and timely observational information on the nature of teacher-child interaction in Finnish preschool classrooms and of its contribution to classroom quality, using a theoretical Teaching Through Interactions framework (Hamre et al., 2013) that is relatively new to Finnish educational culture.

The previous CLASS profiling studies have indicated that teachers' support exists in different combinations within different classrooms (LoCasaleCrouch et al., 2007). Furthermore previous studies - qualitative ones in particular-indicate that teachers develop pedagogical practices in their own personal way, which results in unique educational experiences that differ from classroom to classroom (Bohn et al., 2004). Because Finnish preschool education appears homogenous compared, for instance, to that in the United States, it raises the question of how clearly the differences between quantitative profiles and, furthermore, between individual classroom teachers can be established. As a consequence, there also exists a need to construct a timely qualitative description of the teacher-child interaction and teachers' practices in individual preschool classrooms by exploring teachers' pedagogical practices and teacher-child interaction further on a micro level, through person-centred perspective. Teachers' pedagogical knowledge and sensitivity to children's needs, as well as their comfortable presence with children and their pedagogical contribution to children's development and learning have been recognised in several studies (e.g., Birch \& Ladd, 1998; van Manen, 1991), and the opportunities to study such important features of teacher-child interaction through quantitative and variable-centred approaches are limited. Furthermore, as existing studies with a clear emphasis on teachers' practices or pedagogical decisions of teachers are relatively few in number (e.g., Hännikäinen \& Rasku-Puttonen, 2010; Rosenthal \& Gatt, 2010; Yan, Evans, \& Harvey, 2011), it is necessary to add to the limited understanding by exploring individual classrooms and teachers. In addition, as children in preschool classrooms are soon transitioning to primary school, it is worth bearing in mind how daily interaction in the Finnish preschool classrooms is related to the children's preparation to formal schooling. This topic is current and has been of interest in recent international (LoCasale-Crouch, Mashburn, Downer, \& Pianta, 2008) and national research (Ahtola et al., 2011).

The notions of the socio-cultural approach (e.g., Vygotsky, 1978) and ecological model (e.g., Bronfenbrenner, 1979) serve as the theoretical footing for the present study. These notions provide a firm ground on which to conceptualise the relational nature of teacher-child interaction in preschool classrooms as a situated and contextual phenomenon (Blatchford, Kutnick, Baines, \& Galton, 2003; Greeno \& the Middle School Mathematics Through Applications Project Group, 1998; Greeno \& van de Sande, 2007; Kovalainen \& Kumpulainen, 2007), underlining the importance of both proximal interaction as well as that of broader cultural contexts (e.g., Bronfenbrenner, 1979). Relatedly, the present study is based on the cautious realist ontology and adopts the epistemological assumptions of social constructionism (e.g., Blaikie, 2007). The observational data for this study pertain to 6-year-old children and their teachers in 49 preschool 
classrooms in Finland and were gathered in the spring of 2007 as part of the multidisciplinary First Steps longitudinal study (Lerkkanen et al., 2006). The classroom interactions were assessed by utilising structured assessment tools (CLASS: Pianta et al., 2004; Pianta, La Paro, et al., 2008; ECCOM: Stipek \& Byler, 2004, 2005), and by video or audio recording teacher-child interactions. This study consists of three empirical sub-studies that were conducted sequentially and analysed quantitatively (sub-study I) as well as qualitatively (sub-studies II and III). The present summary report thus utilises the principles of mixed methods research (e.g., Johnson, Onwuegbuzie, \& Turner, 2007), aiming to provide a broad picture of teacher-child interaction in Finnish preschool classrooms from different methodological perspectives. In doing so, the study was aimed at making the role of teachers' pedagogical practices and the individual variation in utilising their practices in classrooms more tangible, suggesting that the evaluation of classroom quality should involve more than just assessing individual variables - it should attempt to see the teacher and his or her childfacing classroom practices as a whole. C. G. Jung's sentiment quoted at the beginning of this chapter expresses this beautifully. 


\section{TEACHER-CHILD INTERACTION AND TEACHERS' PRACTICES}

Interplay between two or more individuals is usually referred to as interaction. Interaction involves interchanges of various content and quality (Hinde, 1987; see also Pianta, 1999). When two individuals have a series of interactions with each other over a considerable period of time, these interactions are usually referred to as a relationship. Relationships involve reciprocal attitudes, hopes and emotions as well as similar intentions toward others, and these factors differentiate a relationship from interaction and may make a relationship between two individuals possible even without frequent interaction (see Hinde, 1987, pp. 2324). Interaction and relationships are always bi-directional: the nature of interaction and relationships depends on both participants (Hinde, 1987). In addition, previous experiences have an effect on subsequent ones; thus, the behaviour of the individual is often affected by his or her relationships experienced in the past (Hinde, 1987). Seen together, it is reasonable to assume that interactions, over time, may also turn into relationships in educational contexts, such as between the children in a classroom and their teacher or peers. In this study, interaction and the nature of relationships are understood in terms of observed interpersonal exchange between the teacher and the children in preschool classrooms during daily activities. Further, this study adopts a relational perspective toward the interaction between the teacher and children, in which individuals (i.e., the teacher and each child) are considered as actively interacting with each other in the situated, cultural and ecological context of the preschool classroom (e.g., Bronfenbrenner, 1979; Greeno et al., 1998; cf., Vygotsky, 1978), and where the quality of the relationships surrounding pedagogical activities is of importance (Blatchford, Kutnick, Baines, \& Galton, 2003; Kutnick, Ota, \& Berdondini, 2008). 


\subsection{Relational approach to learning and development}

Any child is situated within an ever complex set of relations-social, cultural and ecological - that forms the child's developmental environment (Smidt, 2009). As the present study particularly aimed to explore the interaction and relationships in educational environments (i.e., the interaction between the teacher and children in the context of the preschool classroom), considering theoretical approaches that view learning and interaction as relational processes was fundamental. In this study, the socio-cultural approach and ecological model $^{3}$ are utilised as the theoretical starting point and as examples of relational theories-both stressing the relationship between individuals as a stepping stone and prerequisite to learning and development, as well as emphasising the role of the context or environment as a mediating factor within this situated process (e.g., Hicks, 1996). In this study, thus, relational refers to understanding learning and development in the classrooms as situated and contextual by nature (Blatchford et al., 2003; Greeno et al., 1998; Greeno \& van de Sande, 2007; Kovalainen \& Kumpulainen, 2007). In the following paragraphs the key ideas and concepts of the socio-cultural approach and ecological model and their contribution to this study will be illuminated.

Socio-cultural approach. The origins of the socio-cultural approach to learning and development lie in the cultural-historical work of Russian psychologist Lev Vygotsky (see Vygotsky, 1978). Socio-cultural research, however, has expanded in recent decades and does neither create a unified field nor can one point to a single, clearly defined socio-cultural theory. Rather, it is more correct to speak of socio-culturally oriented theories or approaches that share certain regularities (Mercer \& Littleton, 2007). The fundamental idea is that in addition to explicating the relationships between individuals, development and learning are considered as processes that are affected by the surrounding cultural, institutional and historical factors of a society (Mercer \& Littleton, 2007; Rogoff, 2003, 2008; Vygotsky, 1978; Wertsch, del Río, \& Alvarez, 1995).

All higher intellectual functioning has its origin in actual relations between human individuals, meaning that knowledge and understanding are always shared and jointly constructed (Mercer \& Littleton, 2007; Vygotsky, 1978). More specifically, the joint construction of knowledge is seen to result in learning, and learning is considered to be the aim within educational contexts in particular. Vygotsky describes learning as a profoundly social process where dialogue and the various roles of language mediate cognitive growth (Vygotsky, 1978) and in which the affective-volitional basis of thought enables a full under-

3 The ecological model created by Urie Bronfenbrenner (1979) and its corresponding research designs have been referred to as ecological framework (Bronfenbrenner, 1977), ecological model (Bronfenbrenner, 1979), ecological systems theory (Bronfenbrenner, 1989), as well as bio-ecological model (Bronfenbrenner \& Morris, 2006) over the years. Within this study the concept of the ecological model is used to refer to the conceptual core (i.e., the model of five nested systems that are connected via the interaction between them) of this work in order to avoid confusion. 
standing of the motives behind a verbal interaction (Vygotsky, 1961). In other words, the starting point of learning is always social, but in order to be meaningful both cognitive and affective aspects need to be met.

The socio-cultural approach further views children as actively participating individuals who construct their own learning and are thus indirectly prepared for later participation in related events and the intellectual life around them (Rogoff, 2008; Vygotsky, 1978). In line with Vygotsky's ideas, the cultural practices in which the child is involved produce a unique and significant set of circumstances affecting the child, a phenomenon referred to as the social situation of development (van Oers, 2012). For Vygotsky, the social situation is a relational construct in which the characteristics of children are interwoven with the structure of social interactions in their proximal environment to create the starting point for a new cycle of developmental changes (Cole \& Gajdamaschko, 2010). A social situation is not a uniform entity, nor a specific context/setting per se, but one that depends on how the child emotionally relates to the environment and perceives and interprets it (Cole \& Gajdamaschko, 2010; van Oers 2012). Furthermore, a child's social situation includes different spheres of relations (e.g., family, kindergarten, school), all of which are of importance for the child (Karabanova, 2010).

An extensive amount of socio-culturally oriented literature also introduces concepts that resemble that of Vygotsky's social situation: for example, situated learning (Lave \& Wenger, 1991), situative perspective (Greeno et al., 1998; Greeno \& van de Sande, 2007), and situatedness (e.g., Kovalainen \& Kumpulainen, 2007; Kumpulainen, Lipponen, Hilppö, Mikkola, 2014). These concepts all mediate the idea of interaction between individuals in their given social situations and social communities in which the materials and other cultural resources are being actively utilised. Within this study, situatedness is understood more in terms of the situative perspective suggested by Greeno and his colleagues (1998) and Greeno and van de Sande (2007) than in the form of social situation described by Vygotsky ${ }^{4}$, as their perspective emphasises that all learning occurs in some situation and focuses on the activities and practices of learning and includes participation in these practices. Further, in line with Kovalainen and Kumpulainen (2007, p. 143) this understanding is supported by the notion that the nature of "classroom interaction is a dynamic and locally established process that is being constructed and reconstructed within a given social group". The socio-culturally oriented concept of situatedness is useful in this study, particularly in understanding how each of the preschool classrooms studied here is a unique entity within which the interactions between the teacher and children produced and sustained this uniqueness. Along with this idea, the qualitative

4 One of the reasons for this choice is that the current study does not explore individual children's perceptions or experiences as psychological attributes (which is emphasised in the work by Vygotsky), but rather inspects situatedness as an educational, group-level (locally constructed), socially constructed and observable phenomenon. Furthermore, these approaches better enable conceptualising situatedness in terms of specific institutional preschool education than would Vygotsky's definition (cf., Cole \& Gajdamaschko, 2010). 
sub-studies were utilised in particular to unravel the situated nature of the selected classrooms and further justify the use of the principles of the mixed methods approach within this study.

The concept of context bridges the socio-cultural approach and ecological model. The concept of context within this study is mainly drawn from the ecological model by Bronfenbrenner (1979), since Vygotsky himself preferred to use other terms such as situation or environment in reference to context (Cole \& Gajdamaschko, 2010). Furthermore, the term "context" appears to hold different connotations depending on which line of translations of Vygotsky's extensive work one chooses to follow (see also Cole \& Gajdamaschko, 2010). Therefore, within this study, the concept of context is used to bridge together the socio-cultural approach and ecological model, and it is understood concretely as the presence of social, cultural and ecological environments (Bronfenbrenner, 1979) that are mediated through individuals' practices and active engagement with each other within these environments (Cole \& Gajdamaschko, 2010). In practice, this means that individual development occurs through social interaction within a cultural community and society in which personal and interpersonal actions take place (Rogoff, 2008; Smidt, 2009). By adopting the socio-cultural approach and ecological model side by side in this study, an attempt to understand environments as contexts of development is being made. By doing so, this study also aims to bring forth the idea suggested by Sabol and Pianta (2012), which emphasises the need for gaining a socio-cultural and ecological understanding of the complexity of teacher-child interactions.

Ecological model. Bronfenbrenner (1979) uses the concept of proximal processes in describing the profound forms of interaction between a child and people, objects, and symbols in his or her most immediate environment. Examples of such proximal processes in children's lives are their meaningful relationships with parents, relatives, and teachers in different settings. Proximal processes typically become progressively more complex, which results from ongoing reciprocal interactions between the active person and his/her immediate environment (Bronfenbrenner \& Morris, 2006). Furthermore, the idea of shifting the focus from an analysis of individual behaviour and cognition to larger systems that include behaving, cognitive agents interacting with each other and with other subsystems in the environment is also constituted in the situative perspective (Greeno et al., 1998), in which the focus is on interactive systems of different sizes.

In the educational context, proximal processes (i.e., the child's proximal relationships with teachers and peers) are also the primary mechanism through which opportunities to develop are afforded to children (Downer, Sabol, \& Hamre, 2010). As children transition from their home to day care centres, preschools and primary schools, the changes in their proximal processes also change in significant ways as new significant persons - teachers and peersemerge in their daily interactions (Bronfenbrenner \& Morris, 2006). As children enter different educational contexts, they are simultaneously connecting to the educational culture of their society while, for instance, their school, as an insti- 
tution, transmits the values and expectations of the society around them. Thus, the proximal relationships can be seen to interact with and be affected by more remote ones.

The aforementioned interactions are referred to as a nested arrangement of concentric structures consisting of a microsystem, mesosystem, exosystem, macrosystem, and chronosystem (Bronfenbrenner, 1979, 1994). Each of the systems is embedded in the preceding ones and can be seen to affect the developing individual either directly or indirectly. The ecological model (Bronfenbrenner, 1979, 1994) fits in well with and contributes to the theoretical framework of this study, particularly in regard to the concept of transmitting nature of the systems on five ecological levels implying that teaching and teacher-child interaction can never be separated from its context. The microsystem encompasses the personally experienced environment of the child, such as his/her home or school, where the child is interacting through proximal processes. The mesosystem is a combination of the relations between two or more microsystems, for instance those of the home and preschool, as the child is bringing his/her personal experiences, knowledge and history into a new context. Moving beyond the direct experiences of the individual child, the exosystem represents occurrences in the environments outside the child's direct experience that mediate affects. For example, the preschool teacher may be experiencing difficulties in her personal life and these issues may influence her interaction with the children in her preschool classroom. Macrosystem represents the cultural level of belief systems or ideologies, for instance political circumstances or legislation. For instance, a national core curriculum for preschool education could represent such a level in Finnish preschool classrooms, as it mediates the cultural beliefs of child rearing or education without the child being actively or directly involved as a participant in its formation. Finally, the chronosystem represents the importance of time as a characteristic affecting the child as well as the environment in which the child functions (Bronfenbrenner, 1994). This system introduces the idea that a developing person, the child, changes over time, as do the surroundings across historical time. As a relevant example, the chronosystem applies to preschoolers who are changing, learning and growing during the preschool year in that their development is influenced by the context of historical time and its cultural demands. This conceptualisation also further links the ecological model with the socio-cultural approach (e.g., Vygotsky, 1978) and aids in understanding the situated nature (e.g., Greeno et al., 1998) of development and learning: Preschoolers are part of their own age cohort and situated in society, as well as within their day care centre/school in that society, and in turn within the classroom within their day care centre/school.

In the current study, proximal and institutionally situated teacher-child interactions were observed on the micro level. However, it is worth considering how the prevailing relations on the macro level simultaneously extend to what is actually being observed in individual classrooms. For example, legislation extends to the classrooms in certain observable ways: for instance, each classroom has a particular number of children in it (due to legislation on the teach- 
er-child ratio per classrooms), and, specific contents and practices are being observed (due to the obligatory nature of the National Core Curriculum for Preprimary education, 2010). These factors indicate how significantly the broader spheres of the ecological model are present in daily life within preschool classrooms.

\subsection{Interaction and relationships between teachers and children}

As the previous chapter laid the foundation for the relational, situated and contextual nature of development and learning, it is now time to move on to discuss development and learning taking place in the institutional preschool classroom context. In the classroom context, children interact with the teacher, and these interactions have qualities that are unique from those of the children's interactions with, for example, their parents. This chapter aims, in particular, to tackle the uniqueness of teacher-child interactions in the educational context.

Several researchers have suggested that especially teachers should be taken into account as important mediators of learning opportunities (e.g., Moll \& Whitmore, 1993; Pianta, Hamre, \& Stuhlman, 2003). In other words, even if the structure of the classroom promotes children's activity and agency, activities require the teacher's active involvement as well: teachers may, for instance, function as a guide and supporter, active participant in learning, and evaluator or facilitator (Moll \& Whitmore, 1993). Classroom interaction in the school context has been conceptualised in terms of content, teachers and students: content is exchanged through interaction between teachers and students, and teachers set the balance between content and pedagogical knowledge while determining and identifying the individual characteristics of the students (Stürmer, Könings, \& Seidel, 2012). When it comes to younger children, such as preschoolers in this study, content may play a less central role, but the interaction between the teacher and children in the classroom, as well as the element of pedagogy, do not vanish. All in all, interaction and relationships between the teacher and children can be considered to be an essential part of the classroom experience for all children and a potential resource for improving developmental outcomes (Pianta, 1999; Rimm-Kaufman \& Hamre, 2010).

It has been suggested that the interactions that children share with teachers take on similar forms as those with parents in the home context (e.g., affiliation, attachment) and may serve similar functions (Pianta, 1999; Pianta et al., 2003). The relationship between the teacher and children, however, is different in the sense that teachers establish a professional role toward children. The relationship is always an asymmetrical one, meaning that the teacher is more mature and has a bigger role in determining the quality of the relationship (Pianta, 1999; Pramling Samuelson \& Johansson, 2009). Pramling Samuelson and Johansson (2009) suggested that children also recognise the asymmetry in the relationship between teachers and children, but accept it as being part of the tra- 
ditional teacher role. As a consequence, through their professional role, teachers can be considered to be key players in determining what kinds of opportunities are provided to children for learning, social development and play, to name a few (e.g., Hännikäinen, de Jong, \& Rubinstein Reich, 1997; Sylva et al., 2007), and in how such opportunities are organised. Thus, teachers - as adults - are always standing in a potential pedagogical relation to the children (van Manen, 1991).

Kernan, Singer and Swinnen (2011) have suggested that teachers' interaction with children is expressed on three levels, with each level providing unique support for children's well-being in group settings as well as a secure base for learning and development. This idea elaborates the variety of interactions teachers can have with children, as well as children with each other in a group context, and further highlights the fact that different forms of interaction are necessary as these serve differing purposes in children's development. First, the level of interaction between the teacher and individual child serves as a base for security, an idea initially drawn from attachment theories (e.g., Bowlby, 1980; Howes \& Matheson, 1992). Constructs or qualities - such as reciprocity, sensitivity, coordination and mutuality — can be used to describe the interactions and relationships between the teacher and children (e.g., Howes \& Hamilton, 1992; Pianta, 1999). Several studies have indicated that children's experience of secure and warm relationships with their teachers enhances, among other aspects, the children's academic performance (Birch \& Ladd, 1997; Hamre \& Pianta, 2005), as well as supporting positive peer relationships (Howes, Hamilton, \& Matheson, 1994; Jennings \& Greenberg, 2009). Children who have established a secure relationship with their teachers are known to be more eager to explore their environments, as well as considering their peers as potential partners to play with (Howes, 2000; Howes \& James, 2002); therefore, teachers' being supportive of each individual child is of importance.

Second, dyadic (one-to-one) relationships and interactions within subgroups of the whole class serve as means to socialise children and familiarise them with the basics of peer relations. From an early age, children seek the company of other children but often need the support from the teacher to join in activities (Kernan et al., 2011). Teachers, thus, should support children to function constructively with each other in daily interaction. Third, interactions on the level of the whole group, as well as within subgroups, serve as a platform on which to develop relationships among groups of children (Kernan et al., 2011; Vaughn \& Santos, 2008). The relationships on the level of whole group are also of importance in developing children's sense of belonging to the group, also referred to as instilling a feeling of togetherness (Hännikäinen \& van Oers, 2002; van Oers \& Hännikäinen, 2001).

The threefold division of teacher-child interactions according to group size adds a significant perspective for this study as well, since it clearly depicts the different group levels - dyadic, subgroups, whole group-between which teachers are moving as they interact with the children in their classroom. Teaching and interacting is always connected to the whole group of children within a 
classroom: sometimes the interaction takes place with a single child and sometimes with two or more. The beauty of teacher-child interactions lies within the intertwined nature of these different levels as teachers aim to take the needs and abilities of individual children into consideration while keeping the group as a whole in mind. The research conducted by Kernan et al. (2011) focused on the education of toddlers, who are much younger than the children (6-year-olds) examined in this study. However, perhaps the same group levels of interaction are present no matter how young or old the children are, but the amount of time spent on each type on interaction may differ with age (i.e., younger children may spent more time on seeking security from the teacher, but as the children's competence grows with age teachers are able to direct the children's interactions more toward each other, for instance in the form of shared play). What is important is teachers' ability to stay alert concerning children's needs and to transform their pedagogical practices accordingly in a thoughtful manner.

\subsection{Teachers' pedagogical practices ${ }^{5}$}

The interactional relationships between teachers and children enable learning and development in educational contexts, and the practices that teachers produce in daily interaction with children make the interactions meaningful. Indeed, it has been conceptualised that teaching quality takes into account both a teacher's interactions with his or her students leading to learning and the specific behaviours and practices of the teacher in the classrooms (Rimm-Kaufman \& Hamre, 2010). Previous studies on educational contexts have highlighted the importance of teachers to develop practices that offer a fruitful context for early learning and development (e.g., Bredekamp \& Copple, 1997; de Kruif, McWilliam, \& Ridley, 2000). When learning and development are studied, the attention is naturally directed at educationally relevant questions like, 'How teachers approach children?' or, 'What do teachers say and do, and why?' This makes the concepts of pedagogy and teachers' pedagogical practices highly relevant.

Merriam-Webster Dictionary and Thesaurus Online (2013) define pedagogy as 'the art, science, or profession of teaching'. In this broad sense one could say that pedagogy is something that is guiding the teacher. For instance, as van

$5 \quad$ Teaching style has been used as a key concept in educational research, particularly regarding education for older children and adults during the 1980s and 90 s (e.g., Conti, 1985; Goudas, Biddle, Fox, \& Underwood, 1995). During the first decade of the $21^{\text {st }}$ century, the topic of teaching practices has become more prevalent and its focus has increasingly been on teacher-child classroom interaction (e.g., Hamre et al., 2012; Pianta, 1999), considering both parties in the teaching process. In this study, the term practices refers to a teacher's systematic, conscious activity, which is also affected by the teacher's personal values and his or her conception of the child as a learner; hence, referring to teachers' practices as taking place in the interactive system of preschool classrooms (Greeno et al., 1998). 
Manen (2002, pp. 55) writes: "While the teacher may be there for children, he or she is not there to be loved or to be buddy-buddy with children. As a lover is guided by love, as a friend is guided by friendship, so a teacher is guided by pedagogy." Indeed, pedagogy is, above all, purposeful activity reflecting the teacher's factual knowledge of different age stages and children's abilities, but simultaneously the practical ability to distinguish between appropriate and less appropriate ways of producing practices with respect to certain group of children. Pedagogy is thus seen as a combination of teachers' knowledge of learning and development as well as their tact and thoughtfulness in interacting with children (van Manen, 2008). Pedagogy has also been used as a term to refer to teachers' instructional techniques and strategies, as well as regarding aspects of learning environments that enable learning to take place (Siraj-Blatchford et al., 2003).

The concept of pedagogical practices has been given different meanings in previous studies (e.g., Sylva et al., 2007). In this study, pedagogical practices are understood as the teachers' thoughtful actions by which he or she aims to act in the best interests of each child (i.e., considering what is good and what is not good for the child as well as what each child's strengths and interests are), mediated through language, gestures and atmosphere, and which take place in concrete, real-life situations at the heart of the interactions and relationships between the teacher and each child in his or her class (see also van Manen, 1991, 2002, 2008). Similar thoughts have been introduced by authors who acknowledge the idea of developmentally appropriate practices (e.g., Bredekamp \& Copple, 1997). According to this branch of literature, teachers make decisions about children's well-being and learning based on knowledge concerning child-development, the needs and strengths of individual children in their class, and the contexts in which these children live. Although the present study acknowledges these ideas, more emphasis is nevertheless placed on the reciprocal and understanding interaction between the teacher and child in given educational settings as the starting point of development.

What is also of particular interest is that some studies have also established connections between high quality in teachers' pedagogical practices and classroom quality. For example, Sylva and her colleagues (2007) discovered that teachers who worked in centres establishing higher curricular quality (measured with ECERS-E) took a more active role in teaching through pedagogical practices that involve scaffolding children's learning through play, modelling activities/interactions rather than monitoring children's play, or attending care routines. Simultaneously, these children were more engaged and spent more time in one-to-one interactions with their teachers (Sylva et al., 2007), indicating the importance of teacher-child interaction in educational contexts.

In Finnish preschool education, the role of play in children's development and a play-like approach to learning have been emphasised as the objective for learning as well as a mediating factor in learning environments (National Core Curriculum for Pre-primary Education, 2010). Play has also been referred to as the leading activity in preschool children's development (Vygotsky, 1978) 
through which children have the possibility to behave beyond their average age and to practise new skills. From the teacher's point of view, utilising play as a pedagogical practice is thus an effective way of enhancing meaningful learning experiences (e.g., Sylva et al., 2007).

Teachers' pedagogical sensitivity - a call for situational awareness. Each teacher brings his/her own history - experiences and knowledge to the teaching profession and to daily interaction in the classroom. What is known is that teaching is a profession that always involves the whole persona of the teacher. Teaching requires continuous reflection by the teacher on the actions that he or she puts into practice as well as on the personal values he/she holds, which is of importance for the pedagogical relationship between the teacher and the children in his/her class. At the same time, the teachers' decisions and practices are usually executed in their daily work with children without having an excessive amount of time to think them through (van Manen, 1995; Stipek \& Byler, 1997). The most profound ideologies are often subconscious by nature and occur in "the blink of an eye", but they nonetheless have an impact on what teachers consider to be appropriate for any given child in their classroom and direct their decision making and practical actions. This type of 'intuitive pedagogy' is referred to by van Manen (2008) as pedagogical sensitivity. Pedagogical sensitivity means to act tactfully as an educator, that is, to be able to see what goes on inside children, to understand the child's experience, as well as to sense the pedagogical significance of the given situation and to have an idea of what to do, how to do it and why (van Manen, 2008). In a broader sense, this refers to teachers being reflective, situationally aware and weighing educational situations from a pedagogical perspective. Teachers' warmth in interaction, listening to children, as well as so called 'professional love' (Page, 2011), 'pedagogical tact' (van Manen, 2008) or 'pedagogical sensitivity' (van Manen, 1991) are phenomena that are hard to measure, yet they are something that is observable during the interaction between a teacher and children. Teachers' sensitivity has also been proven to be a reliable predictor of secure teacher-child attachment, particularly in day care centres (Ahnert, Lamb, \& Seltenheim, 2006).

In line with this study, utilising the notions of the socio-cultural approach and ecological model, it is worth noting that teachers' work and pedagogical choices can never be extracted from their broader cultural and societal contexts, or from the expectations that these contexts place on teachers. There are, for instance, the different needs of the individual children in the teacher's classroom that need to be taken into consideration, as well as the institution's goals and aims concerning the educational content that need to be met. In addition, parents express expectations and wishes toward the preschool (Hujala, Baclund-Smulter, et al., 2012), and in Finnish preschools (as is the case in many other countries) parents are considered important partners in the educational contexts. Furthermore, in the background, the regulations and legislations of the school, districts and society (e.g., Bronfenbrenner, 1979; Hamre et al., 2013; Pianta, 1999) direct teachers' work on a broader level, despite which Finnish teachers are relatively free to choose their own ways of teaching (Office for 
Standards in Education, 2003). Such aspects tie teachers and their predagogical practices, as well as the teacher-child interactions, to their cultural and societal contexts. 


\section{TEACHERS' CONTRIBUTION TO CLASSROOM PROCESS QUALITY}

Broadly speaking classroom quality can be divided to two sets of features that contribute to quality, namely, structural and process features. Structural features - such as adult-child ratio (La Paro et al., 2009), teachers' educational background or work experience (Early et al., 2006; Gerber, Whitebook, \& Weinstein, 2007; Lamb, 1998), and class size (e.g., Blatchford, 2003; Bredekamp \& Copple, 1997) - have been shown to have effects on classroom quality. The results, however, have not yielded entirely unambiguous results (see, e.g., Early et al., 2007). Furthermore, rapidly increasing evidence indicates that classroom process features (such as the quality of teacher-child interaction and relationships) can indeed be strong predictors of both children's academic and social skills (Howes et al., 2008; Mashburn et al., 2008; Sylva et al., 2007). In measuring classroom quality, observations have been shown to be a more valid tool than teachers' self-reports (Connor, Son, Hindman, \& Morrison, 2005; Pianta \& Hamre, 2009), and the focus on indicators of quality has shifted toward the quality of processes manifested in observed teacher-child interactions (Howes et al., 2008). It has been shown that teachers differ in their practices and interaction with children (Howes et al., 2008; LoCasale-Crouch et al., 2007), and, on that account, it is reasonable to assume that the quality of their classrooms also differs.

It goes without saying that the concept of quality is diverse. When discussing quality in an educational context, it is apparent that there are several theoretical frameworks for conceptualising quality and the components of which quality is constructed. For instance, Sheridan (2007) has suggested using the term 'pedagogical quality', focusing on children's opportunities for learning and development. Her conceptualisation draws from the Early Childhood Environmental Rating Scale (ECERS: Harms \& Clifford, 1980) and Early Childhood Environmental Rating Scale - Revised Edition (ECERS-R: Harms, Clifford \& Cryer, 2005), which conceptualise quality in terms of examining early childhood environments in order to make improvements in provisions for young children. The ECERS framework is of the most frequently used quality assessment 
frameworks in Europe and elsewhere, and several research groups have established revised, translated versions of the original ECERS, such as the ECERS-R in Arabic (Early Childhood Environment Rating Scale - Revised, Hadeed, 2013) and the ECERS-E (The Four Curricular Subscales Extension to the Early Childhood Environment Rating Scale (Sylva, Siraj-Blatchford, \& Taggart, 2010). In the Finnish educational context, in most cases quality has been conceptualised using the quality evaluation model (Hujala-Huttunen, 1995; Hujala et al., 1999; Hujala, Fonsén, et al., 2012), where quality is reviewed from the point of view of different actors and factors in the context of early childhood education. Also, in the Finnish context, Tauriainen (2000) has evaluated quality through a participatory paradigm, where the perceptions, descriptions and interpretations reported by three primary stakeholders - staff, parents, and children-regarding quality in one particular day care group, were considered.

Several researchers have identified three broader theoretical domains of classroom interaction and teachers' practices that contribute to classroom quality: socio-emotional support and atmosphere, classroom organisation and management, and instructional support (Eccles \& Roeser, 1999; Brophy, 2000; Hamre et al., 2007; Hamre et al., 2013). One of the theoretical frameworks that relies on this three-domain structure is the Teaching Through Interactions framework (Hamre et al., 2013), which uses the Classroom Assessment Scoring System (CLASS: Hamre \& Pianta, 2007; Hamre et al., 2007) to objectively assess quality. The Teaching Through Interactions framework is also the main theoretical framework referred to in discussing classroom quality in this study. There is a growing body of ongoing research concerning different age groups in different European countries using the teaching Through Interactions framework, and the CLASS measure (e.g., Cadima, Leal, \& Burchinal, 2010; Cadima, Peixoto, \& Leal, 2014; Pakarinen et al., 2010; Slot, Leseman, Mulder, \& Verhagen, 2014; von Suchodoletz et al., 2014), which indicates the importance of understanding process quality also in terms of teacher-child interactions in the broader realm of educational research, as well as indicating the validity of the CLASS measure and the Teaching Through Interactions framework outside the United States. Classroom quality has also been described in terms of child-centred vs teacherdirected practices (e.g., Perry, Donohue, \& Weinstein, 2007; Stipek \& Byler, 2004). One of the theoretical frameworks that has adopted this perspective is the Early Childhood Classroom Observation Measure (ECCOM: Stipek \& Byler, 2004), which introduces a third set of practices, namely, child-dominated practices. Common to both of these frameworks (Teaching Through Interactions [CLASS] and ECCOM) is that they consider the teacher to be the key to creating high-quality learning opportunities and establishing favourable learning environments. As these two frameworks are a significant part of this doctoral study, the main and broad theoretical underpinnings of both frameworks will now be briefly introduced. 


\subsection{Teacher-child interactions in the Teaching Through Interactions framework}

The Teaching Through Interactions framework consists of three broad domains that relate to interactions between teachers and children in the classroom (Hamre \& Pianta, 2007; Hamre et al., 2007) and are hypothesised to be important in promoting children's learning and social development (Hamre et al., 2013). Teacherchild interaction in the domains of Emotional Support, Classroom Organisation and Instructional Support have been shown to contribute to young children's social and cognitive development in a substantial amount of research (e.g., Early et al., 2007; Mashburn et al., 2008; Rimm-Kaufman, La Paro, Downer, \& Pianta, 2005). By referring to Teaching Through Interactions framework (Hamre et al., 2013), the prior, long lines of theoretical thinking beyond exploring teacher-child interactions are intertwined with the theoretical underpinnings of this doctoral study. The three theoretical domains thus compose a relevant, broader theoretical framework for understanding and conceptualising the interaction between teachers and children in this study. The observational measure developed to assess quality of teacher-child interactions in these domains, the Classroom Assessment Scoring System (CLASS; Pianta, La Paro \& Hamre, 2008), enables detailed descriptions of several specific dimensions of teacher-child interaction that exist within each of the three broader domains. All of the sub-studies conducted as part of this doctoral study are grounded in the use of the CLASS measure, thus both the measure and its validity will be described in detail in Chapter 5.

Positive and supportive teacher-child interactions constitute the domain of Emotional Support, which has been shown to foster children's willingness to explore and participate in classroom activities (Early et al., 2007; Hamre \& Pianta, 2005). More broadly speaking, emotional support encompasses the aspects of a classroom climate that helps children to be acknowledged and cared for as individuals (Curby et al., 2013). It is known that children who experience a close and supportive relationship with their teacher are also likely to show greater selfdirectedness and fewer problem behaviours, and they appear to be more socially competent in the classroom context (Mashburn et al., 2008; Pianta, La Paro, Payne, Cox, \& Bradley, 2002). The motivational aspect of teachers' emotional support has also been pointed out (Pressley et al., 2003). Concrete teachers' practices that have been associated with emotional support include teachers' sensitivity toward children's needs, warm feelings for children, and showing responsiveness as well as respect in their interactions with children (Hamre \& Pianta, 2007; Pianta, Belsky, et al., 2008). In addition, teachers in classrooms where high levels of emotional support are provided tend to allow children developmentally appropriate levels of autonomy and responsibility (Pianta, La Paro, et al., 2008; Wentzel, 2002).

The domain of Classroom Organisation contributes to the development of children's self-control and behavioural self-regulation and making noncompliant behaviour less likely to occur (Rimm-Kaufman et al., 2005; Rimm-Kaufman, Curby, Grimm, Nathanson, \& Brock, 2009). Children's ability to behave in a co- 
operative manner in preschool in turn predicts their early achievements in school (Ladd, Birch, \& Buhs, 1999). In efficiently managed classrooms, children have a constant opportunity to participate in learning activities (Bohn et al., 2004), and as they participate they are also actively engaged in their work (Ponitz, RimmKaufman, Grimm, \& Curby, 2009). In addition, in such classrooms, children are highly motivated to learn (Pakarinen et al., 2010). Furthermore, teachers' highquality practices in the domain of classroom organisation are shown to be connected to children's higher social competence in Finnish preschool classrooms (Siekkinen et al., 2013). Concrete teachers' practices that have been associated with classroom organisation include for instance the use of proactive discipline strategies, showing consistent behavioural expectations, minimising downtime, and using a variety of strategies and modalities during instruction (Pianta, La Paro, et al., 2008). In addition, teachers' efficient use of time, giving children more opportunities to learn, has been found to enhance organisationally supportive interactions (Hamre et al., 2012; Howes et al., 2008).

The domain of Instructional Support captures the ways in which teachers implement instructional discussions and activities to effectively support children's academic learning (Howes et al., 2008; Mashburn et al., 2008; Pianta \& Hamre, 2009) and higher-order thinking skills (Pianta, La Paro, et al., 2008). Instruction is more effective when scaffolding and feedback take children's performance into account and when productive time for learning is maximised (Burnett, 2002; NICHD ECCRN, 2002; Perry, et al., 2007). In particular, teachers' feedback and praise have been noticed to have an effect on children's self-esteem (Burnett, 2002). Concrete teachers' practices that have been associated with classroom organisation include the use of activities that promote analysis and reasoning, focusing on expanding learning (instead of merely on correctness) in ongoing discussions, and the use of rich vocabulary in ongoing interactions (Curby et al., 2013). In classrooms with a high-quality instructional climate, teachers are also known to promote higher-order thinking skills and creativity, and to provide more verbal feedback relevant to the learners' performance (Howes et al., 2008).

\subsection{Teachers' practices in the ECCOM framework}

Another approach to conceptualising instructional and emotional quality in early childhood education classrooms is to apply the concepts of child-centred and teacher-directed practices in relation to the NAYEC guidelines for developmentally appropriate practices (e.g., Bredekamp \& Copple, 1997) and the body of research demonstrating the importance of teacher-child interactions (e.g., Pianta, 1999; Pianta, Steinberg, \& Rollins, 1995). The ECCOM framework utilises the aforementioned division of teachers' practices according to childcentred and teacher-directed practices, but it additionally introduces a third set of practices, namely, child-dominated practices (Stipek \& Byler, 2005).

Child-centred practices are characterised by the teacher providing children with both guidance and opportunities for directing their own exploration of 
objects and academic topics; this approach to teaching is akin to a partnership between the teacher and the children (Schweinhart \& Weikart, 1988; Stipek \& Byler, 2005). In child-centred classrooms, teachers provide strong support for children's learning efforts and social skills and are sensitive to children's needs and interests (Stipek \& Byler, 2005). Some connections between child-centred practices and children's motivation have been reported (Stipek, Feiler, Daniels, \& Milburn, 1995). Furthermore, recent studies have shown that parents also established more trust toward teachers who utilised more child-centred practices (Lerkkanen, Kikas, Pakarinen, Poikonen, \& Nurmi, 2013).

Teacher-directed practices, in contrast, involve an emphasis on structured drill-and-practice group lessons, the teaching of discrete skills in small steps, and praise when predetermined goals are reached (Schweinhart \& Weikart, 1988). This means that certain 'basic' skills need to be mastered before more advanced ones can be introduced (Rasku-Puttonen et al., 2011). Furthermore, practising basic academic skills through oral recitation and worksheets is given considerably more weight, while children's interests and the development of their social skills receive less attention (Stipek \& Byler, 2004).

Child-dominated practices are characterised by teacher's provision of very little control, direction, or feedback for children. A general lack of clear and coherent activities, lessons or rules is apparent in this approach, and teachers using this method have been found to have failed in supporting children's interpersonal skills (Stipek \& Byler, 2005). Somewhat less empirical work has been conducted on the importance of child-dominated practices concerning children's development and achievement (for exceptions, see Lerkkanen et al., 2013; Rasku-Puttonen et al., 2011).

In general, teachers vary in applying these practices and usually establish different combinations of each of the three approaches (Stipek, 2004). Children's achievements have been more often associated with teachers' child-centred practices, such as regarding their academic skill development and behavioural outcomes (Perry et al., 2007), as well as with respect to their motivation (e.g., Lerkkanen et al., 2012). However, some gains regarding children's achievement have also been reported in connection with the use of teacher-directed practices, but mainly in the school rather than preschool context. For example, children in more teacher-directed classrooms had higher scores on letter and reading tests, and achieved greater gains in reading and math, compared to children in childcentred classrooms (Stipek et al., 1998; Stipek et al., 1995).

The Teaching Through Interactions and the ECCOM frameworks are used to view teacher-child interactions from two different, yet complementary perspectives. By adding the ECCOM's theoretical conceptualisation of teaching practices alongside that of teacher-child interactions in Teaching Through Interactions framework, a new understanding of classroom quality is generated since, to the present author's knowledge, other studies combining these particular theoretical frameworks and measures do not yet exist. 


\section{AIM AND RESEARCH QUESTIONS}

In this study, it is assumed that teachers, through their professional role in the education system, possess a certain authority and responsibility regarding what occurs in their classroom (e.g., Hännikäinen et al., 1997; Sylva et al., 2007). Furthermore, teachers' pedagogical practices in regard to the interaction and relationships between them and the children in their classroom, is considered as the core aspect that constructs meaningful learning experiences and opportunities for children (van Oers, 2012; Pramling Samuelson \& Johansson, 2009). If we look at teaching, learning and interaction in preschool classrooms from a broader perspective, it is evident that general descriptive and generalisable information, as well as micro level descriptive information, that can induce practical interventions and concrete practices is needed to understand the phenomenon of teacher-child interaction in its current form. Teacher-child interaction in preschool classrooms - as a phenomenon - requires a methodological perspective that can provide a good overview of what is happening in daily interactions in Finnish preschools as represented by the sample of this study. Under these circumstances, the principles of mixed methods research were utilised to combine the results of the three sub-studies within this study in order to reflect the multiplicity of the phenomenon (i.e., teacher-child interaction as a function of an interactive system in a given situated context).

This study was designed to contribute to the discussion on the importance of teachers' responsiveness and sensitivity in their pedagogical practices and teacher-child interactions in supporting children's favourable development in early educational settings, when the transition to formal schooling is at hand. The general purpose was to create a more profound knowledge and understanding of the role that teachers play in children's learning and development in Finnish preschool classrooms, and thereby to contribute to the discussion on the complexity of classroom interaction and classroom quality from the teacher's perspective. Children's learning and developmental outcomes were not measured within this study; rather, the focus was on teachers and their practices regarding their daily interactions with children. 
Due to the multifaceted nature of the phenomenon, this study pursued two aims. The first research aim was (1) to examine what types of interaction and teachers' pedagogical practices contribute to classroom quality in Finnish preschool classrooms; and the second aim was (2) to construct a timely description of teacherchild interaction and teachers' pedagogical practices in Finnish preschool classrooms, the time when the transition to formal schooling is fast approaching. These aims were addressed in the following specific research questions, the answers to which were sought through three empirical studies (sub-studies I, II, and III). The specific connections between the purpose, aims and research questions are shown in Table 1.

Previous profiling studies have suggested that it is possible to identify generalisable profiles of classroom quality and teacher-child interaction (LoCasale-Crouch et al., 2007; Curby et al., 2009), based on the knowledge of teachers' pedagogical practices and teacher-child interaction being influential in children's development. In order to define and further analyse such classroom quality profiles in the context of Finnish preschool classrooms, the first research question of this study was formulated as follows.

Research question 1: What kinds of profiles of teachers' practices and teacherchild interactions can be identified that reflect the process quality in Finnish preschool classrooms? (Sub-studies I and II)

Teachers' pedagogical practices, of which there is a wide variety, have been shown to be of importance in children's learning and development (Burnett, 2002; Howes et al., 2008; Pianta, 1999). In order to cast light on how individual teachers concretely produce practices regarding their daily interaction with children in their classroom as well as good practices in the more general sense the second research question enquired as follows.

Research question 2: How do teachers support children's pre-academic skills and social interaction in Finnish preschool classrooms during structured learning sessions, and what are the similarities and differences between teachers' practices? (Sub-studies II and III)

Teacher and classroom characteristics - such as education, work experience, and personal goals or beliefs-have been shown to contribute to the ways in which teachers customise their pedagogical practices for children (e.g., Early et al., 2007). In order to take teacher and classroom characteristics as a complimentary part of the teaching process into account, the third research question was phrased as follows.

Research question 3: What types of pedagogical opportunities do the combination of teacher and classroom characteristics and teachers' pedagogical practices create in Finnish preschool classrooms? (Sub-studies I and II) 
TABLE 1 The connections between the purpose, aims and research questions of the study

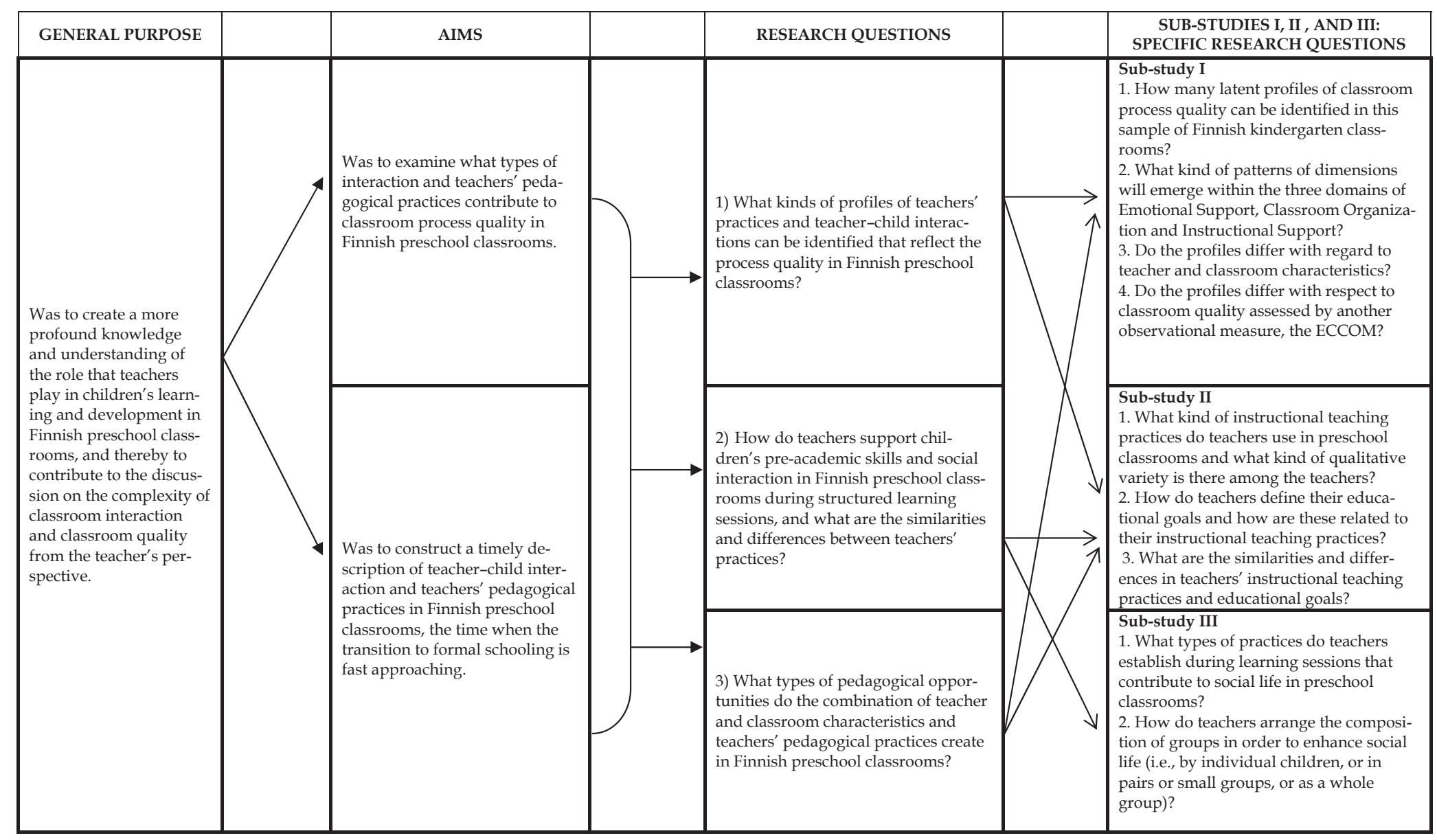




\section{METHOD}

In this section, the context and the participants, and the process of data gathering and analytical process as well as the use of the principles of mixed methods research are explained. An overview of the specific research questions, the data, and the analyses pertaining to each of this study's three sub-studies is presented in Table 3, at the end of this section.

\subsection{Context of the study}

Finland is one of the rare European countries where children begin primary school at seven years of age, a year later than is usual. During the year before they start primary education, however, Finnish children have a statutory right to attend preschool (up to 700 hours during the preschool year), provided free of charge. Despite its voluntary nature, nearly all 6-year-olds (98.4\%) participate in preschool (European Commission, 2014), which means around 59,000 preschoolers on a yearly basis (Statistics Finland, 2012).

In Finland, it is typical that preschool education is provided in close concert with day care services. Day care centres, which provide care and education for children from infancy up to 6 years of age, can also provide preschool education for 6-year old children-in fact, 79\% of the Finnish preschool classrooms are situated in day care centres. Preschool education is also provided in classrooms within primary schools (21\%) (Statistics Finland, 2012). The preschool classrooms situated in primary schools typically offer only preschool education and not day care services, whereas classrooms situated within day care centres are also used for the provision of day care services. Around $71 \%$ of the children who attend preschool also attend day care before and/or after their preschool hours (National Institute for Health and Welfare, 2013, p. 4).

Preschool education is subject to the converged legislations of both early childhood education and primary education. The Children's Daycare Act (Laki lasten päivähoidosta 36/1973) and the Basic Education Act (Perusopetuslaki $628 / 1998$ ) determine the organisation of preschool education. Since the begin- 
ning of 2012, due to changes in the Children's Daycare Act, the responsibility for organising early childhood education in Finland was passed from the Ministry of Social Affairs and Health to the Ministry of Education and Culture, thus making the Ministry of Education and Culture responsible for all levels of schooling. The confluence of early childhood education and primary education is also visible at the level of the national guidelines, such as in curricula: preschool education is organised according to the frameworks of the National Core Curriculum for Preschool/Pre-primary Education (2000, 20106) and the National Core Curriculum for Primary Education (2004), both of which feature specific guidelines for the transition period from preschool to primary school. Regardless of the location where preschool education takes place (i.e., in preschool classrooms at day care centres or primary schools), the legislation is the same and parents usually take their children to the preschool classroom closest to their home. In general, the provision of preschool education in Finland is of relatively good quality and homogenous, but there are some differences in quality between individual preschool groups in particular (Hujala, Backlund-Smulter, et al., 2012).

The role of preschool education is to provide all children with an equal opportunity for learning the basic skills needed for primary school by supporting the children's own interests and motivation toward learning (National Core Curriculum for Pre-primary Education, 2010). The preschool year in Finland, thus, is in many ways characterised by the preparation for formal schooling (Ahtola et al., 2011). As the transition to school is at hand, children are taught and expected to learn responsible and competent ways of interacting with other people and taking care of themselves. The National Core Curriculum for Preprimary Education (2010) presently determines the core subject areas for preschool education, providing national guidelines and recommendations for the content of preschool education. The defined subject areas are: (1) Language and Interaction, (2) Mathematics, (3) Ethics, (4) Environmental Studies and Natural Science, (5) Health, (6) Physical and Motor Development, (7) and Art and Culture.

Finnish preschool teachers typically have either a Bachelor's degree (BA) in early childhood education (kindergarten teacher) or a Master's degree (MA) in education (primary school teachers); as a kindergarten teacher (professional title), having at least a tertiary level (college) education has become mandatory. Since 1995, all prospective kindergarten teachers have to have completed a Bachelor's degree at a university, and these graduates mostly end up working in day care centres. Those teachers who teach 6-year-old children in preschool classrooms located in primary schools typically have a Master's degree in education, but in recent times a growing number of kindergarten teachers with a Master's degree are working in preschool groups within day care centres.

6 During the data collection in February 2007, the Core Curriculum for Preschool Education 2000 was applied in Finnish preschool classrooms. The National Core Curriculum was later updated in 2010, mainly with small additional and defining aspects. The planning of the new National Core Curriculum (expected 2016) is under way. 


\subsection{Participants}

All of the sample data in this study pertain to teachers who participated in the First Steps longitudinal study (Lerkkanen et al., 2006) organised by the Centre of Excellence in Learning and Motivation of the University of Jyväskylä. The First Steps study began in 2006, covering four Finnish municipalities, with an age cohort of children born in the year 2000 and followed up from preschool through $4^{\text {th }}$ grade. Approximately 2,000 children, their parents and teachers participated. The aim of the longitudinal study was to explore, among other aspects, the links between children's academic skill development and motivation and the teacher-student interaction quality in their classrooms during the transition from preschool to primary school.

In sub-study I, a sub-sample of 49 preschool teachers (47 female, 2 male) participating in the classroom observations during the preschool year (Spring semester, 2007) was selected from the total of 137 teachers participating in the First Steps study at that time. These 49 teachers had volunteered to be observed. There were 665 six-year-old children enrolled in the classrooms of the 49 teachers. Thirty-six classrooms were located in day care centres and 13 in primary schools. In primary school settings teachers typically work alone and the group size may be relatively small, whereas in the context of day care centres each group is typically attended to by a minimum personnel of two teachers and one trained assistant and the group size tends to be larger and includes younger children. This is why, in the present sample, classroom sizes ranged from 8 to 24 children. On average, 11 children were present during each classroom observation. All of the teachers were qualified to work as preschool teachers and had at least a tertiary level (college) qualification of relevance. All teachers and the children in their classrooms were Caucasian and spoke Finnish. The teachers' years of work experience in educational settings ranged from less than a year to more than 15 years (mode $=$ more than 15 years). For all of the classrooms, typical preschool equipment and materials were provided and the educational guidelines outlined in the national curriculum (National Core Curriculum for Pre-primary Education, 2010) were followed.

In sub-study II, the participants were four preschool teachers, selected from the original 49 teachers through purposeful sampling. Two of the teachers worked in preschool classrooms located in day care centres (with 22-24 children in their classroom), and two worked in preschool classrooms located on the premises of a primary school (with 7 children in their classroom). The teachers' work experience in educational settings varied from 1-5 years to more than 15 years.

In sub-study III, the participants were 20 teachers, selected from the original 49 teachers through purposeful sampling. The majority of the teachers had relatively extensive work experience: 15 of the teachers had worked for more than 11 years in educational settings. The number of six-year-olds in the classrooms varied from 3 to 24 , with an average of 13 six-year-old children in each class. 


\subsection{Data and data collection}

\subsubsection{Classroom observations}

Quantitative observation data. Preschool classrooms were observed using the Classroom Assessment Scoring System (CLASS, Pre-K: Pianta et al., 2004; Pianta, La Paro, et al., 2008) and the Early Childhood Classroom Observation Measure (ECCOM: Stipek \& Byler, 2005). The CLASS Pre-K manual was translated into Finnish as part of the First Steps study. The observations were conducted by observers who were carefully trained by experienced senior researchers. Each classroom was observed by two independent observers, who conducted the CLASS ratings during the time spent in the classroom and after that completed the ECCOM evaluation. Both the CLASS and ECCOM ratings were thus conducted by the same two observers. These two structured observational measures provided data for sub-study I. The CLASS was used to identify profiles of classroom quality in sub-study I, while the ECCOM was used to validate these profiles (i.e., to compare the ECCOM ratings between the profiles).

The CLASS (Pianta et al., 2004; Pianta, La Paro, et al., 2008) is designed to measure classroom-level variables (i.e., observed indicators of classroom quality) in 10 dimensions under three broader domains: (1) Emotional Support (Positive Climate, Negative Climate, Teacher Sensitivity, Regard for Student Perspectives); (2) Classroom Organisation (Behaviour Management, Productivity, Instructional Learning Formats); and (3) Instructional Support (Concept Development, Quality of Feedback, Language Modelling). Each of the dimensions is rated on a 7-point scale, utilising the behavioural markers provided by the CLASS manual (Pianta et al., 2004; Pianta, La Paro et al., 2008). Scores ranging from 1-2 are seen to represent low, 3-5 mid-range, and 6-7 high classroom quality. The observations were conducted in February 2007. Two trained observers rated each preschool classroom on two observation days in regard to the 10 CLASS dimensions. The observations were conducted in cycles lasting 30 minutes, of which a 20-minute observation period was followed by a 10-minute rating period. Each classroom was observed on two different days and each observer rated the observed situation independently. Inter-rater reliability between the pairs of observers was determined by calculating intraclass correlation coefficients. All of the inter-rater reliabilities were high, varying between .80 and .96 on the first observation day (except for .63 for Concept Development) and between .76 and .94 on the second observation day.

The ECCOM (Stipek \& Byler, 2005) aims to observe and assess a typical day in early childhood education classrooms. The ECCOM is based on three dimensions: (1) Child-Centred Practices, (2) Teacher-Directed Practices, and (3) Child-Dominated Practices. These three dimensions are assessed along the following subscales: the Management subscale (4 items; Child Responsibility, Management, Choice of Activities, Discipline Strategies), the Climate subscale (4 items; Support for Communication Skills, Support for Interpersonal Skills, Stu- 
dent Engagement, Individualization of Learning Activities), and the Instruction subscale (6 items; Learning Standards, Coherence of Instructional Activities, Teaching Concepts, Instructional Conversation, Literacy Instruction, Math Instruction). The observers rated each dimension by giving one score on a 5-point scale for the Child-Centred, one score for the Teacher-Directed, and one score for the Child-Dominated dimension. The rating scale measures the percentage of time that the described practices occur during the observed classroom session on an observation day $(1=$ practices are rarely seen; $0-20 \%$ of time; to $5=$ practices predominate; $80-100 \%$ of time). Teacher's observed mix of practices can be assessed; an assessment may indicate that, for example, child-centred practices were applied $60 \%$, teacher-directed practices $30 \%$, and child-dominated practices $10 \%$ of the time (Stipek \& Byler, 2005). The inter-rater reliabilities between the observers varied between .74 and .90 for the ECCOM items. The Cronbach's alpha reliabilities for the sum scores were as follows: Child-Centred Practices $=.96$, Teacher-Directed Practices $=.93$. Within this study, only the dimensions of child-centred and teacher-directed practices were utilised in the analysis due to the fact that there was more theoretical and empirical evidence available on their usefulness in educational research than on child-dominated practices (cf., Stipek \& Byler, 2004 ).

In the present study, the ECCOM is applied mainly to validate the use of the CLASS measure in sub-study I. The CLASS and the ECCOM are known to reflect highly similar aspects of teacher-child interaction, with the main focus being on teacher-child interactions and on the teachers' practices. Furthermore, the CLASS domains (i.e., Emotional Support, Classroom Organisation, and Instructional Support) and ECCOM scales (child-centred practices and teacherdirected practices) were shown to be highly correlated (see Table 2) in the First Steps study data of 49 preschool classrooms analysed in sub-study 1 of this study. The direction of the correlations is in line with the theoretical assumption that higher emotional, organisational and instructional support, as well as more child-centered practices constitutes good quality (Hamre et al., 2013; Stipek \& Byler, 2004).

TABLE 2 Correlations between CLASS and ECCOM

\begin{tabular}{|l|c|c|}
\hline Teacher-child interactions (CLASS) & \multicolumn{2}{|l|}{ Teaching practices (ECCOM) } \\
\hline & Child-centred & Teacher-directed \\
\hline Emotional support & $.81^{* * *}$ & $-.80^{* * *}$ \\
\hline Classroom organisation & $.76^{* * *}$ & $-.70^{* * *}$ \\
\hline Instructional support & $.66^{* *}$ & $-.67^{* *}$ \\
\hline
\end{tabular}

Note: ${ }^{* *} p<.01 ;{ }^{* * *} p<.001$ 
Qualitative observation data. While the preschool classrooms were observed and assessed according to the CLASS and the ECCOM measures, the teachers were either carrying an MP3-player $(n=41)$ that audio recorded their talk and teacher-child interactions in the classrooms or they were video recorded $(n=8)$. Teacher-child interaction was recorded during the morning assembly (i.e., the time for educational activities in the morning, before lunch and naptime). The length of the recordings varied from 9 minutes to 140 minutes, with the average being 53 minutes. Altogether, 77 successful audio/video recordings (i.e., 69 hours in total) were gathered. All of the recordings were transcribed, and these transcripts of the observed classroom interactions provided the qualitative data for sub-study II (i.e., 10 recordings, 92 pages of transcribed text) and sub-study III (i.e., 34 recordings, 538 pages of transcribed text) of the present study.

\subsubsection{Teacher and parent questionnaires}

Preschool teachers were asked to complete a questionnaire on their demographics (i.e., basic education, years of work experience in educational settings, and number of additional personnel in their present classroom) and to reflect on, among other aspects, their curricular goals and the frequency of their use of curriculum-based instructional activities (specifically, literacy- and math-related activities). Teachers' questionnaire data were collected after the classroom observations had been conducted, in the spring 2007, and these data were utilised in sub-studies I and II.

Parents (both mothers and fathers) were asked to complete a questionnaire regarding their personal background information and, for instance, their conceptions of preschool education and parenthood in general. Parents' questionnaire data were collected in the spring of 2007. Data utilised in this study pertained to the mothers' educational background, and this information was used to validate the classroom quality profiles in sub-study I.

\subsection{Ontological and epistemological assumptions}

In moving on to the methodological discussion of the current study, it is firstly of importance to look at the ontological and epistemological assumptions of this study. Ontology concerns the assumptions made about the nature of the social reality that is being investigated, whereas epistemology concerns assumptions on how knowledge of this reality can be obtained (Blaikie, 2007). The relationship between the ontology, epistemology and methodology of a given study is not unidirectional but they rather reinforce each other (Chatterjee, 2011). This means that ontological and epistemological assumptions guide the choosing of methods; but also methods, data and research decisions may shape our way of perceiving the nature of social reality and knowledge. Furthermore, when a study consists of several methodologies (i.e., mixed methods research), a thor- 
ough discussion on applicable ontological and epistemological assumptions is particularly warranted (Chatterjee, 2011).

The present study is based on the cautious realist ontology, which entails a belief in an external reality consisting of things and events which are controlled by natural and social laws. It asserts that what we observe is what exists, but emphasises that it is impossible for researchers to perceive it completely accurately because the act of observing is an interpretative process and should thus entail a critical stance towards it (Blaikie, 2007). Within this study, this ontological perspective assumes that the observed preschool classrooms and social phenomena within them exist not only in the minds of the involved teachers and children, but also in the objective world. Classrooms are thus considered to represent a reality of the objective world (see also Miles \& Huberman, 1994). Furthermore, the methodological commitments, such as choosing observation as the main data gathering method for all of the sub-studies, are in line with this ontological view: both natural and social phenomena are seen to exist independently of the activities of observer (Blaikie, 2007).

Even though cautious realist ontology suggests that an observable reality exists independent of the human mind and language, the epistemological approach of this study nevertheless adopts a perspective of social constructionism in which knowledge is seen as the outcome of people having to make sense of their encounters with the physical world and with other people (Blaikie, 2007). The activities involved in constructing knowledge occur against the background of shared interpretations, practices and language; they occur within our historical and cultural ways of being (Blaikie, 2007). This means that the interaction between teachers and the children, their involvement with materials, as well as teachers' practices are all negotiated, re-negotiated and contested in the situated discourse within the institutional setting of preschool classrooms (see also Kumpulainen, Lipponen, Hilppö, \& Mikkola, 2014). Such an epistemological perspective is closely tied to the broader, theoretically socio-cultural and ecological framework of this study, where meaningful activities in the observed preschool classrooms are jointly constructed between the teacher and the children (teacher-child interactions and teachers' pedagogical practices) while embedded in the surrounding social, cultural and ecological contexts (see e.g., Mercer \& Littleton, 2007; Bronfenbrenner, 1979). An explanation by Cuphik (2001) nicely draws together the approach to ontology and epistemology within this study:

“...Physical phenomena can exist without human apprehension but they only become meaningful events, in the sense of influencing action, when noticed or observed by a group of people, however small. Social phenomena are contextualised events which are perceived intersubjectively and defined as such. Phenomena are therefore events that unfold and recur in the flow of time and are only meaningful when understood in context; they are processes and not essences (Cuphik, 2001, p. 4)."

When it comes to conducting mixed methods research (an approach also applied in this study), critical perspectives have been raised concerning the challenges in relating the different types of knowledge to each other in such a re- 
search design. Challenges have been raised in particular with respect to different ontological foundations underlining quantitative (positivism) and qualitative (constructivism) research approaches (Lincoln \& Guba, 2000) making them difficult and perhaps even unfeasible to combine. Cupchik (2001) approaches this dilemma by suggesting a position of constructivist realism which acknowledges that social phenomena in fact exist in communities quite independently of professional research (realism). These real phenomena will be named and elaborated by the members of a natural community and scholars then approach this world in their own ways. It is noteworthy that both types of scholars (quantitative and qualitative) are equally selective and ultimately engage in acts of constructing (constructivism) while proceeding from the concrete world to that of abstraction (Cupchik, 2001).

As social phenomena are always multilayered events, the goal of social research should be to reveal the processes of the real world: to proceed with the research 'content first' rather than 'methods first'. This idea suggests that despite the fact that multilayered events often need to be approached with different methodologies, the interplay between descriptive richness and experimental precision can raise accounts of phenomena to progressively greater levels of clarity and bring ontological and epistemological approaches, if not fully integrated, at least closer together-an attempt of the current study as well. These ideas are the philosophical background to the upcoming discussion in the next chapter on this study's mixed methods research approach.

\subsection{Mixing methods: Combining approaches to create a more pro- found understanding}

Different researchers have used different terminology to represent the combined use of multiple methods of analysis in examining phenomena. The most commonly used terms have been triangulation (e.g., Leech \& Onwuegbuzie, 2007; Teddlie \& Tashakkori, 2003), multi-methods research (e.g., Hesse-Biber, 2010), and mixed methods research (e.g., Johnson \& Onwuegbuzie, 2004). For the present study, the term mixed methods research has been chosen to refer to the combining of quantitative and qualitative approaches to analysing, in particular, teacher-child interaction. Mixed method research has received increasing interest and been repeatedly debated over the last few decades (e.g., Bryman, 1988; Greene, Caracelli, \& Graham, 1989), and has become particularly common in recent years (e.g., Bryman, 2006; Johnson et al., 2007; Niglas, 2004). Despite the increase in the number of mixed methods studies, there is still not a clear conceptual consensus on or unified terminology for describing what mixed methods are and how they are being used (Niglas, 2004) - i.e., there are many different labels for the same phenomenon, as well as uses of the same term but for different meanings. For these reasons, a clear case-specific justification regarding the use of mixed methods research terminology is necessary for each 
study, especially in order to avoid the "whatever works" stance sometimes associated with mixed methods research (Bryman, 2006).

The principles of mixed methods research were applied in this study in several ways. The first way was the nature of the dataset (see Figure 1). In order to contribute to the general purpose of this study (i.e., to create a more profound understanding of the role that teachers play in children's learning and development in preschool classrooms, thus contributing to discussion on the complexity of classroom interaction), both quantitative and qualitative data were utilised. The quantitative method tends to yield statistical data in a raw format that enables statistical analysis as well as standardised testing of reliability and validity. Quantitative data can, among other research benefits, be effective in examining broader contexts and yield a good representativeness of cases (Hesse-Biber, 2010). In the present study, the quantitative approach was applied using structured observational tools (e.g., CLASS: Pianta et al., 2004; Pianta, La Paro, et al., 2008) as a starting point, in the first sub-study (I), in aiming for generalisable results, and as a basis for creating and selecting new sets of questions for the subsequent two sub-studies. Qualitative research, on the other hand, is looking for complexity and seeks to understand the range of experiences and their contexts rather than, for example, seeking answers to questions that pertain merely to the general population. Qualitative data, thus, aims to yield a deeper understanding of the results emerging in a research project (Hesse-Biber, 2010). In this study, qualitative sub-studies compliment and aim to more meaningfully explain the quantitative results by exploring teachers' practices on a micro level, in the interactive and situated context (Greeno et al., 1998; Greeno \& van de Sande, 2007) of Finnish preschools. Taken together, the data of the three sub-studies can be seen to comprise a whole, with quantitative and qualitative input (see Figure 1). Through the use of such multi-study arrangement of datasets, a deeper understanding of pedagogy in Finnish preschool classrooms was sought-something that would be difficult to achieve by using only one type of approach or analytical tool. Accordingly, keeping in mind a rationale of completeness (i.e., the researcher can bring together a more comprehensive account of the area of inquiry if both quantitative and qualitative methods are applied; Bryman, 2006) was one of the most earliest decisions in the research process of this study, and was also fundamental in the approach taken by the researchers of the larger First Steps study (Lerkkanen et al., 2006) at the beginning of the data gathering, when the choice of adding qualitative classroom observations to the structured ones was discussed. 


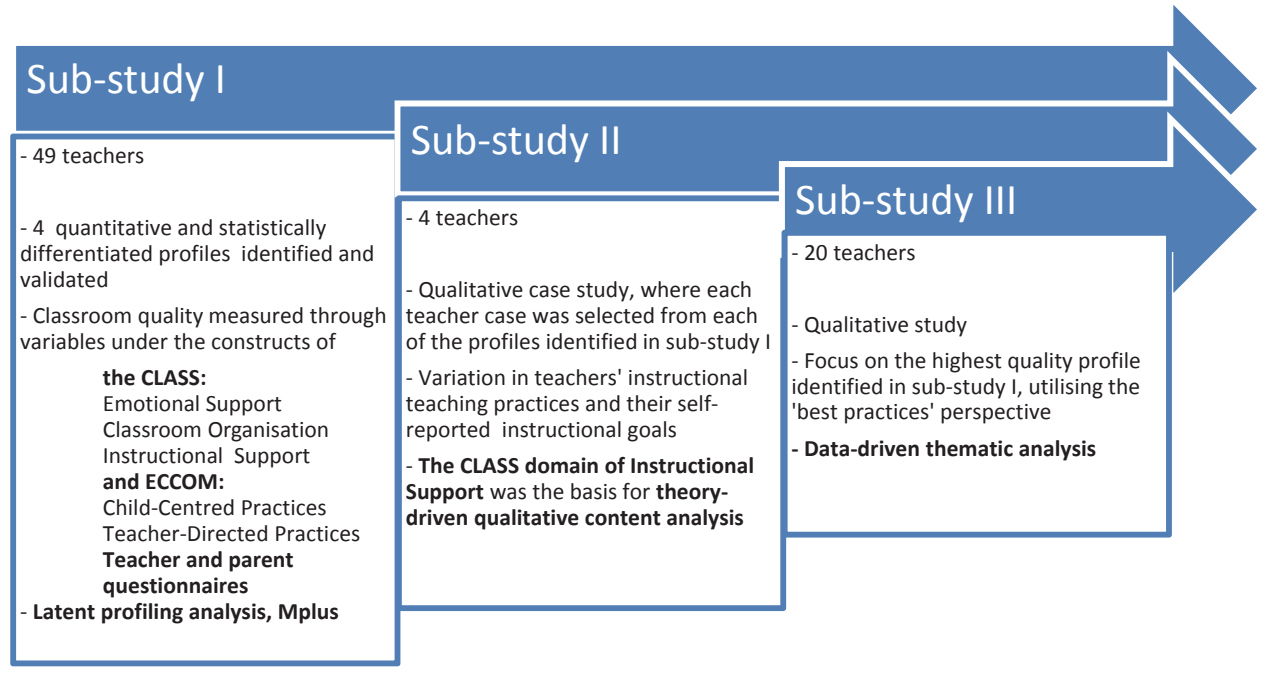

FIGURE 1 The subordinate nature of the data in the three sub-studies

Conducting a study along the principles of mixed methods research, however, is not only about utilising two types of data-quantitative and qualitative- but also entails deliberately and carefully combining these approaches throughout the research process. The second way in which the principles of mixed methods research were applied in this study is by the structure of analysis and interpretation of the different data. Among others, Onwuegbuzie and Johnson (2006), as well as Teddlie and Tashakkori (2009), use the term of sequential mixed methods design when describing mixed methods studies in which quantitative and qualitative strands of research are separate but chronologically connected to each other. Within this type of research, the first strand of research leads to the formulation of design components for the next strand. In this study, the quantitative strand in sub-study I lead to the rationale of conducting a qualitative strand of research in sub-studies II and III. In the sequential design, it is typical that the final inferences are made based on the results of both research strands (Teddlie \& Tashakkori, 2009). This can be seen to apply to the present study as the central findings of the three sub-studies merge here, in the summary report, resulting in a broad interpretation of the results and thus contributing to the main aims of the research. The concrete combining of the separate quantitative and qualitative strands was realised by formulating and pursuing broader and combinatory research questions (as suggested by e.g., Creswell \& Plano Clark, 2007; Hesse-Biber, 2010) in the present summary report (see also Chapter 4), drawing together the most central features of each of the three sub-studies. 


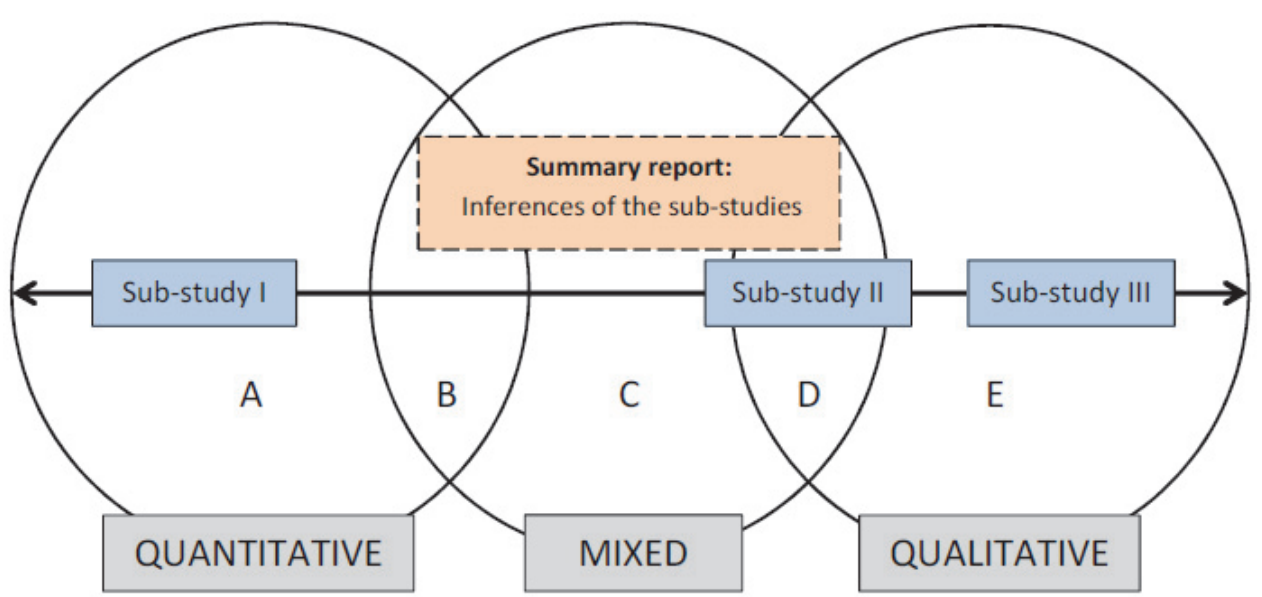

FIGURE 2 Mixed methodological structure of this study (Adapted from Teddlie \& Tashakkori, 2009).

In this study, the principles of mixed methods research have been realised through the merging of the quantitative and qualitative result of the three individual sub-studies. Figure 2 is adapted from that of Teddlie and Tashakkori (2009), and it is used to depict the nature and contribution of each sub-study to the sequential mixed methods design within this study. In the figure, circle A denotes a purely quantitative and circle $\mathrm{E}$ purely qualitative research approach having been used, whereas circle $C$ denotes fully merged mixed methods research. Section $\mathrm{B}$ (the intersection of two circles $\mathrm{A}$ and $\mathrm{C}$ ) denotes the quantitative research method having been applied mainly, but with some components of qualitative research. In similar fashion, section $\mathrm{D}$ (the intersection of circles $\mathrm{C}$ and $\mathrm{E}$ ) denotes the qualitative research method having been used primarily, but with some components of quantification. The three sub-studies are depicted along a two-way continuum (arrow), indicating their position in the overall scope of the research involving the different research methods used. The figure depicts the two separate strands of quantitative and qualitative research methods individually as well as clearly showing their mergers, but the final interpretation of the sub-studies in this summary report can be seen to have involved a truly integrated mixed methods research approach, utilising the information brought in by the two different research traditions. The sequential mixed methods design of this study served two practical purposes in particular: firstly, it allowed the illustration of the quantitative results (Bryman, 2006), that is, authentic real-life situations were observed and contemplated in combination with statistical findings in order to interpret the numerical findings in their context (e.g., assessment of the teacher cases). Secondly, it enables the utility of the results (i.e., improving the usefulness of findings). The portrayal of both approaches for the interpretation of the findings will be more useful to practitioners and other professionals involved in the education system (Bryman, 2006). The power of practical, qualitative examples is significant in explaining and vividly portraying 
quantitative results, as well as in making the findings more usable for professional work in, for example, preschools or in the field of teacher education.

From the beginning of this study, the idea of gathering and analysing both quantitative and qualitative data has prevailed in the aim to generate a more complete picture of teacher-child interaction in preschool classrooms. Regarding the mixed methodological nature of this study, the following definition of mixed methods research has been central from among the various terminology and interpretations used by different social scientists.

Mixed methods research is an approach to investigating the social world that ideally involves more than one methodological tradition and thus more than one way of knowing, along with more than one kind of technique for gathering, analysing and representing human phenomena, all for the purpose of gaining a fuller picture and deeper understanding of the investigated phenomenon (Johnson et al., 2007, pp. 119120).

\subsection{Sampling and analytical strategies}

In this chapter, the main analytical strategies of each of this study's three empirical sub-studies will be briefly illuminated. A general overview of each of the sub-studies will be provided at the end of this chapter, in Table 3. In social sciences, it is common that an initial quantitative study serves as a base for conducting further, qualitative studies (Hesse-Biber, 2010). Accordingly, a quantitative study - utilising mixture modelling and latent profile analysis - was conducted first (sub-study I) in order to examine its results from which to determine new research questions that can be addressed in qualitative follow-up studies. As such, the quantitative method established a generalisable platform and wider net of issues that could then be analysed using qualitative analytical methods, namely qualitative content analysis (sub-study II) and thematic analysis (sub-study III).

\subsubsection{Sub-study I: Mixture modelling procedure-latent profile analysis}

The aim of the first sub-study (I) was to identify classroom quality profiles as well as to explore the differences between the profiles in regard to various teacher and classroom characteristics. The Teaching Through Interactions framework, which uses the CLASS to objectively assess quality (Hamre \& Pianta, 2007; Hamre et al., 2007), allows detecting factors that are known to matter for children's emotional and academic development (i.e., the dimensions and indicators under three broader domains as described earlier). The profiling approach further allows exploring the combinations based on these factors. Thus, the detection of a classroom-based typology that reveals information on patterns among the specific sample and context can advance discussions on policies that could enhance education programme developments and quality (LoCasale-Crouch et al., 2007), as such a typology provides information 
concerning the distribution of different practices and interaction within classrooms. In sub-study I, one of the central needs was to investigate how it would be possible to conduct the profiling procedure in an educational and cultural context, Finland, that differs in many ways from that of the United States and what types of suitable profiles could be identified. Another justification for investigating classroom quality profiles was that preschool teachers in Finland are relatively free to apply teaching practices in their own personal way, compared to the limitations in some other countries (Office for Standards in Education, 2003). In Finland, the National Core Curriculum for Pre-primary Education (2010) provides guidelines according to which teachers can then make their own pedagogical decisions, and Finnish teacher education relies on the ideology that a high level of quality in teaching can be reached through various practices and strategies, not only in one way. In this regard, it was of interest to explore how teachers with similar educational backgrounds varied in their practices in real-life instructional situations.

Sub-study I was designed to be a profiling study similar to that conducted by LoCasale-Crouch and colleagues (2007) in the United States; but unlike their study, this sub-study (I) utilised the three-factor model (i.e., Emotional Support, Classroom Organisation, Instructional Support) of the CLASS measure instead of the two-factor model (i.e., Social-Emotional Climate, Instructional Quality) and explored the differences between the dimensions within the domains rather than the overall domains. In addition, the study by LoCasale-Crouch et al. (2007) used cluster analysis, whereas the mixture modelling procedure of the Mplus 5.0 statistical software programme (Muthén \& Muthén, 1998-2008) was adopted to identify latent profiles in this sub-study (I). The mixture modelling procedure has several advantages over traditional cluster analysis. For instance, the mixture modelling procedure enables both statistical testing for the selection of the most suitable number of latent classes as well as the use of information criteria; hence, it is more flexible and diverse than traditional cluster analysis. In addition, the mixture modelling procedure provides entropy values and posterior probabilities for the evaluation of models. The data analysis in sub-study I involved latent profile analysis (LPA), which was utilised to identify and evaluate the latent subgroups (i.e., profiles) of the nine CLASS dimension scores, namely, the total ratings for the dimensions of Positive Climate, Teacher Sensitivity, Regard for Student Perspectives, Behaviour Management, Productivity, Instructional Learning Formats, Concept Development, Quality of Feedback, and Language Modelling. Previous factor analyses of Finnish CLASS data (Pakarinen et al., 2010) have suggested a poor discriminant validity for Negative Climate (i.e., the modification indices indicated that Negative Climate loaded on more than one factor); based on those findings, the dimension of Negative Climate was excluded from the final model in the present study. In addition, the ratings for Negative Climate were very low in the sample of sub-study I, suggesting that this dimension of classroom quality had not adequately differentiated itself between teachers in the observed Finnish preschool classrooms. 
The mixture modelling procedure enables the identification of mixtures of subgroups (i.e., latent profiles) and provides statistical tests to assist in assessing the existence and number of distinguishable subgroups. Three criteria recommended by B. O. Muthén $(2001 ; 2003)$ were utilised to evaluate the definable number of latent profiles according to a) the fit of the model, b) the classification quality, and c) the interpretability of the latent profiles in practice. The four-subgroup solution was better than the two-, three-, or five-subgroup solution in regard to four information criteria and one statistical test. Consequently, the solution with four subgroups was chosen, as it best described the quantitative differences between the observed teaching practices. In addition, the latent profiles were compared in regard to various teacher characteristics (i.e., work experience, extent of literacy instruction) and classroom characteristics (i.e., class size, number of additional personnel, level of maternal education) using one-way analysis of variance (ANOVA) $(p<.05)$. The pairwise comparisons were conducted using Tukey HSD procedures, and double-checked using the non-parametric Kruskal-Wallis test due to the small sample size. The external validity of the profiles was further examined by evaluating differences between profiles against ECCOM observational ratings using analysis of variance. ANOVAs in the final step of the analyses were conducted using SPSS Statistics version 19.

\subsubsection{Sub-study II: Qualitative content analysis}

The second sub-study (II) aimed to illuminate the qualitative variety of the instructional teaching practices among four preschool teachers. The teachers examined in this study were purposefully selected from four profiles identified in sub-study I (Profile I $=$ Teacher A, Profile $2=$ Teacher B, Profile $3=$ Teacher C, and Profile $4=$ Teacher D), thus studying the profiles more closely by exploring the instructional practices at a micro level - in the context of four Finnish preschool classrooms - and by selecting the teachers who best represented the profile's mean CLASS score with respect to Instructional Support. The results of the quantitative sub-study I had indicated that there were mainly only small differences between teachers' instructional practices, but the profiles differed significantly in regard to one dimension (i.e., Language Modelling). It was of interest to explore teachers' actual instructional practices more thoroughly-on a micro level-and thus unravel the theoretical CLASS construct of instructional sup-

port. It was also of interest to see whether the profiles that were not statistically distinguishable from each other could be differentiated qualitatively. The questionnaires filled in by teachers were utilised to complete the analytical portrait of each teacher as an individual case (e.g., Yin, 2003) and for comparison with the observed variation in practices. In sub-study II, curriculum-based instructional activities consisted of 22 items (both math- and literacy-related activities), whereas only 10 items were utilised in sub-study I. In addition, sub-study II considered curricular goals relating to 13 items. The procedures used in the substudies also differed, since no statistical testing was actually utilised in substudy II. 
To complete the picture of all four teacher cases, qualitative content analysis (Graneheim \& Lundman, 2004; Patton, 2002) was utilised. Qualitative content analysis is used to reveal predominant expressions, concepts and core meanings in text documents (Patton, 2002). Thus, revealing patterns and explaining these in the form of descriptive findings is central in qualitative content analysis. The focus on descriptive findings was one of the central reasons for choosing this analytical tool for the second sub-study, particularly as the correspondence between the research questions and the method used was, in this case, seamless. In addition, as the teacher questionnaire data were utilised to further understand teachers as individual cases and to complement the view provided by the observational data, qualitative content analysis was a suitable methodological choice from this perspective as well. It can be assumed that each teacher has a unique pattern of behaving and interacting with the children in his or her classroom, and by utilising qualitative content analysis in analysing the data, it was possible to unravel and understand such individual patterns - especially since the analytical process allowed importing two types of data, quantitative and qualitative.

The data analysis began with familiarising ourselves with the data and identifying the unit of analysis. In sub-study II, the segments of transcripts (i.e., meaningful interactional episode, including features of instructional practices) were treated as the unit of analysis. The selection of these segments was strongly theory-driven as it included recognising and identifying teachers' instructional practices (i.e., practices related to the dimensions of Concept Development, Quality of Feedback, and Language Modelling) - under the domain of Instructional Support within the CLASS measure. The analytical process progressed from identifying segments according to each CLASS dimension under the domain of Instructional Support in connection with each teacher's data to creating simple organisational themes in relation to each of these dimensions. Each one of the themes was then compared in regard to the data of each of the four teachers, thus identifying the prevailing practices of the four teachers (i.e., what distinguishes and what is common among the teachers). When this process had been finalised, the focus was shifted to teachers' self-reported educational goals (i.e., emphasis on curricular goals and the frequency of producing instructional activities), which were used to complement the observed findings and establish a deeper understanding of each teacher's personal way of interacting with children. No statistical tests were utilised, but merely the reported frequency and emphasis of the goals were compared to the practices teachers established in their daily work with children (i.e., examining whether the teachers practice what they report). By this 'soft quantification', the reasons behind teachers observed practices could be somewhat better understood.

\subsubsection{Sub-study III: Thematic analysis}

Within the third sub-study (III), the focus was shifted to the highest quality classroom profile identified in sub-study I. The aim of the third sub-study was to clarify and deepen the knowledge on and understanding of the role that 
teachers' practices play in creating and enhancing the social life in preschool classrooms during structured learning sessions, with the focus being on teachers' best practices. Compared to sub-study II, the focus in this sub-study was more clearly on describing more categorical and topical forms of practices that teachers establish, rather than seeking out individual patterns, which is more often linked to traits of qualitative content analysis (Patton, 2002). Capturing important elements of and the variation in the social life of the classrooms progressed from a data-driven perspective to considering the phenomenon as a whole, attempting not to let prior theory or knowledge intervene in nor restrict the analysis. For these reasons, thematic analysis (Braun \& Clarke, 2006; Patton, 2002) was utilised in sub-study III to analyse the data of 20 preschool teachers' observations. In this sub-study, thematic analysis was used to investigate an area of research that has not been explored much before (i.e., studies on social life in educational/pedagogical settings). As Braun and Clarke (2006) have also suggested, thematic analysis is a well-suited method for analysing such topic since the analysis allows creating a rich overall description of the entire dataset.

The thematic analysis proceeded through several lengthy stages and began with getting familiarised with the content of the data. The unit of analysis in this sub-study was an episode, which contained one or several meaningful interactional expressions of varying lengths. The data analysis was abductive by nature (e.g., Patton, 2002), which was especially apparent in the way the data were approached: the observational data were the main source, but it was impossible to fully resign the theoretical literature on social development and the researcher's personal views as a pedagogue (kindergarten teacher) while going through the data. The analytical process was abductive in the sense that these preliminary ideas were not ruled out, but rather considered as possibilities. In the first stage of the analysis, 170 episodes were identified and assigned preliminary codes, representing the essence of each episode (i.e., in answer to, 'What is going on with respect to classroom social life here?'). Accordingly, similar episodes received the same code. At the second stage of the analysis, the codes were compared (along with the original episodes they represented) and similarities were sought. The determining factors within this process were, for instance, the content of the episode, the number of children involved (i.e., the group composition), and the level of the teachers' classroom activity; in all, codes were assigned for 9 preliminary themes. As Braun and Clarke (2006, p. 84) have discussed, it is of importance to rise from the level of mere describing and organising to the higher level of interpretation. In the case of sub-study III, interpretation was applied in the third stage of the analytical process, during which the nine preliminary themes were further combined into larger themes reflecting the phenomenon of social life in preschool classrooms. At this stage, the different levels of the data were bound together to make the data yet more generalisable than they were at stage 2, resulting in the final 4 themes to represent teachers' contribution in supporting the social life within their preschool classrooms. Further interpretations continued in the discussion section 
of sub-study III, where inferences were made about the broader aspects (i.e., emotional aspect; managerial/ organizational aspect) of social life that became clear in the analysis of the final four themes.

Table 3 presents the overall description of the three sub-studies, as described in detail here in Chapter 5 . The next chapter draws together the most central findings of the present doctoral study. 


\begin{tabular}{|c|c|c|c|c|c|}
\hline Sub-Study & Aim & Research questions & Data & Unit of analysis & Analysis \\
\hline $\begin{array}{l}\begin{array}{l}\text { I Observed Class- } \\
\text { room Quality Profiles } \\
\text { of Kindergarten }\end{array} \\
\text { Classrooms in Fin- } \\
\text { land } \\
\text { (Salminen, Lerkkanen, } \\
\text { Poikkeus, Pakarinen, } \\
\text { Siekkinen, Hännikäi- } \\
\text { nen, Poikonen, \& } \\
\text { Rasku-Puttonen, 2012) }\end{array}$ & $\begin{array}{l}\text { This study aimed to ex- } \\
\text { amine profiles of ob- } \\
\text { served classroom quality } \\
\text { in a sample of kindergar- } \\
\text { ten classrooms in Finland } \\
\text { and to study the differ- } \\
\text { ences between the profiles } \\
\text { with respect to teacher } \\
\text { and classroom character- } \\
\text { istics. }\end{array}$ & $\begin{array}{l}\text { 1. How many latent profiles of class- } \\
\text { room process quality can be identified } \\
\text { in this sample of Finnish kindergarten } \\
\text { classrooms? } \\
\text { 2. What kind of patterns of dimensions } \\
\text { will emerge within the three domains } \\
\text { of Emotional Support, Classroom } \\
\text { Organization and Instructional Sup- } \\
\text { port? } \\
\text { 3. Do the profiles differ with regard to } \\
\text { teacher and classroom characteristics? } \\
\text { 4. Do the profiles differ with respect to } \\
\text { classroom quality assessed by another } \\
\text { observational measure, the ECCOM? }\end{array}$ & $\begin{array}{l}\text { Observations of } 49 \text { Finnish } \\
\text { kindergarten teachers utilis- } \\
\text { ing the Classroom Assess- } \\
\text { ment Scoring System } \\
\text { (CLASS: Pianta, La Paro, \& } \\
\text { Hamre, 2004, 2008) and } \\
\text { Early Childhood Classroom } \\
\text { Observation Measure (EC- } \\
\text { COM: Stipek \& Byler, 2005). } \\
\\
\text { Teacher and parent ques- } \\
\text { tionnaires. }\end{array}$ & $\begin{array}{l}\text { The nine CLASS dimension } \\
\text { scores, that is, the total } \\
\text { ratings for the dimensions } \\
\text { of Positive Climate, } \\
\text { Teacher Sensitivity, Re- } \\
\text { gard for Student Perspec- } \\
\text { tives, Behaviour Man- } \\
\text { agement, Productivity, } \\
\text { Instructional Learning } \\
\text { Formats, Concept Devel- } \\
\text { opment, Quality of Feed- } \\
\text { back, and Language } \\
\text { Modelling. }\end{array}$ & $\begin{array}{l}\text { Quantitative } \\
\text { mixture modelling pro- } \\
\text { cedure and latent profile } \\
\text { analysis using the Mplus } \\
5.0 \text { statistical package } \\
\text { (Muthén \& Muthén, } \\
\text { 1998-2008). }\end{array}$ \\
\hline $\begin{array}{l}\text { II Descriptive Case } \\
\text { Analysis of Teachers' } \\
\text { Instructional Practic- } \\
\text { es in Finnish Pre- } \\
\text { school Classrooms } \\
\text { (Salminen, Hännikäi- } \\
\text { nen, Poikonen, \& } \\
\text { Rasku-Puttonen, 2013) }\end{array}$ & $\begin{array}{l}\text { This qualitative case } \\
\text { study was designed to } \\
\text { examine the diversity of } \\
\text { teaching practices and to } \\
\text { illuminate the qualitative } \\
\text { variety of instructional } \\
\text { teaching practices among } \\
\text { preschool teachers. }\end{array}$ & $\begin{array}{l}\text { 1. What kind of instructional teaching } \\
\text { practices do teachers use in preschool } \\
\text { classrooms and what kind of qualita- } \\
\text { tive variety is there among the teach- } \\
\text { ers? } \\
\text { 2. How do teachers define their educa- } \\
\text { tional goals and how are these related } \\
\text { to their instructional teaching practic- } \\
\text { es? } \\
\text { 3. What are the similarities and differ- } \\
\text { ences in teachers' instructional teaching } \\
\text { practices and educational goals? }\end{array}$ & $\begin{array}{l}\text { Observations of teacher- } \\
\text { child interactions in the } \\
\text { authentic classroom contexts } \\
\text { of } 4 \text { Finnish preschool teach- } \\
\text { ers. Transcriptions }(92 \text { pag- } \\
\text { es) of audio or video record- } \\
\text { ings. } \\
\text { Teacher questionnaire as } \\
\text { complementary data. }\end{array}$ & $\begin{array}{l}\text { Segments of transcripts (i.e., } \\
\text { meaningful interactional } \\
\text { episodes including fea- } \\
\text { tures of instructional } \\
\text { practices). }\end{array}$ & $\begin{array}{l}\text { Qualitative } \\
\text { (theory-driven) } \\
\text { content analysis. }\end{array}$ \\
\hline $\begin{array}{l}\text { III Teachers' Contri- } \\
\text { bution to Social Life } \\
\text { in Finnish Preschool } \\
\text { Classrooms During } \\
\text { Structured Learning } \\
\text { Sessions } \\
\text { (Salminen, Hännikäi- } \\
\text { nen, Poikonen, \& } \\
\text { Rasku-Puttonen, 2014) }\end{array}$ & $\begin{array}{l}\text { The aim of this study was } \\
\text { to clarify and deepen the } \\
\text { knowledge on and under- } \\
\text { standing of the role that } \\
\text { teachers' practices during } \\
\text { teacher-led learning } \\
\text { sessions play in creating } \\
\text { and enhancing the social } \\
\text { life in Finnish preschool } \\
\text { classrooms. }\end{array}$ & $\begin{array}{l}\text { 1. What types of practices do teachers } \\
\text { establish during learning sessions that } \\
\text { contribute to social life in preschool } \\
\text { classrooms? } \\
\text { 2. How do teachers arrange the compo- } \\
\text { sition of groups in order to enhance } \\
\text { social life (i.e., by individual children, } \\
\text { or in pairs or small groups, or as a } \\
\text { whole group)? }\end{array}$ & $\begin{array}{l}\text { Observations of teacher- } \\
\text { child interactions in the } \\
\text { authentic classroom contexts } \\
\text { of } 20 \text { Finnish preschool } \\
\text { teachers. Transcriptions ( } 538 \\
\text { pages) of audio or video } \\
\text { recordings. }\end{array}$ & $\begin{array}{l}\text { The episodes, each indi- } \\
\text { cating the different as- } \\
\text { pects related to social life } \\
\text { in a classroom context as } \\
\text { well as containing one or } \\
\text { several meaningful inter- } \\
\text { actional expressions of } \\
\text { varying lengths. }\end{array}$ & $\begin{array}{l}\text { Qualitative } \\
\text { (data-driven) } \\
\text { thematic analysis. }\end{array}$ \\
\hline
\end{tabular}




\section{RESULTS}

In order to fulfil the general purpose and aims of this study, three broad research questions were formulated with respect to the principles of mixed methods research, namely: (1) What kinds of profiles of teachers' practices and teacher-child interactions can be identified that reflect the process quality in Finnish preschool classrooms? (2) How do teachers support children's preacademic skills and social interaction in Finnish preschool classrooms during structured learning sessions and what are the similarities and differences between teachers' practices? (3) What types of pedagogical opportunities do the combination of teacher and classroom characteristics and teachers' pedagogical practices create in Finnish preschool classrooms? Before moving to the broader discussion, this chapter draws together the main results of each of the substudies with respect to the three aforementioned research questions and reflects on the central findings against the background of previous literature when appropriate.

\subsection{Profiles of teachers' practices and teacher-child interactions}

The results relating to the first research question are derived from sub-studies I and II. In sub-study I, four latent profiles of observed classroom quality were identified pertaining to nine dimensions under three CLASS domains: (1) Emotional Support (i.e., Positive Climate, Teacher Sensitivity, Regard for Student Perspectives), (2) Classroom Organisation (i.e., Behaviour Management, Productivity, Instructional Learning Formats), and (3) Instructional Support (i.e., Concept Development, Quality of Feedback, Language Modelling). These profiles reflect the process quality in Finnish preschool classrooms, relying on the domains and dimensions of the CLASS, which have been shown to contribute to learning and development (e.g., Curby et al., 2009; Mashburn et al., 2008). The profiles, thus, provide a classroom-based typology related to those domains and indicate in what combinations they appear in Finnish educational context. The profiles create an understanding of where teachers' strengths as 
well as potential targets for development lie. In sub-study I, Profile 1 represented a generally high level and Profile 4 a generally low level of classroom quality compared to the other profiles, whereas the medium-quality Profiles 2 and 3 showed relatively similar levels of support in the assessed dimensions of quality. The majority of the classrooms (82\%) belonged to the higher-quality Profiles 1 and 2. The CLASS dimensions appeared in different combinations within each of the profiles:

- The classrooms in Profile 1 attained scores that were overall higher than the sample means of all the other profiles. The scores were in the high- or midrange for Emotional Support and Classroom Organisation. The scores for Instructional Support were in the mid-range, but still higher than in any of the other profiles. This was the most prevalent $(53 \%)$ profile in the sample.

- The classrooms in Profile 2 attained scores very close to the sample means of all nine dimensions. The scores were in the upper mid-range for Emotional Support and Classroom Organisation, but in the lower mid-range for Instructional Support. Scores for Profile 2 did not differ statistically from those in Profile 3 regarding Classroom Organisation and Instructional Support (except for Language Modelling). This was the second most prevalent (29\%) profile in the sample.

- The classrooms in Profile 3 attained scores that were below the overall sample mean (1 point below the mean regarding Positive Climate, and nearly 1 point below the mean scores for Teacher Sensitivity, Regard for Student Perspectives, Quality of Feedback, and Language Modelling). The clearest distinction between Profiles 2 and 3 was that Emotional Support was clearly lower in Profile 3 and the score for Language Modelling higher in Profile 2 than 3. Profile 3 applied to 6 classrooms in the sample (Prevalence $=12 \%$ ).

- The classrooms in Profile 4 attained scores clearly below the overall sample mean. The scores were below the mean averages of six of the nine dimensions, and the scores for Regard for Student Perspectives, Productivity, and Concept Development were about 1.5 points lower. Emotional Support and Classroom Organisation were clearly lower than in the other profiles and the quality of Instructional Support was strikingly low. This profile applied to only 3 classrooms in the sample (Prevalence $=6 \%$ ).

The profiles differed from one another most clearly in the domain of Emotional Support. The differences in the domain of Emotional support were clear except for the dimension of Regard for Student Perspectives, which received similar scores as in Profiles 3 and 4. These findings reflect, firstly, the high-quality of teacher training. In Finland, kindergarten teacher education is a popular field of study and those students who become teachers are usually highly motivated and skilled in working with children. Second, the natural personal variation between teachers may also explain the differences between the profiles. Profiles differed least in the domain of Classroom Organisation, in which Profiles 2 and 3 also had highly similar scores. In addition, CLASS scores for all dimensions under this domain were relatively high. Their showing the least variation and their generally high levels of Classroom Organisation may be due to a strong emphasis on good pedagogical skills in these teachers' daily work and due to the high amount of supervised practice during teacher education during which 
student teachers receive useful feedback on their practices. Furthermore, the CLASS scores for Productivity were high in all profiles, which may be explained by the timing of the observations: In preschool classrooms, the most productive and best organised activities usually take place in the morning, which was the time when the research observations were conducted in the classrooms.

Regarding the domain of Instructional Support, the scores for classrooms in Profile 1 were higher than those in all of the other profiles, but there was no significant difference between Profiles 2 and 3 in this domain. Statistically significant differences between all profiles occurred only with respect to the dimension of Language Modelling. It is possible that the relatively low scores in this dimension may be due to the less strong emphasis on academic learning through effective language stimulation in Finnish preschool classrooms.

Sub-study II elaborated the findings concerning the teachers' instructional support. The second sub-study sought to examine the diversity of teaching practices and the qualitative differences between teachers' instructional support by assessing four representative preschool teachers. The four teachers' data can, thus be used as examples of practices, but not to generalise the teachers' overall profiles or any specific pattern of behaviour within the profiles. What was of interest and relatively surprising was that the qualitative differences between Teacher A's (Profile 1) and Teacher B's (Profile 2) practices and interactions with the children in their classroom were less easily identified than those between Teachers B (Profile 2) and C (Profile 3), even though Teachers B and C were selected from profiles that did not differ from each other statistically. This may indicate that upon qualitative inspection, teachers whose practices were found to be of higher quality in the quantitative analysis could be found to have more aspects of teaching and interaction in common with each other (i.e., Teachers A and B ) while compared to those whose practices were considered to be of lower quality (i.e., Teachers C and D). Teacher D's (Profile 4) practices differed quite clearly from those of all the other teachers.

Based on the findings from the data of the four teachers, it seems that the higher the quality in classroom with respect to Language Modelling, the more the teacher discussed topics with the children and verbally guided and involved them. As a consequence, there was some level of learning and involvement going on all the time. Teachers A and B both established these types of practices, with frequent conversations. Differences between teachers mainly became visible in regard to their degree of persistence in the provision of concept-related discussions. Teacher A was able to sustain meaningful discussions better than Teacher B. On the other hand, in the lowest-quality profile Teacher D was conversing with children and verbally directing the learning sessions significantly less than other teachers were doing, and as a consequence it was difficult for the children to know what they were expected to do and how in this teacher's classroom. Previous studies have shown that the provision of high-quality language stimulation and providing children with support in articulating their thought processes enhances their cognitive development (e.g., 
Howes et al., 2008; Mashburn et al., 2008). This information, combined with the fact that there were statistically significant differences between profiles in the dimension of Language Modelling (reflecting these aspects of teaching), indicates a need to consider the importance of this area for children's cognitive development and ways in which the differences between classrooms could be equalised.

In sub-study I, Profiles 2 and 3 were only statistically differentiated from each other in regard to the dimension of Language Modelling. The qualitative findings in sub-study II, however, could help to identify the different processes in these two profiles (with respect to the two teachers) and clarify the subtle differences-also concerning the dimensions that were not significantly different from each other (i.e., Quality of Feedback and Concept Development). For instance, in Profile 3, Teacher C's support for Concept Development consisted of introducing important concepts to the children in the classroom, but rarely involved helping the children to understand the connections or meanings more deeply: instead, drilling basic skills was more common. This teacher's feedback was also aiming to support children in finding correct answers rather than providing support for deeper thinking skills or learning as a process. When comparing these findings to Teacher B in Profile 2, it is clear that she is better able to use children's answers as tools to reach a slightly deeper level in the discussion. This was apparent in the dimension of Concept Development, as teacher B linked the topics at hand to children's daily lives or lived experiences. Feedback provided by Teacher B highly resembled that of Teacher C in Profile 3, but Teacher $\mathrm{B}$ more often asked children to give more explicit answers as well as helping them to construct their answers. Teacher $\mathrm{B}$ also provided children with more hints than did Teacher $\mathrm{C}$ in Profile 3 . The importance of teachers' use of Concept Development to children's development has been identified in a previous study by Curby et al. (2009), reporting that when the level of concept development was higher, children gain higher scores in cognitive tasks-which provides support for Teacher B's belonging to the slightly higher-quality Profile 2 , in this study. Furthermore, it is known that a lack of effective feedback hinders deeper understanding (Burnett, 2002), which is reflected in Teacher C's shorter exchanges with children.

\subsection{Teachers' support for children's pre-academic skills and social interaction}

Teacher-led, structured sessions occurred on a daily basis in the observed preschool classrooms, during which the children were being introduced to a variety of topics suggested in the National Core Curriculum for Pre-primary Education (2010). For instance, out of 34 observed sessions in sub-study III, 14 sessions focused on pre-math skills, 12 on pre-literacy skills and only 10 sessions on other content. These sessions were usually organised to accommodate play- 
like learning, but the children were also frequently introduced to different preacademic tasks (i.e., mainly different tasks in math and literacy) that resembled those in primary school. Children's social development to become an ethically responsible citizen is one of the main emphases in Finnish preschool education (National Core Curriculum for Pre-primary Education, 2010), and consequently aspects relevant to this co-occurred with pre-academic ones during the learning sessions. The structured learning sessions thus served many purposes simultaneously and it was of importance to gain knowledge on how teachers' support was applied in the daily interactions with children, which is what sub-studies II and III were designed to examine.

\subsubsection{Teachers' support for pre-academic skills}

In sub-study II, we could elucidate the observed practices through which teachers provided support for children's pre-academic skills and identified how these varied between the four selected teachers. The concepts used to describe the teachers' practices have been adapted from the domain of Instructional Support and its dimensions in the CLASS framework, but brought into practice by describing practices beneath the theoretical concepts. Practices appeared in different combinations of these dimensions, creating ample opportunities for learning pre-academic skills in the four observed preschool classrooms.

In her classroom, Teacher A provided continuous opportunities for children to learn by altering her strategies as well as motivating the children to think for themselves (e.g., learning the letter ' $K$ ' through writing; making a / K/ sound 'kind of like a horse galloping'; forming the letter ' $K$ ' with children's own body and asking 'how would you do that?'). By trying the suggestions, children were experiencing relatively high-quality Concept Development all the time, which can be seen as the teacher having given the children good tools to process the topic at hand through different strategies. The quality of Feedback within Teacher A's classroom was also relatively high. For example, in a simple task of identifying syllables in a word, Teacher A provided tools to help children to learn from their answers by exchanging answers and ideas with the children as well as providing hints. This teacher, for instance, asked a child to clap his hands according to the amount of syllables in the word, then helped him to understand which is the first and which is the second syllable, and then identified the second syllable and asked the child to assist the teacher in finding the aforementioned syllable among a mixture of syllables written on cards lying on a table. Such practices show two uses of feedback in the teaching process; on the one hand, feedback is used to teach the difference between the right and wrong answer, and on the other hand, more purposeful learning occurs when the feedback is used to enhance the process of learning by pointing out connections and meanings. Teacher A established learning sessions that were highly teacher-directed, but the children were being engaged in discussions and motivated to take part in activities all the time, which they did eagerly. Teacher A's use of verbal modelling and frequent discussions with children are good examples of teacher's practices related to Language Modelling. 
Teacher B used familiar examples and linked concepts to children's prior understanding, which served as effective ways to enhance the children's Concept Development. This was seen, for example, in how Teacher B discussed with the children how they were able to receive knowledge of things that happen around the world. As the discussion turned to newspapers through one of the children's initiations, the teacher further asked the children whether their parents read the newspaper and whether they also read to them. Teacher B, however, was not very persistent in keeping this type of situations going. Perhaps this was reflected in the Quality of Feedback provided by Teacher B, which was rather inconsistent. The teacher sometimes listened very closely to the children and replied to them as well as taking their ideas further (i.e., 'Yes, you are right. What do you think that means?'), but sometimes merely replied 'ok' or 'that's

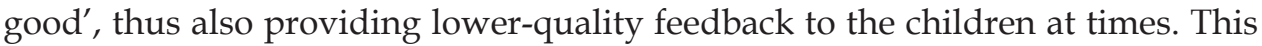
may have also made it more difficult for the children to be continuously involved in meaningful discussions, thus reflecting on the Language Modelling provided by this teacher. Teacher B used somewhat less open-ended questions than Teacher A but verbally modelled the ongoing activities (repeating and rewording) quite effectively, which means indicating what the important part of the ongoing topic is as well as what the children are expected to do.

Teacher C's practices improved continuous participation, but she used a similar strategy and basically drilled simple skills throughout the sessions (e.g., listening to a story, spotting the places where the number ' 6 ' was mentioned, reporting the findings after story reading) and the amount of rote-learning (i.e., remembering facts, repetition and recall) was high. Teacher $\mathrm{C}$ quite rarely linked concepts or topics to children's own lives or experiences, and her examples were rather superficial in nature as well as mostly related to drilling basic skills. For instance, Teacher C said: 'With which letter does the word 'peruna' [potato] begin?' As a child replied, the teacher asked 'Do you like eating potatoes?' These types of practices did not provide rich support for children's Concept Development (i.e., deeper understanding of the concepts). Teacher C's Feedback was of medium quality, mostly concentrating on whether a child was right or wrong. Children rarely had opportunities to share their views or get actively involved in ongoing activities and thus to reflect on their own learning or thinking processes. For example, if a child replied incorrectly, the teacher did not assist the child to think further about what the correct answer may be. However, in regard to the practice of Language Modelling, Teacher C was especially effectively directing the children to understand what the correct answer or expected outcome was. She verbally directed the children and 'spoke out' what she was doing, which gave a clear idea to the children as to what the important part of the topic was as well as what the children were expected to do.

Teacher D aimed to enhance children's Concept Development by connecting concepts and topics to children's daily lives and experiences, and asking simple questions that the children were expected to answer. She allowed children's participation in conversations less often than did other teachers and, thus, sometimes the children's chances for developing their ideas together with the 
teacher were lost and conceptual learning opportunities occurred mainly on a superficial, factual level. The quality of feedback was low, since Teacher D focused mainly on the correctness of the children's responses and often would not elaborate the responses further; the teacher was unable to smoothly use children's responses as tools for further explanation. Teacher $\mathrm{D}$ did discuss some things with the children, but the conversations lasted only a short time. Teacher D often asked closed-ended questions and children were given a quite narrow time frame within which to respond. In addition, the topic frequently shifted to managerial content rather than focusing effectively on things relevant to the topic of the ongoing activity. Perhaps this weaker spot in Teacher D's Language Modelling reflected her ineffective use of verbal modelling and 'speaking out' her expectations from which the children could interpret what was expected of them.

\subsubsection{Teachers' support for social interaction}

While sub-study II described teachers' efforts in supporting children's preacademic skills and analysed variety of teachers' unique instructional practices in four different Finnish preschool classrooms, sub-study III shifted the focus from looking at processing the cognitive content on the level of the individual to observing the opportunities that teachers create for children's social development from a more generalisable perspective among 20 teachers pertaining to the highest quality Profile 1. The general purpose of sub-study III was to explore how social life is constructed in Finnish preschool classrooms. The aim was to clarify and deepen the knowledge on and understanding of the role that teachers' practices during teacher-led learning sessions play in creating and enhancing the social life within their classroom. In other words, the aim was to determine through what types of practices teachers aim to support children's social interactions in the classroom and hence the children's social development.

In sub-study III, four themes were identified that reflected the practices that teachers applied to enhance the social life in their classrooms: (1) managing children's peer relations; (2) promoting the coherence of the group; (3) supporting the individual child as a part of the group; and (4) discussing friendship and respectfulness. Based on these four themes, teachers' support for the social life within the classroom occurred mostly through simple practices such as gestures and directions, but also through organisational arrangements (i.e., changing the group composition) and activities with clear goals for social behaviour. The first theme, called managing children's peer relations, occurred during interactional situations where teachers suggested ways for children to cooperate in pairs or small groups, thus providing children with the opportunity to work in pairs and perhaps learn to cope with misunderstandings and disagreements in doing so (Singer \& de Haan, 2007). Teachers either sensitively scaffolded or more directly directed children to find a mutual way of working together. Scaffolding occurred as teachers made small suggestions or expressions that children could themselves build on, or in support of children's social initiations which teachers elaborated by commenting on or extending them. In addition, teachers also 
modelled polite ways of interacting with others in social contexts. Episodes under Theme 1 occurred most frequently in the data. The second theme, called promoting the coherence of the group, consisted of teachers' practices that aimed to keep the group coherent and functioning. Teachers' practices within this theme were more often directed toward the whole group of children than was the case in the first theme. The teachers' role was usually more straightforward; for instance, appealing to commonly shared social rules (e.g., Smetana, 1993; Hännikäinen, 2005) and principles of fairness as well as enhancing the esprit de corps by boosting the sense of 'our group' or by using physical proximity. Such aspects of feeling mutual joy and sharing in the group have also been referred to as 'togetherness' by Hännikäinen and van Oers (2002). Theme 3, called supporting the individual child as a part of the group, consisted of interesting episodes during which teachers enabled the parallel between individual and group work dynamics. This means that teachers worked with the whole group of children but simultaneously allowed individual children some degree of leadership or personal visibility, thus acting on two levels of social interaction - the individual and the group level- at the same time (Kernan et al., 2011). Opportunities for this occurred, for example, when a teacher would establish a show-and-tell situation where an individual child gets the floor for a while and others learn to listen but are also able to learn more about their friend by asking relevant questions. Finally, Theme 4, called discussing friendship and respectfulness, consisted of episodes during which teachers were using issues of friendship or empathy as clear themes in the whole-group discussion during structured sessions. This theme was different from the other themes in the sense that the teachers were discussing the topics with the children, whereas in the other themes teachers' approached the social interaction more or less as a medium for concrete activities (for example, changing children's seating within the classrooms or encouraging them to cooperate). For instance, teachers had organised a play or a field trip, which they then used as a concrete example and as a tool for tuning into the topic (e.g., discussions on empathy or feelings of being valued, etc.). Such practices may help children to reflect on others and they support children's development into socially responsible citizens who can constructively interact with each other also in broader societal contexts (e.g., Wentzel, 1991).

The four themes seemed to more broadly reflect, in particular, two aspects of teacher support provided to enhance classroom social life: managerial/organisational and emotional. Managerial/organisational aspect included teachers' practices which aimed to concretely direct children's behaviour in a socially appropriate direction. These types of social manners in educational settings are very important for children to learn early on as the children will soon transition to primary school, where they are expected to get along with their teachers and each other and to play by the rules. Teachers in this sub-study referred to preschool as an important stage in children's preparation for becoming a pupil in primary school. This was also seen in teachers' comments in the classroom, such as 'Is this the way prospective schoolchildren behave?' or, 'Okay, preschoolers, show me how you do this, I know you can!' The im- 
portance of such types of practices has also been reported in the past (Hännikäinen, 2003). Emotional aspects included teachers' support for knowing one's friends and accepting them, for forming the esprit de corps, and for being able to feel empathy and to respect friendships. These types of practices delivered a strong message concerning the emotional charge that is embedded in interactions within classrooms and underlined the importance of a positive climate for the social life in classrooms to flourish.

\subsection{Teacher and classroom characteristics and teachers' observed pedagogical practices}

This study provides two sets of findings on how teacher and classroom characteristics can enrich and complement the knowledge on and understanding of teachers' role in preschool classrooms. Sub-study I contributes to the discussion by addressing the relation of teacher and classroom characteristics to classroom quality in the four classroom quality profiles. Sub-study II suggests a complimentary role of teachers' self-reported goals and activities in the process of more deeply understanding why teachers produce practices as they do. The results indicate that children are provided with varying pedagogical opportunities within each classroom, depending on, among other aspects, teacher and classroom characteristics.

In sub-study I, five variables of teachers' background characteristics (i.e., years of experience in educational settings; extent of instructional activities supporting literacy; ECCOM observational scores) and classroom characteristics (i.e., class size; number of additional personnel in the classroom) were analysed with respect to the four classroom quality profiles. Only few statistically significant differences emerged among the profiles regarding classroom and teacher characteristics: the teachers in Profile 4 had the least amount of work experience of all of the teachers $[F(3,43)=3.77, p<.05]$. The results indicate that teachers' shorter work experience is related to the lower classrooms quality, association that has also been reported in previous studies by others (Lamb, 1998; Pianta et al., 2005). Furthermore, teachers in the higher-quality profiles (1 and 2 ) provided more literacy instruction than did teachers in the lower-quality profiles ( 3 and 4$)[F(3,44)=2.86, p<.05]$. This was also observed in practice as the two teachers in higher-quality classrooms were better able to frequently engage children in literacy-related tasks. Also in other studies (Connor, Morrison, \& Slominski, 2006), the amount of such engaging activities has been shown to directly influence children's literacy skills. When it comes to the ECCOM scores, in general, the teachers in higher-quality profiles ( 1 and 2$)$ used child-centred practices more $[F(3,45)=25.66, p<.001]$ than did the teachers in lower-quality profiles $(3$ and 4$)$. Teacher-directed practices $[F(3,45)=26.26, p<.001]$ were also used more commonly in lower-quality profiles than in the higher-quality profiles. The stronger establishing of child-centred practices in higher-quality 
classrooms can also be related to teachers providing more literacy instruction in these classrooms or vice versa: perhaps child-centred teachers are better able to provide instruction in an age-appropriate manner and by using strategies that are appealing to children (see also Sylva et al., 2007, p. 51). In their earlier studies, Stipek and Byler (2004) as well as Pianta et al. (2005) have discovered that teachers who have less work experience tend to utilise more teacher-directed practices. The results of the sub-study I, thus, reflect the overlapping nature of the CLASS and ECCOM constructs, further suggesting that they both measure universal aspects of teacher-child interaction; and the findings establish similar connections regarding teacher characteristics as were reported by Stipek and Byler (2004). This study's results on teachers' background characteristics both validated the profiles but also provided important information on the personal factors that may be connected to the process quality in preschool classrooms.

Teachers' background characteristics analysed in sub-study II were partially the same as those in sub-study I. The data on the self-reported emphasis on particular goals and on the frequency of certain instructional activities were, thus, used to complement the data on the observed practices of individual teachers on a micro level, and considered as creating personal combinations of classroom quality. In regard to the teacher questionnaires, it was discovered that teachers' self-reported educational goals were reflected quite strongly in their observed practices, which complemented the findings as a whole regarding the four teachers' classroom practices. In general, the observed practices and teachers' reports of their educational goals reflected a similar direction. For example, a self-reported strong emphasis on problem-solving and thinking skills was frequently observed as being reflected in high-quality conversations and discussions about concepts. Also teachers who were reporting frequently having the children in their classroom practise the use of a pen and introducing basic mathematical concepts, as well as teachers placing greater emphasis on the learning of factual skills, were observed to invest a greater amount of time in exercising basic skills in a teacher-directed fashion (similar findings have been reported by Stipek and Byler, 1997). In other words, it can be considered that qualitative case examples provided within this study serve as the embodiments of the numeric quantitative ratings teachers reported to describe their teaching from their own perspective. 


\section{DISCUSSION}

This study was set out to enable a more profound understanding of the role that teachers play in children's learning and development in Finnish preschool classrooms and, thereby to contribute to the discussions on the complexity of classroom interaction and classroom quality from teachers' perspective. Accordingly, two aims were established: (1) to examine what types of interaction and teachers' practices contribute to classroom process quality in Finnish preschool classrooms comprising the selected sample, and (2) to construct a timely description of teacher-child interactions and teachers' practices in Finnish preschool classrooms when the transition to formal schooling is approaching. In this chapter, the main results will be discussed with respect to these two aims. The implications, trustworthiness, and ethical considerations of the study are discussed as well as the main conclusions and suggestions for future directions.

\subsection{Classroom quality as a process: Teachers' contribution}

The first aim of this study was to examine what types of interaction and teachers' practices contribute to classroom process quality in the Finnish preschool classrooms of the selected sample. This study adopted the Teaching Through Interactions framework (Hamre et al., 2013) for the theoretical conceptualisation of classroom quality and the CLASS (Hamre \& Pianta, 2007; Hamre et al., 2007) for data gathering. This was important since only a few structured measurement tools have been developed for assessing teacher-child interactions in the Finnish educational context. A recent report of the quality of the Finnish preschools (Hujala, Backlund-Smulter, et al., 2012) utilised a measure that was developed for this purpose. In addition, small scale studies have been conducted using the Early Childhood Environmental Rating Scale (ECERS: Harms \& Clifford, 1980). Aside from these, the field of early childhood education lacks systematic observational tools and no nationally guided quality evaluation has been carried out so far (Hujala, Fonsén, et al., 2012). This study 
contributes to the understanding of process quality in the field of Finnish preschool education by having conjunctively used the Teaching Through Interactions framework and the CLASS measure as quantitative and qualitative research tools in assessing classroom quality profiles within the Finnish context. The results of this study, including the CLASS scores, indicate that the Finnish preschool education practised in the classrooms examined was generally of a high quality, with forty of teachers belonging to the highest-quality profiles (1 and 2) and only three teachers to the lowest-quality profile (4). Further, the CLASS dimension scores differed between the four profiles, revealing finegrained differences in classroom quality. In regard to these combinations, several connections can be seen between quantitative and qualitative findings in regard to classrooms quality.

First, it seems that in order to belong to the higher-quality profiles ( 1 and 2 ), teachers need to have established relatively high levels of Emotional Support and Classroom Organisation in combination with a high level of Instructional Support (especially Language Modelling): warm, sensitive and responsive teachers who established a constructive learning environment and verbally supported children's learning belonged to Profiles 1 and 2. Teachers' emotionally supportive practices played an important role according to the results of both the first and third sub-study (I and III), alongside organisational support and decisions. In sub-study I, profiles reflected a finding that both effectively managing and emotionally responsive teachers were better able to also perform instructionally (i.e., the instructional support was also of higher quality). In sub-study III, teachers were found to utilise shared social rules (e.g., Smetana, 1993) and verbally reminded children how things should be done in their group, and they rarely did this without appealing to children's emotions at the same time (e.g., a teacher asked, 'How would you have felt if you were the one who is excluded?'). The possible connections between the CLASS domains of Emotional Support and Classroom Organisation became evident in both of these sub-studies (I and III) - which utilised different types of data (quantitative and qualitative respectively) - suggesting that perhaps teachers need to first establish practices in these two domains in order to be able to also provide Instructional Support of higher quality. Similar results have previously been reported by Bohn et al. (2004), Curby et al. (2009), as well as Wong and Wong (2004). However, a recent study by Curby et al. (2013) suggested that, in fact, emotional and instructional supports could be more effective in combination. An explanation for this could be that the domains of Instructional Support and Classroom Organisation reflect so many similar features that while teachers perform high-quality instruction, they are naturally also simultaneously effective in classroom organisation. This crossover aspect is also worth taking into consideration in regard to this study's findings since teachers in Profile 2, in sub-study I, particularly showed differences in the dimensions under the domains of Emotional Support (i.e., Teacher Sensitivity, Positive Climate, Regard for Students Perspectives), and Instructional Support (i.e., Language Modelling) compared to teachers in Profile 3; thus, it can be considered that higher CLASS scores in these dimensions caused 
the gains in classroom quality in Profile 2. Regardless, the finding concerning the role of Emotional Support with respect to Classroom Organisation and Instructional Support is significant in the sense that Emotional Support seems to play a special role in enabling the activities in these classrooms. Relatedly, teachers in this study's sample showed the most variation in the CLASS scores pertaining to the domain of Emotional Support. This points to a need to explore teachers' practices of Emotional Support more thoroughly and ponder how teachers could be professionally supported, since the results of this study indicate that particularly the combination of both high-quality Emotional Support and Classroom Organisation may improve good learning experiences within classrooms.

Secondly, in sub-study I, the teachers were least differentiated regarding the CLASS domain of Classroom Organisation meaning that (except for teachers in the lowest-quality subgroup) most teachers had established practices of Classroom Organisation that received around a mid-range score on the CLASS scale. This further indicates that nearly all teachers had established effective methods for preventing and redirecting misbehaviour, as well as having effective routines to manage the time for children's learning within the classroom through various practices and constructive strategies. Sub-study III can be seen to reflect the same phenomenon in relation to how teachers' managerial practices contributed to the social life in their preschool classroom. It was necessary for teachers to establish and refer to social rules to maintain the cohesion in the group of children, and to utilise practices such as fairness in order to enhance the feeling of togetherness, being part of 'our' group. Similar results have also been reported by Hännikäinen (2005), as well as Hännikäinen and van Oers (2002). The association between positive child behaviour and teachers' consistent behavioural expectations as well as proactive monitoring has also been established in earlier studies by others (Emmer \& Stough, 2001), and the latest research further connects effective organisational climate with classroom quality (Dennis \& O'Connor, 2013). The importance of effective Classroom Organisation as part of creating a meaningful learning environment and generating positive child behaviours in preschool classroom arose also from the findings of sub-study II, but in this case through the reflection where a lack of effective organisational practices was perceivable. Teacher D of Profile 4 was involved in managementrelated discussions nearly all the time during learning sessions, struggling to make the planned group work possible. This was clearly connected to the fact that there were a few children misbehaving in the classroom, but more significantly to this teacher's poorer ability to redirect such misbehaviour and prevent it from escalating. This feature, combined with a lack of clear verbal directing and the teacher's less adaptive sensitivity, made this classroom a less productive and inspiring place for learning and reflected a significantly low quality in the domain of Instructional Support.

A recent report on the quality of Finnish preschool classrooms (Hujala Backlund-Smulter, et al., 2012) emphasised that the key to generating higherquality teaching practices is through teachers' better conception of child-centred 
practices. Prior studies have supported this view by showing that child-centred practices, in particular, have a positive effect on children's academic interest (Lerkkanen et al., 2012) and motivation (Stipek et al., 1995). However, in their study, Connor et al. (2005) reported that the combination of teachers' warm responsiveness and spending more time on academic tasks have been shown to contribute to children's stronger vocabulary and basic reading skills, thus suggesting that in fact combining of child-centred and teacher-directed practices produces higher-quality learning experiences in classrooms. The child-centred practices (measured with the ECCOM) were connected to higher classroom quality (measured using the CLASS) also in this study (sub-study I), and teacher-directed practices were predominant in lower-quality classrooms. Yet, the qualitative cases in sub-study II revealed that while Teachers A and B, that is, the teachers with higher-quality profiles, were warm and responsive in their interaction with children, they also spent more time on academic tasks with the children than did Teachers C and D, who had lower-quality profiles. Hence, it is worth keeping in mind that using teacher-directed practices to a certain extent could contribute to increasing classroom quality, a notion that has also been suggested by Connor et al. (2005). Further, it is possible to use this study's qualitative findings and examples of observed classroom practices to aid in enhancing teacher-child interactions and teachers' pedagogical practices. Perhaps by doing so, it would be possible to increase teachers' awareness of the importance of both the warm interactions and purposeful content in teaching, and thus to improve classroom quality - a notion also mentioned in research by others (Hujala, Backlund-Smulter, et al., 2012).

\subsection{Teacher-child interaction and teachers' practices: Subtle contributions to transitioning}

The second aim of this study was to construct a timely description of the teacher-child interactions and teachers' practices in Finnish preschool classrooms, which is the time when the transition to formal schooling is fast approaching. In line with the concepts of the socio-cultural approach, at this time children begin to gain new abilities and acceptance of new social situations, in this case that of primary school (Karabanova, 2010). One of the key findings of this study was that teachers' emotionally supportive practices combined with constructive classroom management strategies create a safe basis and fruitful ground for learning in preschool classrooms. When the atmosphere is supportive and respectful as well as organised in a way that enables clear and shared expectations to be met, children have the courage to also try tasks that feel challenging, and they feel safe enough even to make mistakes and consequently learn from these (see sub-studies II and III). To be able to create these types of learning opportunities in daily work with children requires that teachers, above all, show sensitivity and understanding toward children's perspectives and needs, and further to 
favourably respond to them. Teachers' firm knowledge of individual children in their classroom, combined with thoughtful pedagogical considerations and decisions, can create more fruitful opportunities for children to engage in activities and learn in preschool classrooms both with respect to pre-academic and social skills.

The results of this study suggest that teachers' sensitivity in the preschool context could be more precisely referred to as teachers' pedagogical sensitivity. Features of pedagogical sensitivity have been described, for instance, in previous studies by van Manen $(1991,2002,2008)$. In this study, pedagogical sensitivity is seen to consist of, firstly, a teachers' sense of understanding children's personal and social needs (i.e., teachers' who are conscious of the role and importance of social interaction in classrooms may be better able to support children in their attempts to constructively join in group activities). This aspect of pedagogical sensitivity is most clearly established in sub-study III with respect to teachers' support for social interaction. Teachers' practices, such as fairness or direct encouragement for socially appropriate behaviour, may make the transition to primary school easier for children because practices such as these mediate the important message of becoming socially responsible individuals (e.g., Wentzel, 1991) who understand what the most constructive ways of interacting with each other are in the classroom as well as in larger social spheres, outside of school. Previous studies have also suggested that the relationships children create with their teachers have an impact on what types of relationships they create with teachers later in their educational progression: children have been found to bring their experiences and the ways they perceive teachers to later spheres of interaction (e.g., Birch \& Ladd, 1998). Therefore, teachers' pedagogically sensitive relationship with children is of importance for the imminent preschool context, but may also play a protective and enhancing role when the children have transitioned to primary school.

In regard to the transitioning to primary school, pre-academic learning is naturally of importance as well. Accordingly, the second aspect of teachers' pedagogical sensitivity is teachers' sensitivity toward children's personal preacademic skills and interest in learning (i.e., recognising children's skill level and being able to transform lesson plans accordingly by utilising thoughtful pedagogical practices) in combinations with the use of what the teacher considers to be important contents for learning in preschool. Based on the results yielded by sub-studies I and II, teachers were not able to bring children's cognitive abilities up to full capacity even in the higher-quality profiles (the CLASS scores of highmid range at best). Teachers in the higher-quality classrooms did invite children to join in discussions and tried more purposefully to engage them in learning processes, as well as providing feedback and verbally modelling the ongoing activities. The small portion of teachers with classroom practices of strikingly low quality, however, showed a less sensitive stance towards children's preacademic abilities and needs. It has been suggested that pedagogical sensitivity may be especially challenging for teachers with less work experience (see van Manen, 2008), which could explain the findings of this study when it comes to 
teachers in lowest-quality Profile 4. Previous studies have emphasised that when teachers provide higher-quality instructional support (e.g., helping children to develop their understanding or to model their own thinking processes), the children engaged more in learning activities and developed less taskavoidant behaviours (e.g., Pakarinen et al., 2011). This indicates that children are keen on learning and engage in activities according to their own interest. One of the central ideas in Finnish preschool education is to introduce children to pre-academic skills and create a foundation for inner motivation and eager learning (National Core Curriculum for Pre-primary Education, 2010) instead of merely teaching children to, for instance, read and write. The results of this study are somewhat worrisome because the quality of the selected teachers' instructional support appeared to be relatively low, indicating that such opportunities are not available to all children. Previous studies have shown that children who experience enthusiasm and develop an interest in learning letters or numbers in preschool also perform better in these areas later on in primary school (e.g., Aunola, Leskinen, \& Nurmi, 2006; Lerkkanen et al., 2012). This, more than anything else, calls for a need to pay further attention to teachers' sensitivity in observing and supporting individual children and to develop children's interest in learning already in preschool - when the ground for academic interests is forming. In line with the understanding derived from sociocultural theories, learning always includes social, emotional and cognitive aspects (Vygotsky, 1978, 1961). Considered from this point of view, teachers' pedagogical sensitivity-sensitivity and understanding concerning children's social needs and children's personal skills and interest in learning - may yield positive interactions and increase children's enthusiasm for learning in preschool classrooms, which in turn is of importance to children's transitioning to primary school. Related to this, serious considerations are needed concerning the question of how teachers can sensitively observe children's needs if class sizes increase and the daily interaction in their classrooms subsequently grows in complexity. Even though class size was not found to be associated with the observed classroom quality in this study, recent research on Finnish day care centres has shown there to be a link: larger groups of children have been considered to be a major challenge for establishing child-centred pedagogy (Raittila, 2013). The results of the present study bolster the conception that close and supportive teacher-child interaction is an important and beneficial mechanism already at the preschool level, and consideration of this finding can be useful in planning the future guidelines and legislation for preschool education as well as for early childhood education in the broader sense.

Finnish children have traditionally ranked fairly highly in the past international PISA comparisons (Programme for International Student Assessment; Organisation for Economic Cooperation, 2007, 2009), and quite a number of commendatory statements from researchers abroad have described the Finnish educational system as the elite of the world in popular media. However, the most recent PISA results (established in December 2013) show less encouraging results: Finnish children have lost their leading position among other countries 
(Programme for International Student Assessment; Organisation for Economic Cooperation, 2012). Answers to the reasons for this have been sought from schools as well as teacher education providers in order to meet the expectations of Finnish society. Furthermore, it is yet unknown if children's earliest years, even before school, have an impact in this process (Ojala \& Talts, 2007). What is known from past large-scale studies is that children's developmental trajectories stop altering already before children go to school and hence remain relatively stable during their academic career (e.g., Siraj-Blatchford et al., 2011). Thus, children's early years and interactions do matter and it is of high importance to pay attention to the nature and quality of these earlier experiences, such as seen in preschool (this study's focus), because if we consider learning and development as lifelong processes, something could be learned from what has happened earlier and which aspects of these experiences children bring with them as they transition from one educational level to another.

\subsection{Methodological and theoretical implications}

The methodological and theoretical implications of this study are approached from three viewpoints, namely: (1) the Teaching Through Interactions framework and the CLASS measure, (2) mixed methods design, and (3), the socio-cultural approach and ecological model. The Teaching Through Interactions framework (Hamre et al., 2013) and CLASS (Pianta \& Hamre, 2007; Hamre et al., 2007) as a tool to measure quality are based on large-scale observations according to which their categorisation of domains and dimensions has been constructed, and on empirical studies that have validated the impact of teacherchild interactions on children's development and learning. Thus, the Teaching Through Interactions framework and its CLASS measure yield certain advantages, such as enabling a more detailed observation and evaluation of teacher-child interactions. This study utilised data collected using such structured classroom observations, and general classroom quality profiles were devised according to relevant patterns; thus, the Teaching Through Interactions framework acted as a theoretical starting point for analyzing classroom quality and the CLASS as a tool to measure it, for all three sub-studies. Related profiling studies have been conducted in the United States (Curby et al., 2009; LoCasaleCrouch et al., 2007) in the past, and utilising a profiling procedure in the Finnish context has not provided new implications from the perspective of the CLASS measure per se. However, within this study qualitative observational data were added to complement the quantitative profiles to show what kinds of interactions and practices the CLASS scores were actually based on. The results of this study can be seen to further validate the value of the CLASS measure as an individual assessment tool also in the Finnish context (sub-study I), and also as a good tool for identifying further research areas and openings worth pursuing, such as qualitative research (sub-studies II and III). Such studiesusing the CLASS as a starting point for further qualitative analysis-are so far 
quite few in number (for an exception see Rasku-Puttonen, Lerkkanen, Poikkeus, \& Siekkinen, 2012). Thus, one of the central implications of this study is that the results gained by using the CLASS measure could serve as a basis for selecting prospective areas of research interest. Further, in aiming to understand why different teachers' practices yield different levels of quality regarding children's learning experiences, the results of this dissertation also imply that the relatively normative nature (i.e., if a classroom scores ' 1 ' then its teacher's practices are considered to be 'poor' in quality, and if ' 7 ' then 'good') of the CLASS measure should be combined with additional qualitative methods such as classroom observation and teacher interviews.

When aiming to understand a complex phenomenon - such as the interaction and relationships between teachers and children in their classroom-it is apparent that one set of data is rarely enough to capture the phenomenon as a whole. From a methodological perspective mixed methods were utilised in a relatively conventional manner within this study: it is common to use quantitative data as a starting point and then proceed with qualitative data and questions (e.g., Hesse-Biber, 2010). What is less common, however, is to apply such an approach in the field of early childhood education research. The results of this study imply that, methodologically, the sequential mixed methods design served the aims well and contributed to gaining a deeper understanding and broader conception of teacher-child interaction and teachers' pedagogical practices in Finnish preschool classrooms, results which would have been difficult to reach by using only either quantitative or qualitative methods and thus created a wider perspective (Onwuegbuzie \& Johnson, 2006). Within this study, the mixed methods design particularly aided in making the pedagogical side visible, describing the teachers' pedagogical practices in words rather than merely through the numerical results of the quantitative CLASS assessments.

The socio-cultural approach (e.g., Vygotsky, 1978) and ecological model (e.g., Bronfenbrenner, 1979) were used as the key theoretical stepping stones within this study. In general, the previous studies using the CLASS have particularly utilised the ecological model as their theoretical framework (e.g., Downer et al., 2010; Rimm-Kaufman \& Wanless, 2012). In this study, the use of the sociocultural approach in combination with the ecological model became useful especially with respect to analysing the qualitative data. The analysis of this data emphasised the presence of social, cognitive and emotional aspects in the interaction between teachers and children (e.g., Vygotsky, 1961), areas which are not as precisely represented in the ecological model. Furthermore, it has been suggested that the socio-cultural approach may help in understanding to which extent socio-cultural contexts affect classroom process quality outside the United States, where the CLASS has been developed (Sabol \& Pianta, 2012). This refers to aiming more deeply to understand the situated nature of learning and development in the preschool classroom context, particularly in Finland. In agreement, this study implies that socio-cultural approach can theoretically improve and strengthen future studies utilising the CLASS by enabling finer and deeper understanding of the interactions between teachers and children, com- 
plementing related broader perspectives on learning and development gained using the ecological model. It is, however, also important to note that even though these theories both hold the interaction and relationships between teachers and the children in their classroom to be the key determinants of children's learning and development, the interpretation and analysis of such considerations should go beyond the variable level established in the CLASS measure in order to fully utilise the power of the socio-cultural approach in understanding such interactional processes. The importance of observational data on naturally occurring interactions to understand the interactions more deeply is emphasised by, among others Vygotsky (1978). This study shows that both the socio-cultural approach and the ecological model are conceptually useful theoretical approach to exploring phenomena such as the teacher-child interaction analysed in this study. Nevertheless, the results also imply a challenge for future research and for combining these approaches: this study explored the interaction merely on a micro level and thus further studies are required to more fully intertwine all of the five levels of the ecological model (Bronfenbrenner, 1979) with the rich view of learning presented in the works of Vygotsky (1961, 1978) in particular.

\subsection{Practical and pedagogical implications}

A recent report on the quality of Finnish preschool classrooms has recommended that a good way of positively influencing the prevailing pedagogical practices in preschools is through new research-based knowledge (Hujala, BacklundSmulter, et al., 2012). The current study can produce new knowledge in the field of early childhood education by introducing a global way of seeing teacherchild interaction in preschool classrooms, and perhaps also in day care groups with even younger children. It is worth noting that knowledge of the domains and dimensions of the CLASS measure may help student teachers (and teachers) to become more aware of the broader areas of interactions that are known to play a role in children's development. The advantage of introducing these domains to the field of early childhood education lies in the solid theoretical and empirical foundation of the Teaching Through Interactions framework (Hamre et al., 2013) and the CLASS measure. The CLASS measure could, for instance, be introduced as a tool to practise observing groups and classrooms in early childhood education settings during teacher training. The CLASS measure could serve as a tool to widen the perspective on a variety of significant aspects of teacher-child interaction in a controllable and structured format, which then could be discussed amongst the groups of student teachers and subsequently used to reflect on potential teacher education improvements. As the research base using the CLASS measure is also growing larger in the Finnish context (e.g., Pakarinen et al., 2010; Pakarinen et al., 2011; Rasku-Puttonen et al., 2012), it is gaining in validity and reliability as well as increasing its practical potential to aid in improving the quality of Finnish preschool and primary classrooms. 
Each of the three sub-studies can be further seen to produce unique implications for practice, which will be briefly described. The quantitative results of sub-study I can be used to recognise kindergarten teachers' professional strengths and weaknesses and their distribution in the sample of this study. The quality profiles provide grounded information on sample teachers' practices in conjunction with the CLASS measure and other evaluation tools and may be useful in supporting teachers' professional development in interventions. In particular, the profiles serve as useful information for kindergarten teacher education in terms of indicating in what areas of teacher-child interactions Finnish teachers could still develop and which strengths could be supported in such developments. The results of the sub-study I also indicated a connection between lower classroom quality and shorter working experience in educational settings, which may indicate a need for stronger support in teachers' professional development, especially at the early stage of the teaching career. These aspects could be taken into consideration, for instance, when revising the syllabus for kindergarten teacher training.

The findings of sub-study II suggest pedagogical implications for, in particular, the development of preschool education and teacher training through examples of more and less effective teachers' actual work with children. Further, sub-study II provides interesting examples of instructional teaching practices (i.e., ways of supporting children's cognitive and language learning) in the Finnish cultural context, where play and a less formal curriculum are typically considered essential elements in early learning. Such examples could be used in kindergarten teacher training, as a tool to reflect student teachers' own visions of instructional teaching practices and ponder what one could do better and what could be learned from those examples in order to establish more effective practices? Furthermore, the combined results of sub-studies I and II could also be used as a critical message for the field of preschool education: not all teachers are able to provide high-quality opportunities for children to learn and more deeply develop their understanding of the topics at hand. Such skills are of course important, especially in children's preparation for their transition to primary school where learning processes become ever more important.

The findings of sub-study III are useful in raising teachers' awareness of the importance of the social life in classrooms, not only for children's well-being in their imminent surroundings but also in their wider social contexts and later in life. Teachers' role in supporting children in their attempts to join in group activities and sustain peer relations are of importance as this type of support may help prevent, for instance, social exclusion. It is also promising to see that Finnish preschool teachers utilise a number good practices to enhance social interactions and an awareness of such practices is of particular importance for student teachers who are on the verge of graduating and about to start working with children.

More broadly, the results of this study suggest that it is helpful if teachers are given adequate time to observe the children in their classrooms in order to establish an awareness of and sensitivity toward the needs of each unique indi- 
vidual child. Observing and becoming aware of the features of effective daily interaction could further serve as a tool for self-inspection and improving teachers' personal commitment to their work. Van Manen has suggested that pedagogy requires practical rather than intellectualised forms of knowledge (van Manen, 1991), and, through practical examples, this study may promote reflective thoughtfulness and a sense of improvisational tact as marks of pedagogically sensitive teachers - one of the central findings of this study.

Finally, this study has also yielded a societal implication. The findings of the study pertain to a sample of children on the verge of transitioning to formal schooling, new educational context for them. Issues that teachers should support children with before their transition to school include learning to act as competent and socially skilled individuals who understand the basics of social interaction and developing the constructive abilities necessary to work in different groups, combined with enabling a natural and positive interest towards acquiring basic pre-academic skills. As the next version of the National Core Curriculum for Pre-primary Education (2010) is being revised (due 2016), the discussion naturally also continues in the more popular media. Based on the results of this study, the interaction between teachers and children is the central-most feature impacting classroom quality, with emotional sensitivity toward the children in the classroom having presented itself as being particularly beneficial factor. In addition, the importance and role of teacher support in social development should be clear in the daily work in preschool classrooms as children need to learn adequate social skills for their upcoming school life. Thus, it is plausible that the results of this study may also aid in the process of revising the national Finnish preschool curriculum.

\subsection{Trustworthiness and the limitations}

Discussing the trustworthiness of the research process is a key to creating confidence in any report and to establishing that the findings are indeed reliable and valid. The trustworthiness of this study will be discussed along the concepts of (a) Credibility, (b) Dependability, (c) Confirmability, and (d) Transferability; aspects that are considered to be the central most determinants of the trustworthiness of qualitative research (Lincoln \& Guba, 1985; Shenton, 2004). In this summary report, both quantitative and qualitative sub-studies were drawn together, but the discussion at the level of this summary is more qualitative in nature. For this reason, the trustworthiness of the study is evaluated in terms of criteria primarily used to review qualitative research; however, the aspect of mixing methods is also discussed in the subsequent paragraphs.

(a) Credibility is broadly associated with the question of how well the results of a given study describe the reality and are truthful (Lincoln \& Guba, 1985; Patton, 2002). According to Lincoln and Guba (1985), knowing the phenomenon at hand thoroughly as well as observing it for an adequate amount of 
time increases the credibility of a study. In this study, the whole research process, as well as each sub-study, began with becoming familiarised with related studies. In addition, my pedagogical training as a kindergarten teacher, as well as my active participation in the data gathering, acted as assets in my knowledge of both the field and the data-combined with my conscientious awareness of the importance and value of delivering trustworthy results. Also, the context of the data gathering was another aspect that I felt I needed to keep in mind during analysis, because having observed and conversed with some of the teachers during the observation days may have given me additional information on why those teachers used certain practices while missing that information on teachers I did not personally observe.

When considering the credibility of this study, three aspects are clearly connected to the data gathering. First, it is worth noting that most of the teacherchild interactions in the preschool classrooms were audio recorded and only some video recorded. Subsequently, in the analysis of the data, more verbal expressions and less physical practices used in teaching, such as gestures and facial expressions, were available; thus, more attention has been paid to the verbal ways of establishing teacher-child interaction and teachers' guidance. Admittedly, having video material on all observed teachers would have brought more detail and depth to the descriptions of teachers' practices and would have represented all teachers more equally in the analytical process.

Secondly, since the data were gathered during live classroom observations with two observers present in the classroom, the role of the observers in the classroom could have had some effects on what occurred during the sessions, thus affecting the nature of the data that were gathered. Such an effect is possible, but most likely insignificant in this case; since the observations were conducted for 3 hours at a time in each of the classrooms and on two different days - quite a good coverage - the teachers and children were most likely acting like they normally would. Personal feedback discussions in January 2013 with two of the teachers participating in the observations strengthened this assumption, as the teachers reported feeling unaffected by the observations as well as reporting that the children were acting as they would on any normal day of preschool.

Thirdly, the 49 preschool teachers who participated to the classroom observations and to whom the data of this study pertains were all volunteers, which could be seen to have an effect on the credibility of the study. When the teachers who participated in the observations were compared to those who chose not to participate in the classroom observations, no statistically significant differences were found concerning teacher work experience, number of 6-yearolds in the classroom, exhaustion at work, curricular goals, or interactional style. However, a trend $(p<.10)$ toward higher teacher efficacy beliefs was found for the participating vs nonparticipating teachers, but the finding was not statistically significant (Pakarinen et al., 2010). This trend could mean that the voluntary teachers were more self-reliant and felt more competent, thus having the confidence to invite observers to their classrooms. 
The credibility of the study can also be discussed with respect to the data analysis. During the data analyses for the three sub-studies, the preliminary results were introduced to different groups of researchers and practitioners in the field of early childhood education who were not as deeply familiar with the topic - an activity recommended to increase the credibility of any research according to Lincoln and Guba (1985). Such groups included, for example, a PhD student seminar group as well as a variety of audiences at international and national scientific conferences who could listen and comment on the findings from an outsider perspective. Furthermore, the results of the sub-studies were also presented to outside teachers working in Finnish preschool classrooms who could confirm whether the inferences made from the data were appropriate and reflected situations that they themselves also meet in daily work. In addition, during the feedback discussions with two participating teachers in January 2013, they recognised the resemblance between what was being observed (i.e., the results of the study) and how they viewed their own role and practices in their classroom.

From a methodological perspective, the credibility of this study is supported mostly through the use of the CLASS measure (Pianta et al., 2004; Pianta, La Paro, et al., 2008). As a measure and assessment tool of process quality, the CLASS seems to reflect the quality of preschool education in Finland relatively well. In comparing the CLASS scores with the qualitative observations, a clear connection could be seen to confirm that the CLASS was an accurate quantitative measure of what was qualitatively observable in the video and audio recordings regarding the teacher-child interaction. Furthermore, the observers who conducted the CLASS and the ECCOM observations in the classrooms were carefully trained before they proceeded to conduct the official observations in the classrooms. Utilising two independent observers in each of the classrooms was one way of enhancing the credibility of the study. Furthermore, this study utilised both quantitative and qualitative research methods in order to investigate interactions in classrooms, thus establishing the credibility on a data level as well, creating a deeper and more trustworthy understanding of the observed phenomenon (i.e., teacher-child interaction and teachers' practices).

(b) Dependability is associated with the transparent nature of research which enables other researchers to conduct similar research, with similar methods and receive similar results, and is thus closely connected to methodological choices made throughout the research process (Lincoln \& Guba, 1985; Shenton, 2004). It has also been emphasised that when the dependability of a research study is assured, this establishes a ground for its credibility as well (Lincoln \& Guba, 1985). In designing each sub-study progressively, it was important to critically evaluate the data and the method of analysis that was being utilised in each completed sub-study, and to simultaneously determine how particular choices could contribute to ultimately understanding the phenomenon from a broader perspective. This is where the principles of mixed methods research (Creswell \& Plano Clark, 2007; Hesse-Biber, 2010) became useful. The main research questions created for this summary report (see chapter 4 ) can be seen as 
having provided a platform for evaluating the methodological, analytical and practical aspects of each sub-study in order to construct a concise entity.

The dependability of this study has to a great extent been established through trustworthy reporting of the research process and the results. The research design of sub-study I was based on a previous profiling study conducted in the United States (LoCasale-Crouch et al., 2007), and we were able to design and conduct a research plan that resembles that well-reported study with respect to the profiling strategy but applied to the Finnish context. In order to guarantee a relevant continuity between the sub-studies of this study, attention was paid to carefully reporting the protocol of each sub-study with respect to previous theories as well as in regard to clearly establishing the details of the data collection and selection through the CLASS measure, as well as in regard to the data analysis and the causes that may limit the research (see also Onwuegbuzie \& Johnson, 2006). Since the amount of space for these types of descriptions was limited in the individual sub-studies, this summary report further describes each of the sub-studies to generate a consensus and thus increase the dependability of the research. Needing to introduce and reword the main ideas of each of the sub-studies for this summary report was a good way to revisit each sub-study's analysis and to ensure each process is clearly and understandably presented in the summary report.

(c) Confirmability is associated with ensuring that the findings of a study are based on the experiences, ideas or behaviours of the participants, rather than on the bias of the researcher (Lincoln \& Guba, 1985; Shenton, 2004). Confirmability is thus closely connected to the objectivity of a study's results and interpretations. In this study the structured observational CLASS measure (Pianta et al., 2004; Pianta, La Paro, et al., 2008) was utilised in the data collection and as a tool to identify participants for the subsequent qualitative sub-studies. Thus, the objective use of the CLASS is a major factor contributing to the confirmability of this study. The observers who conducted the CLASS and ECCOM observations in the classrooms were carefully trained before they were allowed to conduct the official observations in the classrooms, and sufficient inter-rater reliability was required (>.80) in the observer pairs' results. This reflects the aim to collect information on classroom situations that is as objective as possible. However, the majority of the observers worked in the same pairs throughout their data collection and this could have also contributed to their high interrater reliability. Another aspect to consider is Miles and Huberman's (1994) notion that the confirmability of any research is also dependent on the extent to which the researcher admits his or her own predispositions that may be reflected in the interpretations. Regarding the analysis and interpretation of the qualitative data in sub-studies II and III, all researchers involved in evaluating the results had pedagogical training either as kindergarten teacher or primary school teacher. While this could be considered as a factor hindering the confirmability of this study, it can also be seen to bring practical knowledge to the interpretation of the results and thus help to increase the practical implications of the findings by providing applicable results that are useful to the field of ear- 
ly childhood education. Also, while there were three researchers evaluating the analyses and interpretations of the first author, open and critical exchanges of ideas took place. Such active exchanges further served as an effective way of making sure that everyone involved in research remained sensitive to what is being said about the participants. This was especially important in regard to the qualitative data extracts and the interpretations that were made regarding those moments in the everyday life. This consideration was fulfilled by carefully observing the whole data of individual teachers, and, while extracting the analytical units from the data, paying attention not to over- or underestimate the power of short incidents in the classroom, keeping their place in the context of the whole observation session in mind.

(d) Transferability in research is concerned with the extent to which the findings of a study can be applied to other situations (Merriam, 1998; Shenton, 2004). In qualitative research, it is often not of specific interest to generalise results to a broader population, but instead transferability is used to increase the applicability of the results in other contexts (Lincoln \& Guba, 1985). In this study, the mixed methodological connection of the three sub-studies can be seen to add to both the generalisability and transferability of the research to a certain extent. The quantitative results describe somewhat general combinations of teacher-child interactions, which could be generalised but with certain limitations (e.g., the limited representativeness of teachers examined in three municipalities with respect to those in all municipalities of Finland). Simultaneously when these findings were further inspected through qualitative micro level designs, a more detailed view of different interactional features of interactions and micro contexts appearing during observations was possible. It has been suggested previously that only by providing detailed descriptions of the context, participants, methods and limitations involved is it possible to be able to transfer the findings of a research study to another context (Lincoln \& Guba, 1985).

Limitations. The limitations of this study are as follows. First, considering previous profiling studies (Curby et al., 2009; LoCasale-Crouch et al., 2007), it would have been useful to compare the teacher profiles also with child outcomes in order to reveal whether the different combinations of support measured with the CLASS result in different gains with respect to the different classrooms. In this study, the connections between teachers' practices (classroom quality) and child outcomes were not explored; hence, it is not possible to show what kinds of effects different types of teacher support have on developing children. This, however, is one of the many ideas for further studies. Second, utilising longitudinal data, covering several CLASS observation time points, would have enabled an inspection of the effectiveness of the preschool education as well as the stability of and/or change in teachers' practices in relation to classroom process quality (as measured with the CLASS) in the Finnish context. However, these aims were impossible to pursue given the limits of the data set of this study, and would have required a) conducting more observations during the preschool year to assess the stability of and/or changes in teachers' practic- 
es, and b) having data gathered on the same teachers after the preschool year in order to inspect the effectiveness of the preschool education. These questions remain very important and much needed areas of investigation for future studies.

Third, the use of profiling procedure (sub-study I) similar to the US study by LoCasale-Crouch and others (2007) created a tempting opportunity to conduct cross-cultural comparisons between the US and Finland. Unfortunately, such comparisons would be impossible to conduct reliably as the sample sizes $(\mathrm{FIN}=49$; US $=676)$ and specific items (e.g., not using all of the CLASS dimensions) of the two studies differed substantially from each other. Furthermore, children in the US sample were younger (3-4 years old) than those in the Finnish sample (6 years old).

Fourth, the first sub-study (I) dealt with statistical modelling and one of the main concerns was the small sample size $(n=49)$. This issue was dealt with by utilising non parametric statistical tests to take the small sample size into consideration. These tests yielded similar results as the parametric tests. Furthermore, at the summary stage of this study, the inspection of the data was increased to the micro level and thus complemented the statistical analyses by utilising the principles of mixed methods research (e.g., Johnson et al., 2007).

Fifth, this study introduced two sub-studies (II and III) providing micro level examples of daily classroom interaction between teachers and children, and it might easily be assumed that these interactions represent implications for how teachers should work with children. That is why it is necessary to clarify that it is both impossible and purposeless to provide one specific way of teaching in preschool classrooms and the examples should not simply be assumed as recommendations for practice. Furthermore, the intention of the research was not to prescribe "normative" practices that should be seen to be more right than others, but rather to yield information that can be used as a tool to reflect on one's own practices: 'What is it that I do and could I do it better?' or, 'Are there practices that I do better but are not mentioned in this report?' It is also pedagogically relevant to remember that what works within one group of children may not work within another (cf., the situated nature of practices within individual groups, involving negotiating and re-negotiating mutual ways of working together). This type of children's 'evocative effect' has recently become a significant area of research in educational and social sciences (e.g., Nurmi et al., 2013).

Sixth, only a small portion of the observational data has been explored in great detail using the CLASS measure. Sub-study I considered all the domains of the CLASS, but only sub-study II delved deeper and only into some of the areas measured by the CLASS. In sum, only the domain of Instructional Support was subjected to more thorough inspection, leaving the domains of Classroom Organisation and Emotional Support without similarly detailed attention. Thus, it remains for future studies to conduct fine-grained qualitative analyses in the domain of Emotional Support, which showed the greatest variation between profiles, and to identify why Finnish preschool teachers have established 
such high CLASS scores in the domain of Classroom Organisation within the present research. Furthermore if we look at the data on all 49 preschool teachers who were examined in the research, only 4 teachers' qualitative data in substudy II and 20 teachers' data in sub-study III were explored in depth. One particularly interesting way of further using the qualitative observational data would be to analyse it regarding micro patterns within the profiles; in other words, to continue to seek individual similarities and differences that occur among teachers within each of the four profiles. That way, it would be possible to gain more knowledge and thus an even deeper understanding of the nature of the pedagogy applied in a variety of Finnish preschool classrooms.

Seventh, the use of the CLASS as the main observational tool in this study also created some methodological limitations, alongside its advantages. The scoring sheet determined from which perspective the live classroom situations were to be interpreted and what perspectives were to be adopted. For this reason, including qualitative data was essential. Relatedly, observing for three hours per day and only during the forenoon hours does not allow to generalising the findings across the preschool day, but only to the similarly situated moments of more purposefully organised activities. The aim of this study was to examine classroom interactions from the teachers' perspective and the CLASS measure also narrows the observational focus to teachers (see the How to observe guidelines of the CLASS: Pianta, La Paro, et al., 2008). Finnish preschool education is traditionally considered to be child-centred with a strong emphasis placed on children as active learners in daily activities. Through its micro level analytical approach to situated moments of the preschool day, this study found that Finnish preschool teachers do in fact actively aim to consider children's perspectives. Several extracts from sub-studies II and III show how teachers aim to respect children's perspectives and activate them in different pre-academic and social situations; however, the research frame and research questions direct the discussion toward the children's perspective as seen from the teachers' standpoint.

Lastly, within the two qualitative sub-studies (II and III) a fair number of episodes were observed during which the preschool teachers utilised play or play-like activities as pedagogical devices to engage children in pre-academic learning activities, to introduce an important topic, or to vary the strategy of teaching. Since the observations were conducted during formal learning sessions, teachers had integrated learning tasks into play-but situations in which children had opportunities for free play did not occur. Opportunities for free play would have probably been much richer and more self-determined during other times of observation (i.e., outside formal learning sessions) since playtime is generally given an important role in Finnish preschool classrooms. Furthermore, perhaps different theoretical approaches need to be utilised in future studies, since, due to its strong emphasis on the teacher's role during observations, it may be difficult to assess children's free play using the CLASS measure. The importance of free play as part of the preschool curriculum in Finland may not be sufficiently reflected using the standard CLASS, but further studies 
could attempt to enrich the CLASS with a structured coding scheme for situations during which play occurs.

\subsection{Ethical considerations}

The National Advisory Board on Research Ethics (2009) provides ethical guidelines for humanities and social sciences which are designed to assist in critical scientific reviewing through joint ethical rules, and which Finnish universities have agreed to comply with. The board's ethical principles cover three broader areas along which the ethical issues of this study will be discussed, namely: respecting the autonomy of research participants; avoiding harm; and ensuring privacy and data protection.

Respecting the autonomy of research participants in this study was ensured by emphasising voluntary participation and by asking for a written informed consent from each participant (Christians, 2000; The National Advisory Board on Research Ethics, 2009). These aspects were mainly considered as part of the larger data gathering in the First Steps study. Teachers in whose classrooms the observations were conducted volunteered to be observed and to fill in questionnaires, and gave their informed consent for their own part. Further, the parent(s) of each child in the classrooms were asked to give their written informed consent for their child's participation in the First Steps study as well as for their own participation (i.e., willingness to fill in parent questionnaires). Children were not directly addressed regarding their willingness to participate, but instead their parents asked their children and wrote the consent form on their behalf. Participants were also informed that they were free to drop out of the research project at any time if they wished to do so. Those children whose parents did not give their consent for their child to be video recorded were given a place in the classroom where they could participate in the classroom activities without being shown in the recording. Usually these children were very few in number.

The second aspect of research ethics applied in this study regards avoiding harm, both in terms of mental and social harm (the National Advisory Board on Research Ethics, 2009). When conducting observations of young children's behaviour such as in the classrooms explored in this study, these aspects become especially important. All of the observers were trained to introduce themselves and explain for what purposes they were conducting the observation. Observers were also trained to be sensitive to the situations in the classrooms and to notice whether any of the children were bothered by the observers' presence. Prior to the observations, teachers were also given general information, on what types of things would be observed-but without going into detail regarding the two observational instruments (i.e., the CLASS and the ECCOM). Great care was taken to reduce the possibility of the children or the teachers experiencing any mental harm during the data gathering phase or at any other time of the research, thus ensuring the ethicality of the research activities. During the data 
analysis, ethical issues needed to be considered once again and avoiding mental and societal harm became a central aspect to be kept in mind. Observational data are highly personal by nature and it requires sensitivity from the researcher to work with such data (Mason, 1996). For instance, the tone of reporting results is significant; the data pertaining to any individual must be reported with respect and without being derogatory. This issue was especially of concern in reporting the findings of sub-study II, which (due to the use of normative observational tools) emphasised that Teachers A and B had generated a higher classroom quality than Teachers $\mathrm{C}$ and $\mathrm{D}$. These issues were carefully discussed among the researchers involved in sub-study II and attention was paid to how the different aspects of quality were worded. More broadly, when exploring teachers from such a small dataset $(n=49)$, it is particularly important to take the ethical aspect of exploring human cases into consideration and present the cases in a way that represents the aim of understanding the teachers.

The third aspect of research ethics, concerning privacy and data protection (Christians, 2000; the National Advisory Board on Research Ethics, 2009), was also handled carefully as part of the First Steps study in the data preservation for the whole project. When the observations were conducted, the audio and video recordings were temporarily stored and password protected on a computer of the research coordinator of the First Steps study. Persons who were in charge of transcribing the recording were few in number and were instructed to keep the recordings in safe and private places as well as to delete the recordings right after the transcripts are completed. During the transcribing process, the teachers' and children's names were coded (using pseudonyms) to protect their identities and the written coding key linking the real names to the pseudonyms was kept in separate file. Teachers were additionally assigned a four-digit ID number, which was used to link for instance, teachers' questionnaires and observational data to the correct teacher in the larger datasets while protecting their public identity. The original audio and video recordings were archived with necessary care among the other data gathered in the First Steps study. The original and all copies of recorded observations for this study were kept safe in a folder on a password protected computer and deleted after the research had been completed. Furthermore, the real names of teachers or children have not been utilised at any point of reporting the research findings. All of the data extracts that have been reported in the three sub-studies have been carefully selected and blinded so that the true identity of the participants cannot be identified.

\subsection{Concluding remarks and future directions}

The general purpose of this study was to create a more profound knowledge and understanding of the role that teachers play in children's learning and development in Finnish preschool classrooms and to thus contribute to the discussion on the complexity of classroom interaction and classroom quality 
from the teachers' perspective. Through the findings of its three individual substudies, this study reflects the importance of continuous and reciprocal interacting between teachers and children to produce learning opportunities of high quality, as has also been suggested in several previous studies (Bronfenbrenner \& Morris, 2006; Pianta, 1999). In this study, the provision of such high-quality learning opportunities were found to be established through teachers': 1) ability to recognise the needs and abilities of each individual child as well as the group; 2) responding to these needs by utilising thoughtful, pedagogically sensitive practices; and 3) their ability to exert this sensitivity in practice through humane and respectful interactions with children. This study's findings call for a need to pay attention to what degree teachers are using emotionally supportive practices already during teacher training, as well as to reflect on how teachers' use of higher-quality instructional support could serve as a tool to engage children in meaningful higher-order thinking and reasoning that might also increase their interest in learning pre-academic skills. The results of the study also emphasise that even though the preschool year relates in many ways to the transitioning to school and learning the necessary social and pre-academic skills relevant to this transition, it is equally important for teachers to establish a constructive and friendly atmosphere in their classrooms, so that a joy for learning may flourish through their daily interactions.

In future studies, it would be insightful to explore the profiles identified in sub-study I with respect to children's outcomes. In the previous study by Curby et al. (2009), the profiles that were identified in the context of the United States (LoCasale-Crouch et al., 2007) were explored with respect to children's achievement and social competence. Their results suggested that the greatest gains in children's cognitive outcomes were achieved in classrooms where the dimension of Language Modelling was of high quality and the greatest gains in social competence were observed in classrooms where Emotional Support was of higher quality. It would also be promising to conduct this type of study in the Finnish context since the sub-studies of this doctoral study, as well as previous studies using the CLASS measure in the Finnish context (Pakarinen et al., 2010), have shown that even though there are differences between the US and Finnish contexts, the CLASS is also able to measure important variation also in the relatively homogenous educational system of Finland. The data of the First Steps study would enable this type of analysis. Furthermore, it would be worthwhile to explore the impact of high-quality practices provided in Finnish preschools on children's later adjustment in primary school or even later in life, as the importance of the role of high-quality education early on has been suggested by others (e.g., Peisner-Feinberg et al., 2001). The issue of this relation to children's outcome is of particular interest, but could unfortunately not be assessed within the limitations of this study and remains open for further studies to investigate.

Relatedly, the usefulness of the CLASS as a valid assessment tool in conducting observations amongst even younger children (i.e., toddlers and infants) has been attempted both in and outside the United States (Thomason \& La Paro, 
2009; Slot et al., 2014). However, this area is yet unexplored in the Finnish context. Finnish early childhood education and day care have certain unique features compared to other European countries (Hännikäinen \& Rautamies, 2008), and the field of early childhood education could benefit from the use of a structured observational tool in assessing the quality of interactions between teacher and children. The findings of this study suggest that the CLASS measure could also be useful in future education research with respect to even younger children in the Finnish context.

It is necessary to keep in mind that the results of this study are based on outsiders' perspective of teachers' role in the classroom, that is, the perspective of the observing researchers rather than that of the teachers and children themselves. The teacher questionnaire data were utilised to compliment the data of the observed practices, but cannot yield the same level of understanding regarding individual teachers that interviews would. Perhaps in the future, observational studies will feature interviews with observed teachers-including their watching and discussing their video-recorded classroom practices and interactions - combined with questionnaires or teacher logs examining the teachers' values and emphases, an idea also suggested by Hamre et al. (2013). This would be an appropriate way of studying teachers' practices and interaction with children in their classrooms as purposeful and pedagogically goaloriented action. It would also be insightful if children's experiences would be gathered in a similar fashion. Such studies could really tackle the complexity of teacher-child interactions and their impact on classroom quality as an observed and, more importantly, situated experiential phenomenon. 


\section{YHTEENVETO}

Tämän väitöskirjatutkimuksen tarkoituksena on saada uutta tietoa ja lisätä ymmärrystä opettajan roolista lasten oppimisen ja kehityksen tukijana suomalaisissa kuusivuotiaiden lasten esiopetusryhmissä kuvaamalla opettajien ja lasten välisen vuorovaikutuksen sekä pedagogisen toiminnan laatua opettajien toiminnan näkökulmasta. Tutkimus koostuu kolmesta empiirisestä osatutkimuksesta sekä teorian, metodit ja tulokset kokoavasta yhteenveto-osasta. Osatutkimusten aineisto kerättiin osana suomalaista Alkuportaat-seurantatutkimusta (Lerkkanen ym., 2006) keväällä 2007. Havainnointeihin osallistui 49 vapaaehtoista esiopetusryhmien opettajaa kolmelta paikkakunnalta. Havainnoinnit toteutettiin kunkin opettajan esiopetusryhmässä kahtena eri päivänä, joista kumpanakin havainnoitiin opettajan ja lasten välistä vuorovaikutusta kolmen tunnin ajan. Havainnointiaineiston kerääminen toteutettiin hyödyntämällä kahta strukturoitua havainnointimenetelmää Classroom Assessment Scoring System -menetelmää (CLASS: Pianta, La Paro, et al., 2008) ja Early Childhood Classroom Observation Measure -menetelmää (ECCOM: Stipek \& Byler, 2004). Kaksi koulutettua havainnoijaa arvioi ja kirjasi niiden avulla numeerisesti opettajan ja lasten välistä vuorovaikutusta sekä opettajan pedagogisen toiminnan laatua. Samanaikaisesti esiopetusryhmän toimintaa nauhoitettiin tai videoitiin. Lisäksi tutkimuksen aineistona käytettiin opettajien ja vanhempien kyselylomakevastauksia. Opettajien kyselylomakkeet sisälsivät kysymyksiä muiden muassa opettajien työkokemuksesta, koulutuksesta sekä esiopetuksen tavoitteista. Vanhempien lomakkeet sisälsivät kysymyksiä muiden muassa vanhempien koulutustaustasta, kodin ja esiopetuksen välisestä yhteistyöstä sekä vanhemmuudesta. CLASS-menetelmä pohjautuu kattavaan empiiriseen ja teoreettiseen tutkimustyöhön Yhdysvalloissa. Menetelmässä opettajan ja lasten välisen vuorovaikutuksen laatua tarkastellaan emotionaalisen tuen, ryhmän organisoinnin sekä ohjauksellisen tuen osa-alueella. Tätä kolmen osa-alueen mallia käytettiin tämän tutkimuksen keskeisenä teoreettisena mallina sekä aineistonkeruun työkaluna.

Numeerista aineistoa analysoitiin tilastollisen monitasomallinnuksen keinoin (osatutkimus I). Laadullinen, nauhoitettu havainnointiaineisto analysoitiin laadullisen sisällönanalyysin (osatutkimus II) sekä temaattisen analyysin (osatutkimus III) keinoin. Koska osatutkimukset koostuivat sekä määrällisestä että laadullisesta aineistosta, yhteenvedon kokoamisessa hyödynnettiin mixed method-tutkimuksen keskeisiä periaatteita ja osatutkimukset yhdistettiin sen mukaisesti laajemmalla tavoitteen- ja kysymyksenasettelulla. Näin tutkimuksen päälöydöksiä pyrittiin tarkastelemaan yli yksittäisten osatutkimusten. Näin ollen tutkimuksen tavoitteena oli tarkastella, millainen opettajan ja lasten välinen vuorovaikutus sekä millaiset opettajien pedagogiset käytännöt ovat yhteydessä esiopetusryhmien toiminnan laatuun. Lisäksi tavoitteena oli kuvata opettajien ja lasten välistä päivittäistä vuorovaikutusta sekä opettajien pedagogisia käytäntöjä. 
Ensimmäinen tutkimuskysymys oli millaisia opettajan ja lasten välisen vuorovaikutuksen laatuun perustuvia profilleja voidaan tunnistaa suomalaisissa esiopetusryhmissä. Tutkimuksen tulokset osoittivat, että CLASS-menetelmän avulla oli mahdollista tunnistaa esiopetusryhmistä neljä profiilia havainnoidun opettajan ja lasten välisen vuorovaikutuksen pohjalta. Suurin osa esiopetusryhmistä $(82 \%)$ kuului korkealaatuisiin profiileihin. Profiilit erosivat toisistaan erityisesti opettajien tarjoaman emotionaalisen tuen ja ohjauksellisen tuen perusteella. Ryhmän organisoinnissa profiilien erot olivat hyvin vähäisiä. Ensimmäisen osatutkimuksen perusteella näytti siltä, että mitä laadukkaampaa opettajan emotionaalinen tuki ja ryhmän organisointi olivat, sitä laadukkaampaa oli myös opettajan ohjauksellinen tuki, erityisesti kielellisen mallintamisen osalta. Toisen osatutkimuksen laadullisen analyysin tulokset tukevat tätä oletusta osoittaen, että kaikki tapaustutkimukseen valitut neljä opettajaa keskustelivat lasten kanssa ja mallinsivat toimintaa kielellisesti, mutta erityisesti opettajat, jotka edustivat korkeampilaatuisia profiileja, tekivät tätä lapsilähtöisemmin ja systemaattisemmin kuin opettajat heikompilaatuisissa profiileissa. Vaikka erot ohjauksellisen tuen muilla osa-alueilla eivät olleet profiilien välillä tilastollisesti merkitseviä, laadullisen analyysin keinoin pystyttiin tunnistamaan hienovaraisia mikrotason eroja opettajien välillä myös niiden osalta. Esimerkiksi, vaikka profiilien välillä ei ollut tilastollisesti merkitsevää eroa opettajien antaman palautteen laadussa, yksittäisiä opettajia laadullisesti tarkastelemalla voitiin todeta, että eräs opettaja antoi palautetta useammin siitä ovatko lasten vastaukset oikein vai väärin, kun taas toisella opettajalla oli pyrkimyksenä ennemminkin ottaa selvää vastauksen perusteluista.

Toinen tutkimuskysymys oli millaisin käytännöin opettajat tukevat lasten akateemisia oppimaan oppimisen taitoja ja sosiaalista vuorovaikutusta opettajajohtoisten tuokioiden aikana. Opettajilla oli paljon hyviä pedagogisia käytäntöjä, joiden avulla molempia osa-alueita tuettiin ohjattujen tuokioiden aikana, mutta myös kehittämiskohteita havaittiin. Tulokset osoittivat myös, että akateemisiin sisältöihin tutustuminen oli tärkeä osa esiopetusta ja että kullakin opettajalla oli omanlaisensa tapa tutustuttaa lapsia näihin sisältöihin. Eroja opettajien välillä oli ennen kaikkea siinä, kuinka monenlaisin pedagogisin käytännöin tämä tutustuminen tapahtui. Osa tapaustutkimukseen valituista neljästä opettajasta huomioi herkemmin lasten ideat ja oivallukset sekä antoi heille sopivan haastavia tehtäviä, joiden kautta lasten havainnoitu innostus opeteltavia asioita kohtaan vahvistui. Opettajat siis mahdollistivat sen, että lapset saattoivat saada onnistumisen kokemuksia. Toisaalta jotkut opettajat hyödynsivät opettajajohtoisia, yksinkertaisia ja toistavia menetelmiä, jotka auttoivat lapsia kohdistamaan huomionsa yksinkertaisiin faktoihin.

Esiopetusryhmien ohjatun toiminnan aikana harjoiteltiin myös sosiaalisia taitoja ja yhdessä toimeen tulemista. Tulokset osoittivat, että opettajilla oli neljän tyyppisiä hyviä käytäntöjä tukea ryhmiensä sosiaalista elämää. Opettajat (1) tukivat lasten keskinäistä, erityisesti kahdenkeskeistä, vuorovaikutusta, eli he mallinsivat toivottavaa vuorovaikutusta tai ohjasivat hienovaraisesti lapsia toimimaan yhdessä. Opettajat myös (2) edistivät yhteenkuuluvuutta koko ryh- 
män tasolla, esimerkiksi vetoamalla reilun pelin periaatteisiin tai yhteisiin sosiaalisiin sääntöihin. Lisäksi he (3) huomioivat lapsia yksilöinä ryhmätoiminnassa tarjoamalla lapsille tilaisuuksia olla vuorotellen toiminnassa keskeisessä roolissa sekä (4) keskustelivat ystävyydestä ja arvostamisesta koko ryhmän tasolla.

Kolmas tutkimuskysymys oli miten opettajien persoonalliset taustatekijät ovat yhteydessä siihen, millaisia pedagogisia oppimistilaisuuksia esiopetusryhmissä esiintyy. Opettajien työkokemus näytti olevan yhteydessä esiopetusryhmien toiminnan laatuun siten, että heikompilaatuisissa profiileissa opettajilla oli suhteessa vähemmän työkokemusta kuin korkeampilaatuisissa profiileissa. Vähäisempi työkokemus yhdistyi siis heikompaan opettajan emotionaaliseen tukeen ja ryhmän organisoinnin keinoihin mutta erityisesti opettajien heikompaan ohjaukselliseen tukeen. Opettajat laadukkaammissa profiileissa ilmoittivat antavansa lapsille useammin kirjaimia ja lukutaitoa koskevaa ohjausta kuin opettajat heikompilaatuisissa profiileissa. Tämä näkyi myös havainnoinneissa monipuolisempina strategioina kirjaimiin ja lukutaitoon liittyvissä tehtävissä. Opettajien lapsilähtöisiä opetuskäytäntöjä havaittiin useammin niissä esiopetusryhmissä, jotka edustivat korkeampilaatuisia profiileja. Sitä vastoin opettajajohtoisia käytäntöjä havaittiin useammin niissä ryhmissä, jotka sijoittuivat laadultaan heikompiin profiileihin.

Kaiken kaikkiaan väitöskirjatutkimuksen tulokset osoittavat, että erityisesti opettajan emotionaalisesti positiivinen vuorovaikutuksen vire sekä kyky organisoida toimintaa sujuvasti ovat vuorovaikutuksellisen laadun keskeisiä tekijöitä suomalaisissa esiopetusryhmissä. Jos opettajat olivat luoneet toiminnalle selkeät tavoitteet ja välittivät ne lapsille luottamuksellisessa ilmapiirissä, laatu oli korkea myös ohjauksellisen tuen osa-alueella. Erityisesti tämän tutkimuksen tulokset osoittavat, että hyvä ryhmän organisointi on tärkeä osa laadukasta esiopetusta. Samanaikaisesti erityisesti laadulliset tulokset viittaavat siihen, että opettajan pedagoginen sensitiivisyys on tärkeä osa havainnoitujen esiopetusryhmien tavoitteellista toimintaa ja myönteisten oppimiskokemusten tarjoamista. Jos opettajalla on herkkyyttä tunnistaa lasten yksilölliset tarpeet ja intressit, hänellä on myös paremmat mahdollisuudet tukea lasten akateemista oppimista ja sosiaalisia suhteita.

Tämän tutkimuksen löydösten pohjalta voidaan nostaa kaksi keskeisistä esiopetuskentän kehittämishaastetta. Ensinnäkin opettajilla tulisi olla riittävästi aikaa ja mahdollisuuksia havainnoida ryhmänsä lasten toimintaa sekä oppia tuntemaan heidät yksilöinä voidakseen ymmärtää, mikä on kullekin lapselle ja lapsiryhmälle paras keino oppia. On myös tärkeää pohtia, millaiset mahdollisuudet opettajalla on yksilöitä kunnioittavan vuorovaikutuksen sekä tietämyksen rakentamiseen, jos ryhmän koko on suuri. Tämän tutkimuksen tulokset antavat viitteitä läheisten vuorovaikutussuhteiden merkityksestä kuusivuotiaiden lasten opetuksessa, ja niitä voidaan hyödyntää suunniteltaessa suomalaisen varhaiskasvatuksen ja esiopetuksen tulevaisuuden linjauksia ja periaatteita. Toiseksi, tutkimuksen tuloksista kumpuaa kehittämishaasteena uransa alkuvaiheessa olevien lastentarhanopettajien ammatillinen tukeminen, sillä tässä 
tutkimuksessa heikoimman laadun profiiliin kuuluvien esiopetusryhmien opettajilla oli muita vähäisempi työkokemus.

Tämän tutkimuksen tulokset antavat myös ymmärtää, että jatkotutkimuksia on syytä toteuttaa opettajien emotionaalisen tuen osa-alueella, sillä suomalaisten opettajien emotionaalisen tuen laadussa on merkittävää vaihtelua opettajaprofiilien välillä. Lisäksi tutkimuksessa tunnistettuja profiileja tulisi jatkossa tarkastella suhteessa lasten taitoihin ja myöhempään kehitykseen. Siten olisi mahdollista saada lisätietoa opettajien erilaisten käytäntöjen ja vuorovaikutuksen laadun vaikutuksesta lasten sosiaaliselle ja akateemiselle kehitykselle ja näin saada kaivattua tietoa esiopetuksen vaikuttavuudesta.

Johtopäätöksenä voidaan todeta, että tämän väitöskirjatutkimuksen tulokset viestivät jatkuvien ja luottamuksellisten opettajan ja lasten välisten suhteiden puolesta ja korostavat niiden merkitystä laadukkaiden oppimistilanteiden rakentumisessa. Tutkimuksen tulosten mukaan tällaiset tilanteet perustuvat (1) opettajan kykyyn tunnistaa lasten yksilö- ja ryhmätasoisia tarpeita ja taitoja. Tilanteissa toimiminen edellyttää opettajalta myös (2) taitoa vastata lasten mielenkiinnon kohteisiin hyödyntämällä sopivia, pedagogisesti sensitiivisiä käytäntöjä ja (3) sensitiivisyyden välittämistä jokapäiväisiin vuorovaikutustilanteisiin. Tämän tutkimuksen tulosten perusteella voidaan todeta, että erityisesti opettajien emotionaalisen tuen käytäntöihin olisi hyvä kiinnittää huomiota jo koulutusvaiheessa. Lisäksi olisi hyvä pohtia enenevässä määrin, millainen merkitys opettajien laadukkailla ohjauksellisen tuen käytännöillä on lasten syvempien ajattelutaitojen ja päättelykyvyn kehitykselle, sekä välillisesti lasten akateemiselle kiinnostukselle. Vaikka esiopetusvuosi suomalaisissa esiopetusryhmissä liittyy monin tavoin koulun aloitukseen ja akateemisiin taitoihin tutustumiseen, on vähintään yhtä tärkeää korostaa esiopetuksen itseisarvoista merkitystä: Lapsen hyvinvoinnin kannalta on ensiarvoisen tärkeää, että opettajat luovat lapsiryhmään tervetulleeksi toivottavan ilmapiirin, jossa arvostavat ja miellyttävät päivittäiset kohtaamiset sekä oppimisen ilo kulkevat käsi kädessä. 


\section{REFERENCES}

Ahnert, L., Pinquart, M., \& Lamb, M. (2006). Security of children's relationships with nonparental care providers: A meta-analysis. Child Development, 74, 664-679. doi: 10.1111/j.1467-8624.2006.00896.x

Ahtola, A., Silinskas, G., Poikonen, P.-L., Kontoniemi, M., Niemi, P., \& Nurmi, J.-E. (2011). Transition to formal schooling: Do transtion practices matter for academic performance? Early Childhood Research Quarterly, 26, 295-302. doi:10.1016/j.ecresq.2010.12.002

Aunola, K., Leskinen, E., \& Nurmi, J.-E. (2006). Developmental dynamics between mathematical performance, task-motivation, and teachers' goals during the transition to primary school. British Journal of Educational Psychology, 76, 21-40. doi:10.1348/000709905X51608

Birch, S. H., \& Ladd, G. W. (1997). The teacher-child relationship and children's early school adjustment. Journal of School Psychology, 35, 61-79. doi:10.1016/S0022-4405(96)00029-5

Birch, S. H., \& Ladd, G. W. (1998). Children's interpersonal behaviors and the teacher-child relationship. Developmental Psychology, 34, 934-946. doi:10.1037/0012-1649.34.5.934

Blaikie, N. (2007). Approaches to social inquiry (2nd ed.). Cambridge, UK: Polity Press.

Blatchford, P. (2003). A systematic observational study of teachers' and pupils' behaviour in large and small classes. Learning and Instruction, 13, 569-595. doi:10.1016/S0959-4752(02)00043-9

Blatchford, P., Kutnick, P., Baines, E., \& Galton, M. (2003). Toward a social pedagogy of classroom group work. International Journal of Educational Research, 39, 153-172. doi:10.1016/S0883-0355(03)00078-8

Bohn, C. M., Roehrig, A. D., \& Pressley, M. (2004). The first days of school in the classrooms of two more effective and four less effective primary-grades teachers. Elementary School Journal, 104, 269-287.

Bowlby, J. (1980). Attachment and loss, Vol. 3: Loss, sadness and depression. New York, NY: Basic Books.

Braun, V., \& Clarke, V. (2006). Using thematic analysis in psychology. Qualitative Research in Psychology, 34, 934-946. doi:10.1191/1478088706qp063oa

Bredekamp, S., \& Copple, C. (1997). Developmentally appropriate practice in early childhood programs (Rev. Ed). Washington, DC: National Association for the Education of Young Children.

Bronfenbrenner, U. (1977). Toward an experimental ecology of human development. American Psychologist, 32, 513-531.

Bronfenbrenner, U. (1979). The ecology of human development: Experiments by nature and design. Cambridge, MA: Harvard University Press.

Bronfenbrenner, U. (1989). Ecological systems theory. In R. Vasta (Ed.), Six theories of child development: Revised formulations and current issues (pp. 187249). London: JAI Press. 
Bronfenbrenner, U. (1994). Ecological models of human development. In M. Gauvain \& M. Cole (Eds.), Readings on the development of children (2nd ed., pp. 37-43). New York, NY: Freeman.

Bronfenbrenner, U. \& Morris, P. (2006). The bioecological model of human development. In W. Damon \& R. M. Lerner (Series Ed.), R. M. Lerner (Vol. Ed.), Handbook of child psychology, Vol 1: Theoretical models of human development (6th ed., pp. 793-828). Hoboken, N.J.: Wiley.

Brophy, J. (2000). Teaching. Educational practices series 1. Geneva, Switzerland: International Bureau of Education.

Bryman, A. (1988). Quantity and Quality in Social Research. London: Unwin Hyman.

Bryman, A. (2006). Integrating quantitative and qualitative research: How is it done? Qualitative Research, 6, 97-113. doi: 10.1177/1468794106058877

Burchinal, M. R., Cryer, D., Clifford, R. M., \& Howes, C. (2002). Caregiver training and classroom quality in child care centers. Applied Developmental Science, 6, 2-11. Doi:10.1207/S1532480XADS0601_01

Burnett, P. C. (2002). Teacher praise and feedback and students' perceptions of the classroom environment. Educational Psychology, 22, 5-16. doi:10.1080/01443410120101215

Buysse, V., Goldman, B. D., \& Skinner, M. L. (2003). Friendship formation in inclusive early childhood classrooms: What is the teacher's role? Early Childhood Research Quarterly, 18, 485-501. doi:10.1016/j.ecresq.2003.09.007

Cadima, J., Leal, T., \& Burchinal, M. (2010). The quality of teacher-student interactions: Associations with first graders' academic and behavioral outcomes. Journal of School Psychology, 48, 457-482. doi:10.1016/j.jsp.2010.09.001

Cadima, J., Peixoto, C., \& Leal, T. (2014). Observed classroom quality in first grade: Associations with teacher, classroom, and school characteristics. European Journal of Psychology of Education, 29, 139-158. doi:10.1007/s10212-013-0191-4

Chatterjee, A. (2011). Ontology, epistemology, and multimethod research in political science. Philosophy of the Social Sciences, 43, 73-99. doi:10.1177/0048393111415380

Christians, C. G. (2000). Ethics and politics in qualitative research. In N. K. Denzin \& Y. S. Lincoln (Eds.), Handbook of qualittaive research (2 nd ed., pp. 133-155). Thousand Oaks, CA: Sage.

Cole, M., \& Gajdamaschko, N. (2010). Vygotsky and context: Toward a resolution of theoretical disputes. In S. R. Kirschner \& J. Martin (Eds.), The sociocultural turn in psychology: The contextual emergence of mind and self (pp. 253-280). New York, NY: Columbia University Press.

Connor, C. M., Morrison, F. J., \& Slominski, L. (2006). Preschool instruction and children's emergent literacy growth. Journal of Educational Psychology, 98, 665-689. doi: 10.1037/0022-0663.98.4.665

Connor, C. M., Son, S., Hindman, A., \& Morrison, F. J. (2005). Teacher qualifications, classroom practices, and family characteristics: Complex 
effects on first graders' language and early reading. Journal of School Psychology, 43, 343-375. doi:10.1016/j.jsp.2005.06.001

Conti, G. J. (1985). The relationship between teaching style and adult student learning. Adult Education Quarterly, 35, 220-228. doi:10.1177/0001848185035004004

Core Curriculum for Preschool Education. (2000). Esiopetuksen opetussuunnitelman perusteet 2000 [Core Curriculum for Preschool Education 2000]. Helsinki: National Board of Education.

Core Curriculum for Primary Education. (2004). Perusopetuksen opetussuunnitelman perusteet [The National Core Curriculum for Primary Education]. Helsinki: National Board of Education.

Creswell, J. C., \& Plano Clark, V. L. (2007). Designing and conducting mixed methods research. Thousand Oaks, CA: Sage.

Cupchik, G. (2001). Constructivist realism: An ontology that encompasses positivist and constructivist approaches to the social sciences [33 paragraphs]. Forum Qualitative Social Research / Qualitative Sozialforschung, 2(1), Art. 7. Retrieved from:

http://www.qualitative-research.net/index.php/fqs/ article/view/968/2112

Curby, T. W., LoCasale-Crouch, J., Konold, T. R., Pianta, R. C., Howes, C., Burchinal, M., . . Barbarin, O. (2009). The relations of observed pre-k classroom quality profiles to children's achievement and social competence. Early Education and Development, 20, 346-372. doi:10.1080/10409280802581284

Curby, T. W., Rimm-Kaufman, S. E., \& Abry, T. (2013). Do emotional support and classroom organization earlier in the year set the stage for higher quality instruction? Journal of School Psychology, 51, 557-569. doi:10.1016/j.jsp.2013.06.001

Dennis, S. E., \& O'Connor, E. (2013). Reexamining quality in early childhood education: Exploring the relationship between the organizational climate and the classroom process quality. Journal of Research in Childhood Education, 27, 74-92. doi: 10.1080/02568543.2012.739589

Downer, J., Sabol, T. J., \& Hamre, B. K. (2010). Teacher-child interactions in the classroom: toward a theory of within- and cross-domain links to children's developmental outcomes. Early Education and Development, 21, 699-723. doi:10.1080/10409289.2010.497453

Early, D. M., Bryant, D. M., Pianta, R. C., Clifford, R. M., Burchinal, M. R., Ritchie, S., . . . Barbarin, O. (2006). Are teachers' education, major, and credentials related to classroom quality and children's academic gains in pre-kindergarten? Early Childhood Research Quarterly, 21, 174-195.

doi:10.1016/j.ecresq.2006.04.004

Early, D. M., Maxwell, K. L., Burchinal, M., Alva, S., Bender, R. H., Bryant, D., . . Z Zill, N. (2007). Teachers' education, classroom quality, and young children's academic skills: results from seven studies of preschool programs. Child Development, 78, 558-580. doi: 10.1111/j.1467-8624.2007.01014.x 
Eccles, J. S., \& Roeser, R. W. (1999). School and community influences on human development. In M. H. Boorstein \& M. E. Lamb (Eds.), Developmental psychology: An advanced textbook (4th ed., pp. 503-554). Hillsdale, NJ: Erlbaum.

Emmer, E. T., \& Stough, L. (2001). Classroom management: A critical part of educational psychology, with implications for teacher education. Educational Psychologist, 36, 103-112.

European Commission /EACEA/Eurydice/Eurostat (2014). Key Data on Early Childhood Education and Care in Europ. 2014 Edition. Eurydice and Eurostat Report. Luxembourg: Publications Office of the European Union.

Gerber, E. B., Whitebook, M., \& Weinstein, R. S. (2007). At the heart of child care: Predictors of teacher sensitivity in center-based child care. Early Childhood Research Quarterly, 22, 327-346. doi:10.1016/j.ecresq.2006.12.003

Goudas, M., Biddle, S., Fox, K., \& Underwood, M. (1995). It ain't what you do, it's the way that you do it! Teaching style affects children's motivation in track and field lessons. The Sport Psychologist, 9, 254-264.

Graneheim, U. H., \& Lundman, B. (2004). Qualitative content analysis in nursing research: Concepts, procedures and measures to achieve trustworthiness. Nurse Education Today, 24, 105-112. doi:10.1016/j.nedt.2003.10.001

Greene, J. C., Caracelli, V. J., \& Graham, W. F. (1989). Toward a conceptual framework for mixed-method evaluation designs. Educational Evaluation and Policy Analysis, 11, 255-274.

Greeno, J. G., \& the Middle School Mathematics Through Applications Project Group (1998). The situativity of knowing, learning, and research. American Psychologist, 53, 5-26. doi: 10.1037/0003-066X.53.1.5

Greeno, J. G., \& van de Sande (2007). Perspectival understanding of conceptions and conceptual growth in interaction. Educational Psychologist, 42, 9-23. doi: 10.1080/00461520709336915

Hadeed, J. (2013). Reliability and validity of the early childhood environment rating scale, revised edition, ECERS-R in Arabic. Early Child Development and Care, 181, 1291-1313. doi:10.1080/03004430.2013.818991

Hamre, B. K., \& Pianta, R. C. (2005). Can instructional and emotional support in the first-grade classroom make a difference for children at risk of school failure? Child Development, 76, 949-967. doi:10.1111/j.1467-8624.2005.00889.x.

Hamre, B. K., \& Pianta, R. C. (2007). Learning opportunities in preschool and early elementary classrooms. In R. C. Pianta, M. J. Cox, \& K. L. Snow (Eds.), School readiness and the transition to kindergarten in the era of accountability (pp. 49-84). Baltimore: Brookes.

Hamre, B. K., Pianta, R. C., Burchinal, M., Field, S., LoCasale-Crouch, J., Downer, J., . . . Scott-Little, C. (2012). A course on effective teacher-child interactions: Effects on teacher beliefs, knowledge, and observed practice. American Educational Research Journal, 49, 88-123.

doi:10.3102/0002831211434596 
Hamre, B. K., Pianta, R. C., Downer, J. T., DeCoster, J., Mashburn, A. J., Jones, S., . . . Hamagami, A. (2013). Teaching Through Interactions: Testing a developmental framework of teacher effectiveness in over 4,000 classrooms. The Elementary School Journal, 113, 461-487. Retrieved from http://www.jstor.org/stable/10.1086/669616

Hamre, B. K., Pianta, R. C., Mashburn, A. J., \& Downer, J. T. (2007). Building a science of classrooms: Application of the CLASS framework in over 4,000 early childhood and elementary classrooms. Retrieved from http://fcdus.org/sites/default/files/BuildingAScienceOfClassroomsPiantaHamre. pdf

Harms, T., \& Clifford, R. (1980). Early childhood environment rating scale. New York, NY: Teachers College Press.

Hesse-Bieber, S. N. (2010). Mixed methods research: Merging theory with practice. New York, NY: Guilford Press.

Hicks, D. (1996). Contextual inquiries: A discourse-oriented study of classroom learning. In D. Hicks (Ed.), Discourse, learning, and schooling (pp. 104-141). Cambridge: Cambridge University Press.

Hinde, R. A. (1987). Individuals, relationships and culture: Links between ethology and the social sciences. Cambridge, MA: Harvard University Press.

Howes, C. (2000). Social-emotional classroom climate in child-care, childteacher relationships and children's second grade peer relations. Social Development, 9, 191-204. doi: 10.1111/1467-9507.00119

Howes, C., Burchinal, M., Pianta, R., Bryant, D., Early, D., Clifford, R., \& Barbarin, O. (2008). Ready to learn? Children's pre-academic achievement in pre-kindergarten programs. Early Childhood Research Quarterly, 23, 27-50. doi:10.1016/j.ecresq.2007.05.002

Howes, C., \& Hamilton, C. E. (1992). Children's relationships with caregivers: Mothers and child-care teachers. Child Development, 63, 859-866. doi: 10.1111/j.1467-8624.1992.tb01666.x

Howes, C., Hamilton, C. E., \& Matheson, C. C. (1994). Children's relationships with peers: Differential associations with aspects of teacher-child relationships. Child Development, 65, 253-263.

doi: 10.1111/j.1467-8624.1994.tb00748.x

Howes, C., \& James, J. (2002). Children's social development within the socialisation context of childcare and early childhood education. In P. K. Smith \& C. H. Hart (Eds.), Blackwell handbook of childhood social development (pp. 137-155). Oxford, UK: Blackwell.

Howes, C., \& Matheson, C. (1992). Sequences in the development of competent play with peers: Social and social pretend play. Developmental Psychology, 28, 961-974. doi:10.1037/0012-1649.28.5.961

Hujala, E., Backlund-Smulter, T., Koivisto, P., Parkkinen, H., Sarakorpi, H., Suortti, O., .. . Korkeakoski, E. (2012). Esiopetuksen laatu 2012. [The quality of pre-primary education 2012]. Publications by the Finnish Education Evaluation Council 61. Jyväskylä. Retrieved from http://www.edev.fi/img/portal/1354/julkaisu_61.pdf 
Hujala, E., Fonsén, E., \& Elo, J. (2012). Evaluating the quality of the child care in Finland. Early Child Development and Care, 182, 299-314. doi:10.1080/03004430.2011.646721

Hujala, E., Parrila, S., Lindberg, P., Nivala, V., Tauriainen, L., \& Vartiainen, P. (1999). Laadunhallinta varhaiskasvatuksessa [Quality management in early childhood education]. Oulun yliopisto [University of Oulu], Finland: Varhaiskasvatuskeskus.

Hujala-Huttunen, E. (1995). Varhaiskasvatuksen laadunarviointi [Early childhood education quality assessment]. In E. Hujala \& E. Estola (Eds.), Näkökulmia varhaiskasvatukseen (pp. 69-82). Oulu, Finland: Oulun lastentarhanopettajaopisto.

Hännikäinen, M. (2003). Transition to school in Finland: From early childhood end preschool education to basic education. In S. Broström \& J. T. Wagner (Eds.), Early childhood education in five nordic countries: perspectives on the transition from preschool to school (pp. 77-99). Århus: Systime.

Hännikäinen, M. (2005). Rules and agreements and becoming a preschool community of learners. European Early Childhood Education Research Journal, 13, 97-110. doi:10.1080/13502930585209581

Hännikäinen, M., \& van Oers, B. (2002). Togetherness as a quality of the learning context. In M. Karlsson Lohmander (Ed.), Social competence and communication. Researching Early Childhood 4 (pp. 83-96). Göteborg University: Early Childhood Research and Development Centre.

Hännikäinen, M., de Jong, M., \& Rubinstein Reich, L. (1997). Our heads are the same size! A study of quality of the child's life in Nordic day care centres. Educational information and debate 107. Malmö, Sweden: Malmö University School of Education.

Hännikäinen, M., \& Rasku-Puttonen, H. (2010). Promoting childrens participation: The role of teachers in preschool and primary school learning sessions. Early Years: An International Journal of Research and Development, 30, 147-160. doi:10.1080/09575146.2010.485555

Hännikäinen, M. \& Rautamies, E. (2008). Developing good practice in Finnish day care centres: Focus on relationships and interaction. In P. Kutnick, M. L. Genta, A. Brighi, \& A. Sansavini (Eds.), Relational approaches in early education: Enhancing social inclusion and personal growth for learning (pp. 144-176). Bologna: CLUEB.

Jennings, P. A., \& Greenberg, M. T. (2009). The prosocial classroom: Teacher social and emotional competence in relation to child and classroom outcomes. Review of Educational Research, 79, 491-252.

Johnson, R. B., \& Onwuegbuzie, A. J. (2004). Mixed methods research: A research paradigm, whose time has come. Educational Researcher, 33, 14-26.

Johnson, R. B., Onwuegbuzie, A. J., \& Turner, L. A. (2007). Toward a definition of mixed methods research. Journal of Mixed Methods Research, 1, 112-133. doi:10.1177/1558689806298224 
Karabanova, O. A. (2010). Social situation of child's development: The key concept in modern developmental psychology. Psychology in Russia: State of the Art, 1, 130-153.

Kernan, M., Singer, E., \& Swinnen, R. (2011). Introduction. In M. Kernan \& E. Singer (Eds.), Peer relationships in early childhood education and care (pp. 114). New York, NY: Routledge.

Kovalainen, M., \& Kumpulainen, K. (2007). The social construction of participation in an elementary classroom community. International Journal of Educational Research, 46, 141-158. doi:10.1016/j.ijer.2007.09.011

de Kruif, R. E. L., McWilliam, R. A., \& Ridley, S. M. (2000). Classification of teachers' interaction behaviors in early childhood classrooms. Early Childhood Research Quarterly, 15, 247-268.

Kumpulainen, K., Lipponen, L., Hilppö, J., \& Mikkola, A. (2014). Building on the positive in children's lives: A co-participatory study on the social construction of children's sense of agency. Early Child Development and Care, 184, 211-229. doi:10.1080/03004430.2013.778253

Kutnick, P., Ota, C., \& Berdondini, L. (2008). Improving the effects of group work in classrooms with young school-aged children: Facilitating attainment, interaction and classroom activity. Learning and Instruction, 18, 83-95. doi:10.1016/j.learninstruc.2006.12.002

Ladd, G. W., Birch, S. H., \& Buhs, E. S. (1999). Children's social and scholastic lives in kindergarten: Related spheres of influence? Child Development, 70, 1373-1400.

Laki lasten päivähoidosta. [The Children's Day Care Act]. (36/1973). Suomen laki ja asetuskokoelma.

Lamb, M. E. (1998). Non-parental child care: Context, quality, correlates. In W. Damon, I. E. Sigel, \& K. A. Renninger (Eds.), Handbook of child psychology: Vol. 4. Child psychology in practice (5th ed., pp. 73-134). New York, NY: Wiley.

La Paro, K. M., Hamre, B. K., Locasale-Crouch, J., Pianta, R. C., Bryant, D., Early, D., . . . Burchinal, M. (2009). Quality in kindergarten classrooms: Observational evidence for the need to increase children's learning opportunities in early education classrooms. Early Education and Development, 20, 657-692. doi:10.1080/10409280802541965

Lave, J., \& Wenger, E. (1991). Situated learning: Legitimate peripheral participation. Cambridge, UK: Cambridge University Press.

Leech, N. L., \& Onwuegbuzie, A. J. (2007). An array of qualitative data analysis tools: A call for data analysis triangulation. School Psychology Quarterly, 22, 557-584. doi: 10.1037/1045-3830.22.4.557

Lincoln, Y. S., \& Guba, E. G. (1985). Naturalistic inquiry. Newbury Park, CA: Sage.

Lincoln, Y. S., \& Guba, E. G. (2000). Paradigmatic controversies, contradictions, and emerging confluences. In N. K. Denzin \& Y. S. Lincoln (Eds.), The handbook of qualitative research (2nd ed., pp. 163-188). Newbury Park, CA: Sage. 
LoCasale-Crouch, J., Konold, T., Pianta, R., Howes, C., Burchinal, M., Bryant, D., . . Barbarin, O. (2007). Observed classroom quality profiles in statefunded pre-kindergarten programs and associations with teacher, program, and classroom characteristics. Early Childhood Research Quarterly, 22, 3-17. doi:10.1016/j.ecresq.2006.05.001

LoCasale-Crouch, J., Mashburn, A. J., Downer, J. T., \& Pianta, R. C. (2008). Prekindergarten teachers' use of transition practices and children's adjustment to kindergarten. Early Childhood Research Quarterly, 23, 124-139. doi:10.1016/j.ecresq.2007.06.001

Lerkkanen, M.-K., Kikas, E., Pakarinen, E., Poikonen, P.-L., \& Nurmi, J.-E. (2013). Mothers' trust toward teachers in relation to teaching practices. Early Childhood Research Quarterly, 28, 153-165. doi: 10.1016/j.ecresq.2012.04.005

Lerkkanen, M.-K., Kiuru, N., Pakarinen, E., Viljaranta, J., Poikkeus, A.-M., Rasku-Puttonen, H., . . . \& Nurmi, J.-E. (2012). The role of teaching practices in the development of children's interest in reading and mathemathics in kindergarten. Contemporary Educational Psychology, 37, 266-279. doi:10.1016/j.cedpsych.2011.03.004

Lerkkanen, M.-K., Niemi, P., Poikkeus, A.-M., Poskiparta, E., Siekkinen, M., \& Nurmi, J.-E. (2006). The First Steps Study [Alkuportaat tutkimus]. Unpublished data. University of Jyväskylä: Finland.

van Manen, M. (1991). The tact of teaching. The meaning of pedagogical thoughtfulness. Ontario: Althause.

van Manen, M. (1995). On the epistemology of reflective practice. Teachers and Teaching: Theory and Practice, 1, 33-50. doi:10.1080/1354060950010104

van Manen, M. (2002). The tone of teaching: The language of pedagogy. Ontario: Althouse.

van Manen, M. (2008). Pedagogical sensitivity and teachers practical knowingin-action. Peking University Education Review, 1, 2-20.

Mashburn, A., Pianta, R., Hamre, B., Downer, J., Barbarin, O., Bryant, D., . . . Howes, C., (2008). Measures of classroom quality in prekindergarten and children's development of academic, language, and social skills. Child Development, 79, 732-749. doi:10.1111/j.1467-8624.2008.01154.x.

Mason, J., (1996). Qualitative researching. London: Sage.

Mercer, N., \& Littleton, K. (2007) Dialogue and the development of children's thinking. London: Routledge.

Merriam, S. B. (1998). Qualitative research and case study applications in education. San Francisco: Jossey-Bass.

MerriamWebster Dictionary and Thesarus Online. (2013). Retrieved from: http://www.merriam-webster.com/dictionary/pedagogy

Miles, M. B., \& Huberman, A. M. (1994). Qualitative data analysis: An expanded sourcebook (2nd ed.). Thousand Oaks, CA: Sage.

Moll, L. C., \& Whitmore, K. (1993). Vygotsky in educational practice. In E. Forman, N. Minick, \& C. A. Stone (Eds.), Contexts for learning: Sociocultural dynamics in children's development (pp. 19-42). New York, NY: Oxford University Press. 
Muthén, B. O. (2001). Latent variable mixture modeling. In G. A. Marcoulides \& R. E. Schumacker (Eds.), Advanced structural equation modeling: New developments and techniques (pp. 1-33). Mahwah, NJ: Erlbaum.

Muthén, B. O. (2003). Statistical and substantive checking in growth mixture modeling: Comment to Bauer and Curran (2003). Psychological Methods, 8, 367-377. doi:10.1037/1082-989X.8.3.369

Muthén, L. K., \& Muthén, B. O. (1998-2008). Mplus users guide and Mplus version 5.0. Retrieved from http:/ / www.statmodel.com/index.shtml

National Advisory Board on Research Ethics. (2009). Ethical principles of research in the humanities and social and behavioural sciences and proposals for ethical review. Retrieved:

http://www.tenk.fi/sites/tenk.fi/files/ethicalprinciples.pdf

National Core Curriculum for Pre-primary Education. (2010). Esiopetuksen opetussuunnitelman perusteet 2010 [The National Core Curriculum for Preprimary Education 2010]. Helsinki: National Board of Education. http://www.oph.fi/download/153504_national_core_curriculum_for_pre -primary_education_2010.pdf

National Institute for Health and Welfare. (2013). Lasten Päivähoito 2012 [Children's Day Care 2012]. Helsinki: National Institute for Health and Welfare.

National Institute of Child Health, and Human Development Early Child Care Research Network [NICHD/ECCRN]. (2002). The relation of global firstgrade classroom environment to structural classroom features and teacher and student behaviors. Elementary School Journal, 102, 367-387.

Niglas, K. (2004). The combined use of qualitative and quantitative methods in educational research (Doctoral dissertation). Retrieved from http://eait.tlulib.ee/66/1/niglas_katrin2.pdf

Nurmi, J.-E., Kiuru, N., Lerkkanen, M.-K., Niemi, P., Poikkeus, A.-M., Ahonen, T., . . \& \& Lyyra, A.-L. (2013). Teachers adapt their instruction in reading according to individual children's literacy skills. Learning and Individual Differences, 23, 72-79. Doi:10.1016/j.lindif.2012.07.012

van Oers, B. (2012). Developmental education: Foundations of a play-based curriculum. In B. van Oers (Ed.), Developmental education for young children. Concept, practice and implementation (pp. 13-25). Dordrecht: Springer.

van Oers, B., \& Hännikäinen, M. 2001. Some thoughts about togetherness: An introduction. International Journal of Early Years Education 9, 101-108. doi:10.1080/713670686

Office for Standards in Education (Ofsted). (2003). The education of six-year-olds in England, Denmark, and Finland: An international comparative study. Retrieved from http://www.ofsted.gov.uk/resources/education-of-sixyear-olds-england-denmark-and-finland

Ojala, M., \& Talts, L. (2007). Preschool achievement in Finland and Estonia: Cross-cultural comparison between the cities of Helsinki and Tallinn. Scandinavian Journal of Educational Research, 51, 205-221.

doi: 10.1080/00313830701191670 
Onwuegbuzie, A. J., \& Johnson, R. B. (2006). The validity issue in mixed research. Research in the Schools, 13(1), 48-63.

Organisation for Economic Co-operation and Development/OECD. (2007). PISA Country profiles. Retrieved from http: // pisacountry.acer.edu.au

Organisation for Economic Co-operation and Development/OECD. (2009). PISA 2009. Preliminary results in Finland. Retrieved from http://www.minedu.fi/export/sites/default/OPM/Julkaisut/2010/liitte et/okm21.pdf?lang=fi

Organisation for Economic Co-operation and Development/ OECD. (2012). PISA 2012 Results: What students know and can do: student performance in mathematics, reading and science (vol I). Retrieved from http:/ / www.oecd.org/ pisa/ keyfindings/ pisa-2012-results-volume-I.pdf

Page, J. (2011). Do mothers want professional carers to love their babies? Journal of Early Childhood Research, 9, 310-323. doi: 10.1177/1476718X11407980

Pajares, M. F. (1992). Teachers' beliefs and educational research: Cleaning up a messy construct. Review of Educational Research, 62, 307-332. doi:10.3102/00346543062003307

Pakarinen, E., Kiuru, N., Lerkkanen, M.-K., Poikkeus, A.-M., Ahonen, T., \& Nurmi, J.-E. (2011). Instructional support predicts children's task avoidance in kindergarten. Early Childhood Research Quarterly, 26, 376-386. doi:10.1016/j.ecresq.2010.11.003

Pakarinen, E., Lerkkanen, M.-K., Poikkeus, A.-M., Kiuru, N., Siekkinen, M., Rasku-Puttonen, H., \& Nurmi, J. (2010). A validation of the classroom assessment scoring system in Finnish kindergartens. Early Education and Development, 21, 95-124. doi:10.1080/10409280902858764

Patton, M. Q. (2002). Qualitative research \& evaluation methods (3rd ed.), Thousand Oaks, CA: Sage.

Peisner-Feinberg, E. S., Burchinal, M. R., Clifford, R. M., Culkin, M. L., Howes, C., Kagan, S. L., Yazegian, N. (2001). The relation of preschool child-care quality to children's cognitive and social development trajectories through second grade. Child Development, 72, 1534-1553. doi:10.1111/14678624.00364

Perry, K. E., Donohue, K. M., \& Weinstein, R. S. (2007). Teaching practices and the promotion of achievement and adjustment in first grade. Journal of School Psychology, 45, 269-292. doi:10.1016/j.jsp.2007.02.005

Perusopetuslaki. [The Act of Basic Education]. (628/1998). Suomen laki ja asetuskokoelma.

Pianta, R. C. (1999). Enhancing relationships between children and teachers. Washington, DC: American Psychological Association.

Pianta, R. C., Belsky, J., Vandergrift, N., Houts, R., \& Morrison, F. J. (2008). Classroom effects on children's achievement trajectories in elementary school. American Educational Research Journal, 45, 365-397. doi:10.3102/0002831207308230 
Pianta, R. C., \& Hamre, B. K. (2009). Conceptualization, measurement and improvement of classroom processes: Standardized observation can leverage capacity. Educational Researcher, 38, 109-119. doi:10.3102/0013189X09332374

Pianta, R. C., Hamre, B. K., \& Stuhlman, M. (2003). Relationships between teachers and children. In W. Reynolds \& G. Miller (Eds.), Handbook of Psychology: Vol. 7 Educational psychology (pp. 199-312). Hoboken, NJ: John Wiley \& Sons.

Pianta, R. C., Howes, C., Burchinal, M., Bryant, D., Clifford, R., Early, D., \& Barbarin, O. (2005). Features of pre-kindergarten programs, classrooms, and teachers: Do they predict observed classroom quality and childteacher interactions? Applied Developmental Science, 9, 144-159. doi:10.1207/s1532480xads0903_2

Pianta, R. C., La Paro, K. M., \& Hamre, B. K. 2004. Classroom assessment scoring system (CLASS). Unpublished measure, University of Virginia, Charlottesville, VA.

Pianta, R. C., La Paro, K. M., \& Hamre, B. K. 2008. Classroom assessment scoring system. Manual, Pre-K. Baltimore, MD: Paul H. Brookes Publishing Company.

Pianta, R. C., La Paro, K. M., Payne, C., Cox, M. J., \& Bradley, R. (2002). The relation of kindergarten classroom environment to teacher, family, and school characteristics and child outcomes. Elementary School Journal, 102, 225-238.

Pianta, R. C., Steinberg, M. S., \& Rollins, K. B. (1995). The first two years of school: Teacher-child relationships and deflections in children's classroom adjustment. Development and Psychopathology, 7, 295-312. doi:10.1017/S0954579400006519

Ponitz, C. C., Rimm-Kaufman, S. E., Grimm, K. J., \& Curby, T. W. (2009). Kindergarten classroom quality, behavioral engagement, and reading achievement. School Psychology Review, 38, 102-120.

Pramling Samuelson, I., \& Johansson, E. (2009). Why do children involve teachers in their play and learning? European Early Childhood Education Research Journal, 17, 77-94. doi:10.1080/13502930802689053

Pressley, M., Dolezal, S. E., Raphael, L. M., Mohan, L., Roehrig, A. D., \& Bogner, K. (2003). Motivating primary-grade students. New York, NY: Guilford Press.

Raittila, R. (2013). Pienryhmätoiminta ja leikkialueet. Varhaiskasvatuksen pedagoginen toimintaympäristö rakentuu arkisissa käytännöissä. [Small group and play area activity. Pedagogical environments are constructed through daily practices]. In K. Karila \& L. Lipponen (Eds.), Varhaiskasvatuksen pedagogiikka (pp. 69-94). Tampere: Vastapaino.

Rasku-Puttonen, H., Lerkkanen, M.-K., Poikkeus, A.-M., Siekkinen, M. (2012). Dialogical patterns of interaction in pre-school classrooms. International Journal of Educational Research, 53, 138-149. doi:10.1016/j.ijer.2012.03.004

Rasku-Puttonen, H., Pakarinen, E., Trossman, K., Lerkkanen, M.-K., Kikas, E., \& Poikkeus, A.-M. (2011). Classroom practices in Finnish and Estonian 
preschools: Subgroups of observed teaching practices. In M. Veisson, E. Hujala, P. K. Smith, M. Waniganayake, \& E. Kikas (Eds.), Global perspectives in early childhood education: Diversity, challenges and possibilities (pp. 313-331). Baltische Studien zur Erziehungs- und Sozialwissenschaft 20. Frankfurt am Main: Peter Lang.

Rimm-Kaufman, S. E., Curby, T. W., Grimm, K. J., Nathanson, L., \& Brock, L. L. (2009). The contribution of children's self regulation and classroom quality to children's adaptive behaviors in the kindergarten classroom. Developmental Psychology, 45, 958-972. doi: 10.1037/a0015861

Rimm-Kaufman, S. E., \& Hamre, B. K. (2010). The role of psychological and developmental science in efforts to improve teacher quality. Teachers College Record, 112, 2988-3023.

Rimm-Kaufman, S. E., La Paro, K. M., Downer, J. T., \& Pianta, R. C. (2005). The contribution of classroom setting and quality of instruction to children's behavior in kindergarten classrooms. Elementary School Journal, 105, 377394.

Rimm-Kaufman, S. E., \& Wanless, S. B. (2012). An ecological perspective for understanding the early development of self-regulatory skills, social skills, and achievement. In R. C. Pianta (Ed.), Handbook of early childhood education (pp. 299-323). New York, NY: Guilford Press.

Rogoff, B. (2003). The cultural nature of human development. New York, NY: Oxford University Press.

Rogoff, B. (2008). Observing sociocultural activity on three planes: Participatory appropriation, guided participation, and apprenticeship. In K. Hall, P. Murphy, and J. Soler (Eds.) Pedagogy and practice: Culture and identities (pp. 58-74). Thousand Oaks, CA: Sage.

Rosenthal, M. K., \& Gatt, L. (2010). 'Learning to live together': Training early childhood educators to promote socio-emotional comptence of toddlers and pre-school children. European Early Childhood Education Research Journal, 18, 373-390. doi:10.1080/1350293X.2010.500076

Sabol., T. J., \& Pianta, R. C. (2012). Recent trends in research on teacher-child relationships. Attachment \& Human Development, 14, 213-231. doi:10.1080/14616734.2012.672262

Schweinhart, L. J., \& Weikart, D. P. (1988). Education for young children living in poverty: Child-initiated learning or teacher-directed instruction? Elementary School Journal, 89, 213-225.

Shenton, A. K. (2004). Strategies for ensuring trustworthiness in qualitative research projects. Education for Information, 22, 63-75.

Sheridan, S. (2007). Dimensions of pedagogical quality in preschool. International Journal of Early Years Education, 15, 197-217. doi:10.1080/09669760701289151

Siekkinen, M., Pakarinen, E., Lerkkanen, M.-K., Poikkeus, A.-M., Salminen, J., Poskiparta, E., \& Nurmi, J.-E. (2013). Social competence among 6-year old children and classroom instructional support and teacher stress. Early Education and Development, 24, 877-897. doi:10.1080/10409289.2013.745183 
Singer, E., \& de Haan, D. (2007). Social life of young children. Co-construction of shared meanings and togetherness, humour, and conflicts in child care centers. In B. Spodek \& O. N. Saracho (Eds.), Contemporary perspectives on research in early childhood social learning (pp. 309-332). Charlotte, NC: Information Age Publishers.

Siraj-Blatchford, I., Mayo, A., Melhuis, E., Taggart, B., Sammons, P., \& Sylva, K., (2011). Performing aggainst the odds: Developmental trajectories of children in the EPPSE 3-16 study. Department of Education. Research Report DFERR128.

Siraj-Blatchford, I., Sylva, K., Taggart, B., Melhuis, E., Sammons, P., \& Elliot, K. (2003). The effective provision of pre-school education (EPPE) project (19972003). Technical paper 10 'intensive case studies of practice across the foundation stage.' Research Brief RBX16-03.

Slot, P. L., Leseman, P. P. M., Mulder, H., \& Verhagen, J. (2014). Quality and curriculum of early childhood center-based care predicting growth of two-yearold's vocabulary and attention skills over one year. Manuscript submitted for publication.

Smetana, J. G. (1993). Understanding of social rules. In M. Bennet (Ed.), The development of social cognition: The child as psychologist (pp. 111-141). New York, NY: Guilford Press.

Smidt, S. (2009). Introducing Vygotsky: A guide for practitioners and students in early years education. London: Routledge.

Statistics Finland. (2012). Suomen virallinen tilasto (SVT): Esi- ja peruskouluopetus. [Official Finnish statistics: Preschool and primary education]. Helsinki: Tilastokeskus. Retrieved from: http://www.tilastokeskus.fi/til/pop/ index.html

Stipek, D. J., \& Byler, P. (1997). Early childhood education teachers: Do they practice what they preach? Early Childhood Research Quarterly, 12, 305-325. doi:10.1016/S0885-2006(97)90005-3

Stipek, D. J., \& Byler, P. (2004). The early childhood classroom observation measure. Early Childhood Research Quarterly, 19, 375-397. doi:10.1016/j.ecresq.2004.07.007

Stipek, D. J., \& Byler, P. (2005). The early childhood classroom observation measure. Coding manual.

Stipek, D. J., Feiler, R., Byler, P., Ryan, R., Milburn, S., \& Salmon, J. M. (1998). Good beginnings: What difference does the program make in preparing young children for school? Journal of Applied Developmental Psychology, 19, 41-66. doi:10.1016/S0193-3973(99)80027-6

Stipek, D., Feiler, R., Daniels, D., \& Milburn, S. (1995). Effects of different instructional approaches on young children's achievement and motivation. Child Development, 66, 209-223. doi:10.1111/j.1467-8624.1995.tb00866.x

Stürmer, K., Könings, K. D., \& Seidel, T. (2012). Declarative knowledge and professional vision in teacher education: Effect of courses in teaching and learning. British Journal of Educational Psychology, 83, 467-483.

doi:10.1111/j.2044-8279.2012.02075.x 
von Suchodoletz, A., Fäsche, A., Gunzenhauser, C., \& Hamre, B. K. (2014). A typical morning in preschool: Observations of teacher-child interactions in German preschools. Early Childhood Research Quarterly, 29, 509-519. doi:10.1016/j.ecresq.2014.05.010

Sylva, K., Siraj-Blatchford, I., \& Taggart, B. (2010). Assessing quality in the early years (2nd ed.). London: Trentham Books.

Sylva, K., Taggart, B., Siraj-Blatchford, I., Totsika, V., Ereky-Stevens, K., Gilden, R., \& Bell, D. (2007). Curricular quality and day-to-day learning activities in pre-school. International Journal of Early Years Education, 15, 49-65. doi:10.1080/09669760601106968

Tauriainen, L. (2000). Kohti yhtenäistä laatua. Henkilökunnan, vanhempien ja lasten laatukäsitykset päiväkodin integroidussa lapsiryhmässä [Towards a common quality: Staff's, parents' and chidren's conceptions of quality in an integration group at a day-care center] (Doctoral dissertation). Retrieved from https://jyx.jyu.fi/dspace/bitstream/handle/123456789/37835/978951-39-4743-9.pdf?sequence $=1$

Teddlie, C., \& Tashakkori, A. (2003). Major issues and controversies in the use of mixed methods in the social and behavioral sciences. In A. Tashakkori \& C. Teddlie (Eds.) Handbook of mixed methods on social \& behavioral research (pp. 3-50). Thousand Oaks, CA: Sage.

Teddlie, C., \& Tashakkori, A. (2009). Foundations of mixed methods research: Integrating quantitative and qualitative approaches in the social and behavioral sciences. Thousand Oaks, CA: Sage.

Thomason, A. C., \& La Paro, K. M. (2009). Measuring the quality of teacherchild interactions in toddler child care. Early Education and Development, 20, 285-304. doi:10.1080/10409280902773351

Vaughn, B. E., \& Santos, A. J. (2008). Structural descriptions of social transactions among young children: Affiliation and dominance in preschool groups. In K. H. Rubin, W. Bukowski, \& B. Laursen (Eds.), Handbook of peer interactions, relationships, and groups (pp. 195-214). New York, NY: Guilford Press.

Vygotsky, L. S. (1961). Thought and language. Cambridge, MA: The M.I.T. Press.

Vygotsky, L. S. (1978). Mind in society. The development of higher psychological processes. Cambridge, MA: Harvard University Press.

Wentzel, K. R. (1991). Social competence at school: Relation between social responsibility and academic achievement. Review of Educational Research, 61,1-24. doi:10.3102/00346543061001001

Wentzel, K. R. (2002). The contribution of social goal setting to children's school adjustment. In A. Wigfield \& J. Eccles (Eds.), Development of achievement motivation (pp. 221-246). San Diego: Academic Press.

Wertsch, J. V., del Río, P., \& Alvarez, A. (1995). Sociocultural studies of mind. Cambridge: Cambridge University Press.

Wong, H. K., \& Wong, R. T. (2004). The first days of school: How to be an effective teacher. Mountain View, CA: Hary K. Wong Publications Inc. 
Yan, E. M., Evans, I. M., \& Harvey, S. T. (2011). Observing emotional interactions between teachers and students in elemntary school classrooms. Journal of Research in Childhood Education, 25, 82-97.

doi:10.1080/02568543.2011.533115

Yin, R. K. (2003). Case study research: Design and methods (3rd ed.). Thousand Oaks, CA: Sage. 


\section{ORIGINAL PAPERS}

\section{I \\ OBSERVED CLASSROOM QUALITY PROFILES OF KINDERGARTEN CLASSROOMS IN FINLAND}

by

Jenni Salminen, Marja-Kristiina Lerkkanen, Anna-Maija Poikkeus, Eija Pakarinen, Martti Siekkinen, Maritta Hännikäinen, Pirjo-Liisa Poikonen, \& Helena RaskuPuttonen, 2012

Early Education and Development, 23, 654-677

Reproduced with kind permission from the Taylor \& Francis Group. 
II

A DESCRIPTIVE CASE ANALYSIS OF INSTRUCTIONAL TEACHING PRACTICES IN FINNISH PRESCHOOL CLASSROOMS

by

Jenni Salminen, Maritta Hännikäinen, Pirjo-Liisa Poikonen, \& Helena RaskuPuttonen, 2013

Journal of Research in Childhood Education, 27, 127-152

Reproduced with kind permission from the Taylor \& Francis Group. 


\title{
III
}

TEACHERS' CONTRIBUTION TO THE SOCIAL LIFE IN FINNISH PRESCHOOL CLASSROOMS DURING STRUCTURED LEARNING SESSIONS

\begin{abstract}
by
Jenni Salminen, Maritta Hännikäinen, Pirjo-Liisa Poikonen, \& Helena RaskuPuttonen, 2014
\end{abstract}

Early Child Development and Care, 184, 416-433

Reproduced with kind permission from Taylor \& Francis Group. 